Prepared in cooperation with the Flood Control Districts of Maricopa County, Pima County, Pinal County, Yavapai County, Mohave County, Cochise County, Navajo County, Greenlee County, and Salt River Project, U.S. Forest Service, and Bureau of Reclamation

\title{
Methods for Estimating Magnitude and Frequency of Floods in Arizona, Developed with Unregulated and Rural Peak-Flow Data through Water Year 2010
}
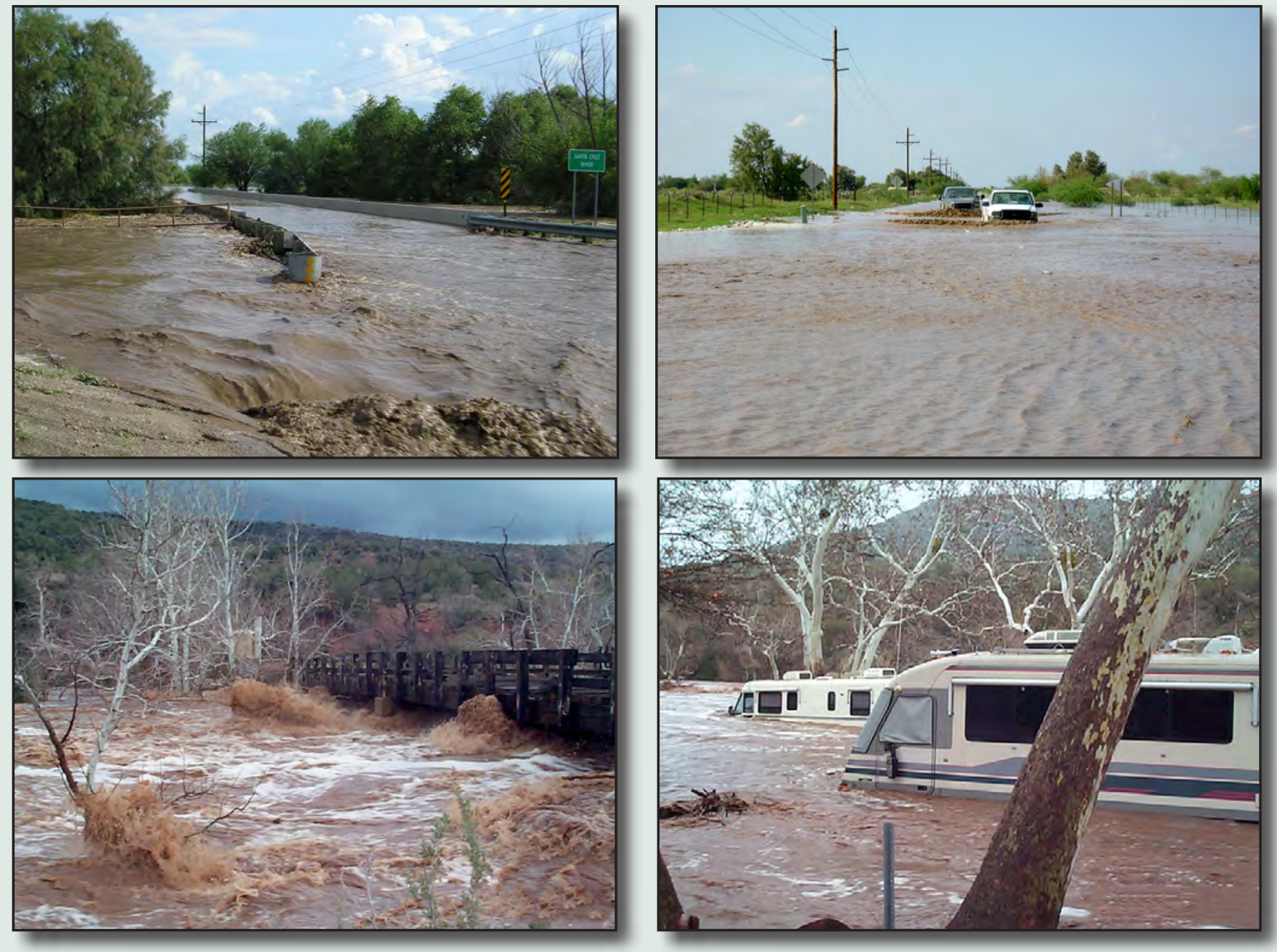

Scientific Investigations Report 2014-5211 
Cover photographs. Top left and top right: Santa Cruz River near Trico Road, 2006 (photographs by Fletcher Brinkerhoff). Bottom left: Dry Beaver Creek, 2004 (photograph by Mike Sanders). Bottom right: Oak Creek Canyon, 2004 (photograph by Mike Sanders). 


\section{Methods for Estimating Magnitude and Frequency of Floods in Arizona, Developed with Unregulated and Rural Peak-Flow Data through Water Year 2010}

By Nicholas V. Paretti, Jeffery R. Kennedy, Lovina A. Turney, and Andrea G. Veilleux

Prepared in cooperation with the Flood Control Districts of Maricopa County, Pima County, Pinal County, Yavapai County, Mohave County, Cochise County, Navajo County, Greenlee County, and Salt River Project, U.S. Forest Service, and Bureau of Reclamation

Scientific Investigations Report 2014-5211 


\title{
U.S. Department of the Interior SALLY JEWELL, Secretary
}

\section{U.S. Geological Survey Suzette M. Kimball, Acting Director}

\author{
U.S. Geological Survey, Reston, Virginia: 2014
}

For more information on the USGS - the Federal source for science about the Earth, its natural and living resources, natural hazards, and the environment, visit http://www.usgs.gov or call 1-888-ASK-USGS.

For an overview of USGS information products, including maps, imagery, and publications, visit http://www.usgs.gov/pubprod

To order this and other USGS information products, visit http://store.usgs.gov

Any use of trade, firm, or product names is for descriptive purposes only and does not imply endorsement by the U.S. Government.

Although this information product, for the most part, is in the public domain, it also may contain copyrighted materials as noted in the text. Permission to reproduce copyrighted items must be secured from the copyright owner.

Suggested citation:

Paretti, N.V., Kennedy, J.R., Turney, L.A., and Veilleux, A.G., Methods for estimating magnitude and frequency of floods in Arizona, developed with unregulated and rural peak-flow data through water year 2010: U.S. Geological Survey Scientific Investigations Report 2014-5211, 61 p., http://dx.doi.org/10.3133/sir20145211.

ISSN 2328-0328 


\section{Contents}

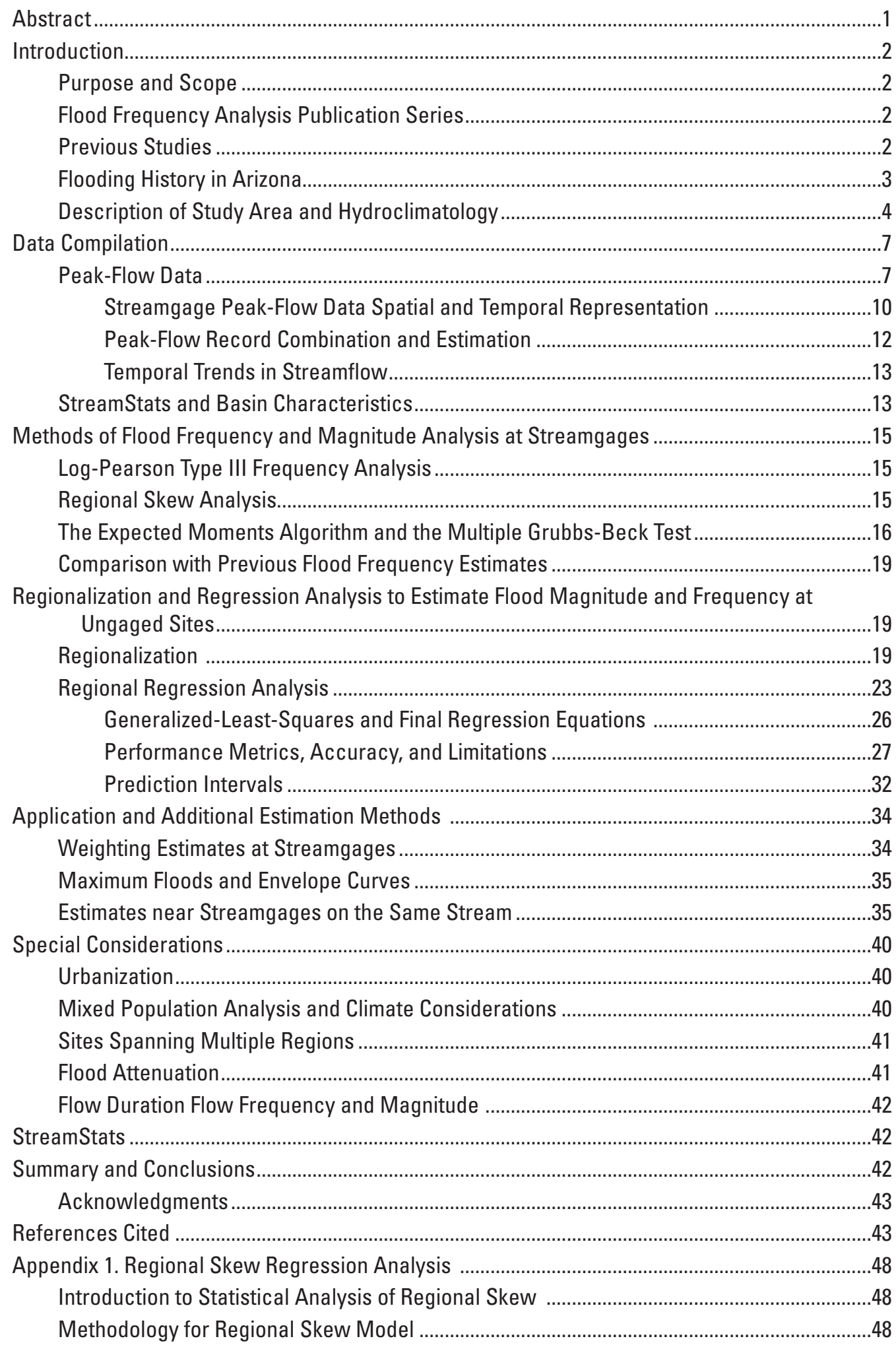


Ordinary Least Squares Regression Analysis.............................................................48

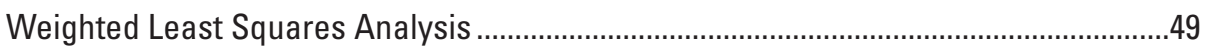

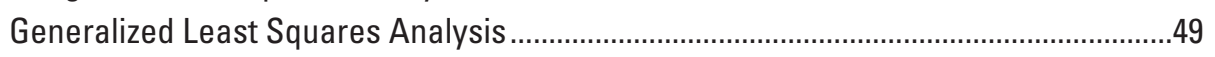

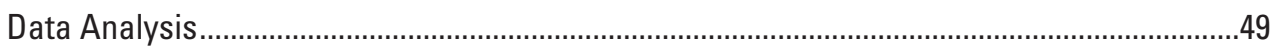

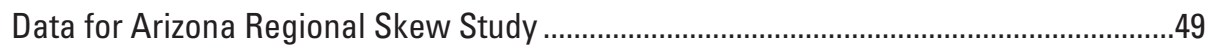

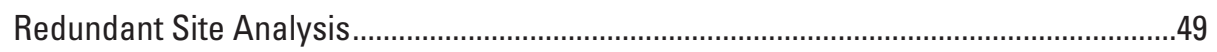

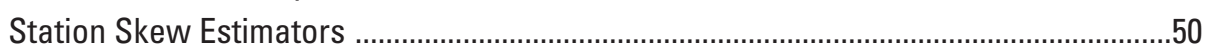

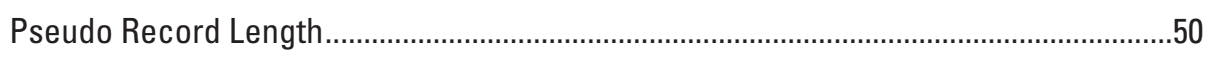

Unbiasing the Station Estimators ...............................................................................51

Estimating the Mean Square Error of the Skew Estimator ...............................................51

Cross-Correlation Models .................................................................................52

Pseudo Concurrent Record Length ...........................................................................52

Arizona Study Area Cross-Correlation Model of Concurrent Annual Peak Flow ...........52

Arizona Regional Skew Study Results ........................................................................52

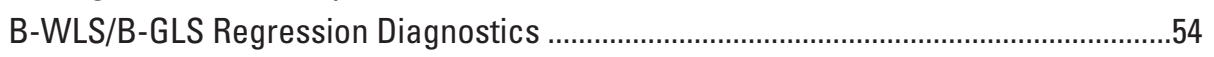

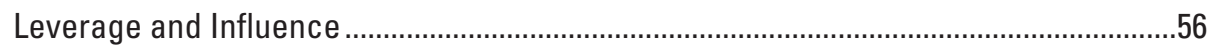

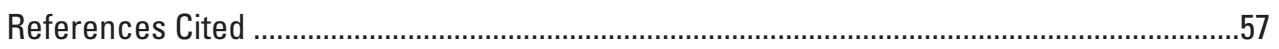

Appendix 2. StreamStats Development .........................................................................59

Geographical Information Systems and Basin Characteristic Data Processing ....................59

Edits and Adjustments ..........................................................................................59

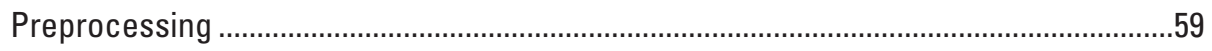

Hydrodem Processing ...........................................................................................

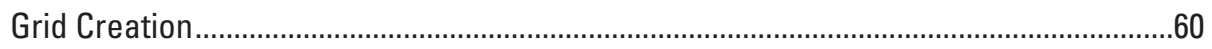

Gage Snapping and Watershed Delineation ...............................................................60

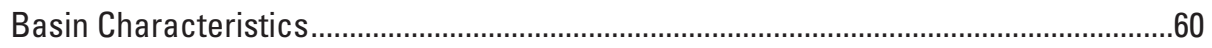

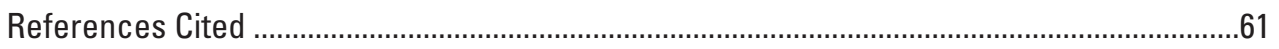

\section{Figures}

1. Map of Arizona and major physical landscape features ....................................................

2. Maximum peak-flow discharges of the 448 streamgages investigated and the yearly losses from flooding in Arizona from water years 1955 to 2010.

3. Maps of Arizona showing, $A$, physiographic regions; $B$, generalized zones of elevation; $C$, generalized zones of mean annual precipitation; and $D$, Level III ecoregions.

4. Location of hydrologic regions and streamgages evaluated for use in the regional skew analysis and annual exceedance-probability regional regression analysis

5. Number of streamgages classified by number of years operating grouped by physiographic region

6 . The $A$, number of streamgages operating; $B$, median drainage area; $C$, median and coefficient of variation of peak flows between water years 1910 and 2010

7. Map of Arizona showing streamgages with $\mathbf{3 0}$ or more years of record that have significant trends in annual peak flows determined using a Kendall's tau trend test 
8. Examples of the fitted Log Pearson Type III frequency curve using the Expected Moments Algorithm with a multiple Grubbs-Beck test and the Bulletin 17B method with a Grubbs-Beck test.

9. Relation of 1-percent annual exceedance probability flood and boxplot of the relative percent difference between updated estimates through water year 2010 and WSP-2433 estimates. . .20

10. Maps of Arizona showing regionalization schemes....................................................21

11. A principal components analysis ordination plot............................................................24

12. Density contour plot of the 1-percent annual exceedance probability plotted as a function of the first principal component from the PC analysis of the normalized drainage, mean annual precipitation, and mean basin elevation

13. The relation between the observed and predicted flood discharges for 1-percent annual exceedance probability by flood region.

14. The maximum recorded peak-flow discharge plotted with the frequency curves for the 1- and 0.2-percent annual exceedance probability and the Crippen envelope curve region, by region

1-1. Relation between Fisher $Z$ transformed cross-correlation of logarithm of annual peak flow and distance between basin centroids for 1,032 stationpairs with concurrent record lengths $\geq 50$ years from 52 streamgages in Arizona and neighboring states

1-2. Relation between untransformed cross-correlation of logs of annual peak flow and distance between basin centroids based for 1,032 station-pairs with concurrent record lengths $\geq 50$ years from 52 streamgages in Arizona and neighboring states

1-3. Leverage and influence diagnostic statistics for the Arizona study area B-WLS/B-GLS Constant model

\section{Tables}

[Tables 1-3, 5-8, 12-14, and 1-1 are available online only at http://pubs.usgs.gov/sir/2014/5211/.]

1. Arizona streamgages used in the flood frequency and regional regression analyses.

2. Description of streamgages considered in the regional regression analysis in Arizona.

3. Basin characteristic descriptions, units, and sources.

4. T-year recurrence intervals with corresponding P-percent annual exceedance probabilities for flood frequency flow estimates.

5. The 50-, 20-, 10-, 4-, 2-, 1-, 0.5-, and 0.2-percent annual exceedance probability flow estimates and Log Pearson Type III statistics at streamgages considered in the regional regression analysis.

6. Summary and comparison of the ordinary-least-squares regression analysis of the different regional schemes.

7. Streamgages removed from the regional regression analysis.

8. Streamgages with leverage or influence statistic exceedances, by flood region.

9. Regional regression equations for predicting the $50-, 20-, 10-, 4-, 2-, 1-, 0.5-$, and 0.2-percent annual exceedance probability flows in 5 flood regions of Arizona .......28

10. Average variance of prediction, standard error of prediction, and pseudo- $\mathrm{R}^{2}$ for the regional regression equations 
11. Applicable ranges of explanatory variables used to develop the regional regression equations

12. Covariance matrix of basin characteristic values needed to determine the 90-percent prediction intervals for estimates obtained from regional regression equations.

13. Variance estimates of station, regression, and weighted food-frequency statistics for streamgages in Arizona.

14. Final flood frequency estimates for station, regression, and weighted computation for streamgages in Arizona.

1-1. Description of streamgages located in Arizona and in neighboring States that were evaluated for use in the regional skew analysis for Arizona.

1-2. Regional skew models for Arizona study area

1-3. Pseudo Analysis of Variance table for the Arizona regional skew study for the constant model

2-1. Basin characteristic statistics for streamgages.

\section{Conversion Factors}

Inch/Pound to SI

\begin{tabular}{|c|c|c|}
\hline Multiply & By & To obtain \\
\hline \multicolumn{3}{|c|}{ Length } \\
\hline inch (in.) & 2.54 & centimeter $(\mathrm{cm})$ \\
\hline inch (in.) & 25.4 & millimeter $(\mathrm{mm})$ \\
\hline foot $(\mathrm{ft})$ & 0.3048 & meter $(\mathrm{m})$ \\
\hline mile (mi) & 1.609 & kilometer $(\mathrm{km})$ \\
\hline \multicolumn{3}{|c|}{ Area } \\
\hline square mile $\left(\mathrm{mi}^{2}\right)$ & 259.0 & hectare (ha) \\
\hline square mile $\left(\mathrm{mi}^{2}\right)$ & 2.590 & square kilometer $\left(\mathrm{km}^{2}\right)$ \\
\hline \multicolumn{3}{|c|}{ Volume } \\
\hline cubic foot $\left(\mathrm{ft}^{3}\right)$ & 28.32 & cubic decimeter $\left(\mathrm{dm}^{3}\right)$ \\
\hline cubic foot $\left(\mathrm{ft}^{3}\right)$ & 0.02832 & cubic meter $\left(\mathrm{m}^{3}\right)$ \\
\hline \multicolumn{3}{|c|}{ Flow rate } \\
\hline cubic foot per second $\left(\mathrm{ft}^{3} / \mathrm{s}\right)$ & 0.02832 & cubic meter per second $\left(\mathrm{m}^{3} / \mathrm{s}\right)$ \\
\hline
\end{tabular}

Temperature in degrees Celsius $\left({ }^{\circ} \mathrm{C}\right)$ may be converted to degrees Fahrenheit $\left({ }^{\circ} \mathrm{F}\right)$ as follows:

${ }^{\circ} \mathrm{F}=\left(1.8 x^{\circ} \mathrm{C}\right)+32$

Temperature in degrees Fahrenheit $\left({ }^{\circ} \mathrm{F}\right)$ may be converted to degrees Celsius $\left({ }^{\circ} \mathrm{C}\right)$ as follows:

${ }^{\circ} \mathrm{C}=\left({ }^{\circ} \mathrm{F}-32\right) / 1.8$

Vertical coordinate information is referenced to the North American Vertical Datum of 1988 (NAVD 88).

Horizontal coordinate information is referenced to the North American Datum of 1983 (NAD 83).

Elevation refers to distance above or below NAVD 88.

Water year is the 12-month period, 0ctober 1 through September 30, and is designated by the calendar year in which it ends. Thus, the water year ending September 30, 2001 is called "water year 2001." 


\section{Abbreviations}

\begin{tabular}{|c|c|}
\hline AEP & annual exceedance probability \\
\hline AVP & average variance of prediction \\
\hline B17B & Bulletin 17B \\
\hline B17B-GB & Bulletin 17B Grubbs-Beck test \\
\hline BGLS & Bayesian generalized-least-squares \\
\hline EMA & Expected Moments Algorithm \\
\hline EMA-MGB & Expected Moments Algorithm multiple Grubbs-Beck test \\
\hline EVR & error variance ratio \\
\hline FEMA & Federal Emergency Management Agency \\
\hline GB & Grubbs-Beck low-outlier test \\
\hline GIS & geographic information system \\
\hline GLS & Generalized-least-squares \\
\hline LPIII & Log-Pearson Type 3 \\
\hline $\mathrm{MBV}^{*}$ & misrepresentation of the beta variance statistic \\
\hline MSE & mean square error \\
\hline NED & national elevation dataset \\
\hline NHD & national hydrologic dataset \\
\hline NLCD & national land cover dataset \\
\hline NWIS & National Water Information System \\
\hline OLS & ordinary-least-squares \\
\hline PILF & potentially influential low outlier \\
\hline PRISM & parameter-elevation regressions on independent slopes model \\
\hline USACE & U.S. Army Corps of Engineers \\
\hline USGS & U.S. Geological Survey \\
\hline WBD & watershed boundary dataset \\
\hline WIE & weighted independent estimates \\
\hline WLS & weighted-least-squares \\
\hline WREG & weighted-multiple-linear regression \\
\hline
\end{tabular}





\title{
Methods for Estimating Magnitude and Frequency of Floods in Arizona, Developed with Unregulated and Rural Peak-Flow Data through Water Year 2010
}

\author{
By Nicholas V. Paretti, Jeffery R. Kennedy, Lovina A. Turney, and Andrea G. Veilleux
}

\section{Abstract}

Flooding is among the worst natural disasters responsible for loss of life and property in Arizona, underscoring the importance of accurate estimation of flood magnitude for proper structural design and floodplain mapping. Twenty-four years of additional peak-flow data have been recorded since the last comprehensive regional flood frequency analysis conducted in Arizona. Periodically, flood frequency estimates and regional regression equations must be revised to maintain the accurate estimation of flood frequency and magnitude.

Annual peak-flow data collected through water year 2010 were compiled from 448 unregulated streamflow-gaging stations, hereafter referred to as streamgages, in Arizona having a minimum of 10 years of record. Flood frequency estimates were first computed with station (or at-site) skew using the Expected Moments Algorithm with a multiple Grubbs-Beck test to identify multiple potentially influential low flows to fit a Pearson Type III distribution. Next, a multiple step Bayesian least-squares-regression approach was used to determine a new statewide regional skew of -0.09 . No basin characteristics analyzed were statistically significant in explaining the variation in skew and as a result, the constant model was chosen as the best regional skew model for the Arizona study area. The mean square error used in Bulletin 17B (B17B) of the Interagency Advisory Committee on Water Data is used to describe the precision of the regional skew. The constant model had a mean square error equal to 0.08 , which corresponds to an effective record length of 85 years. This is a marked improvement over a previous Arizona regional skew analysis, with a reported mean square error of 0.31 , for a corresponding effective record length of around 17 years. Thus the new regional model had almost five times the information content (as measured by effective record length) of that calculated in USGS Water Supply Paper 2433, published in 1997, or the value of 0.302 reported in the B17B generalized skew map. The flood frequency estimates were recalculated using a weighted skew of the station and regional skew. Station flood frequency estimates for each streamgage are presented for the
50-, 20-, 10-, 4-, 2-, 1-, 0.5-, and 0.2-percent annual exceedance probabilities.

Geographical information systems were used to compute basin characteristic information for each streamgage for the purpose of developing regional equations to estimate flood statistics at ungaged basins. Five hydrologic flood regions in Arizona were defined in a multivariate regionalization process based on mean basin elevation, mean annual precipitation, and soil permeability. A regional generalized least-squaresregression analysis was used to develop five sets of equations from 344 nonredundant streamgages, corresponding to five regions, for estimating the 50-, 20-, 10-, 4-, 2-, 1-, 0.5-, and 0.2 -percent annual exceedance probabilities at ungaged basins in Arizona. The regression equations developed for these five regions were based on one or more of the statistically significant explanatory variables: drainage area, mean basin elevation, and mean annual precipitation. Average standard errors of prediction for the regression regions for the five regions ranged from 27 to 122 percent and the pseudo-coefficients of determination (pseudo- $\mathrm{R}^{2}$ ), a measure of the proportion of peak-flow variation that is explained by the basin characteristics, ranged from 68 to 98 percent. Regression equations for Central Highlands (region 4) had the lowest model error and the greatest pseudo- $\mathrm{R}^{2}$ metrics. The equations for Colorado Plateau (region 2) regression equations generally had greater model error and lower pseudo- $\mathrm{R}^{2}$ metrics. The improvement of regional regression equation model error and pseudo- $\mathrm{R}^{2}$ metrics was related to higher numbers of streamgages, longer period of record, and even spatial coverage within a region.

The regional regression equations were integrated into the U.S. Geological Survey's StreamStats program. The StreamStats program is a national map-based web application that allows the public to easily access published flood frequency and basin characteristic statistics. The interactive web application allows a user to select a point within a watershed (gaged or ungaged) and retrieve flood-frequency estimates derived from the current regional regression equations and geographic information system data within the selected basin. StreamStats provides users with an efficient and accurate 
means for retrieving the most up to date flood frequency and basin characteristic data. StreamStats is intended to provide consistent statistics, minimize user error, and reduce the need for large datasets and costly geographic information system software.

\section{Introduction}

Flooding in Arizona has caused approximately 1.3 billion dollars' worth of damage between 1955 and 2000 (Pielke and others, 2002 [adjusted for inflation, 1995 dollars]), and of all natural hazards, flooding is the most frequent and costly to the State (Arizona Division of Emergency Management [AZDEM], 2010). Between 1964 and 2012, AZDEM reported 63 flooding events that required a state or federal disasterdeclaration and over 100 undeclared flooding events large enough to cause reportable damage. Flooding was responsible for the deaths of 128 persons and for 252 injuries (AZDEM, 2010).

Reliable estimates of flood frequency and magnitude are necessary to ensure human safety, to effectively minimize the damage caused by floods, and to accurately determine flood risk for the National Flood Insurance Program. Federal, state, and local agencies use flood frequency information to manage water resources, provide for public safety, establish flood-hazard regulations, and plan infrastructure. For many streams and rivers in Arizona, flood information is collected at U.S. Geological Survey (USGS) streamflow gaging stations, hereafter referred to as streamgages, and the data are readily available through the USGS National Water Information System Web Interface. Flood information exists for only a small proportion of streams in the State, however, because it is cost prohibitive and logistically unfeasible to gage every watershed in the State. To estimate flood frequency and magnitude for streams in areas without streamgages, multiple-linear regression models can be developed that relate flood frequency estimates to physical basin characteristics at gaged streams, and the models are then applied to ungaged basins.

In Arizona, the existing regional regression equations used for estimating magnitude and frequency of floods were developed on the basis of peak-flow data and basin characteristic data through 1986 (Thomas and others, 1997). Since then, 24 years of additional peak-flow data have been collected, advances have been made in the statistical procedures for conducting flood frequency analysis, geographical information system (GIS) datasets have been improved, and new GIS tools have been developed. The USGS, in cooperation with the Flood Control Districts of Maricopa County, Pima County, Pinal County, Yavapai County, Mohave County, Cochise County, Navajo County, and Greenlee County; the Salt River Project, U.S. Forest Service, and the Bureau of Reclamation, completed the investigation described here to update the regional regression equations for Arizona on the basis of peakflow data through water year 2010 using new statistical tools and GIS methods, and to provide easy, public access to flow statistics through the USGS StreamStats webpage.

\section{Purpose and Scope}

This report presents methods for estimating the magnitude and frequency of floods on rural streams in Arizona, following the framework developed in the Bulletin 17B Guidelines (Interagency Advisory committee on Water Data [B17B], 1982). The report (1) describes methods for determining updated flow estimates of the 50-, 20-, 10, 4-, 2-, 1-, $0.5-$, and 0.2-percent annual exceedance probabilities (AEP) for 448 streamgages in Arizona; (2) explains the procedure for determining a new regional skew value for the State; (3) documents the development of regional regression equations and other methods for estimating flood magnitudes of the AEPs for ungaged locations; (4) discusses the limitations of the regional regression equations; (5) provides special considerations of flood frequency analysis and regionalization in Arizona; and (6) describes the implementation of a webbased map called StreamStats for determining flood and basin characteristic statistics.

\section{Flood Frequency Analysis Publication Series}

This publication is the second in a series of five publications that utilize similar flood frequency estimation techniques. The first report, by Paretti and others (2013), analyzed the effects of applying the proposed updates to the B17B flood frequency methods recommended by the Subcommittee on Hydrology, Advisory Committee on Water Information Hydrologic Frequency Analysis Work Group, primarily the Expected Moments Algorithm and the Multiple Grubbs-Beck test to peak-flow records in Arizona. The methodology and tools described by Paretti and others (2013) were utilized in the present publication. The third and fourth reports, by Kennedy and others (2014), and Kennedy and Paretti (2014), use methods and regression equations presented in this report. Those published reports describe flood frequency estimates and development of a regional regression equation for estimating the $n$-day flood volume frequency in Arizona and the application of flood-frequency methods in urbanized watersheds in Tucson and Phoenix, Arizona. The fifth publication by Zamora-Reyes and others (2013) describes the implications of considering hydroclimatology on flood frequency and regional regression analysis in Arizona.

\section{Previous Studies}

The first statewide investigation for estimating flood frequency and magnitude for gaged and ungaged watersheds in Arizona was conducted by Roeske (1978), using B17B methods with data from 221 streamgages up to water year (WY) 1975. The average length of peak-flow records, among the regions of the State delineated for the purpose of Roeske's investigation, ranged from 14 to 33 years, and the important regression explanatory variables were drainage area, mean elevation, and mean annual precipitation. An evaluation of the 
regional regression equations found them to be biased towards larger watersheds, and peak flows from small watersheds were likely underrepresented (Reich and others, 1979). Standard error of prediction was between 45 and 91 percent for the 1-percent AEP in Roeske's (1978) 6 flood regions. The high standard error of prediction was attributed to the extreme time and spatial variability in streamgage records and locations.

Subsequent studies focused on smaller regions of the State. Eychaner (1984) completed a flood frequency and regression analysis of data from streamgages in Pima County, Arizona. Eychaner developed rural and urban regression equations for southern Arizona, and presented a complex (second order polynomial) and a simplified (linear single explanatory variable) set of equations for the 50-, 20-, 10-, 4-, 2-, 1-, 0.5-, and 0.2-percent annual exceedance probabilities (AEP). The second order polynomial modeling procedure was applied to more accurately fit a curvilinear relation between peak flow and drainage area. This modeling approach lowered standard errors from 5 to 6 percent for the lower AEP floods. The polynomial models included drainage area, mean elevation, main channel length, main channel slope, and a shape factor as explanatory variables. Because this approach was so effective, later studies, including the current one, used this approach in Southern Arizona. Flood attenuation in channels that experience distributary flow was another important consideration. Eychaner suggested adjustments for areas that are affected by flood attenuation, and also recognized that streamgages affected by flood attenuation have negatively skewed flood distributions and poor frequency fits. Standard error of prediction for the area was improved by more than 35 percent from the previous regional regression equation for southeastern Arizona.

Building on earlier work at Walnut Gulch Experimental Watershed (Osborn and Laursen, 1973), Boughton and Renard (1984) compared log-Pearson Type III distribution (LPIII) and log-Boughton distributions for several watersheds in southeastern Arizona using a graphical fitting method. An envelope curve for the 1-percent AEP quantile based on drainage area was developed, but after the October 1983 floods in southeastern Arizona, the magnitude of the envelope curve was revised upward (Boughton and others, 1987). Hill and others (1987) investigated flood frequency near Flagstaff, Ariz., using B17B methods. Only the most frequent AEP floods (50-, 20-, $10-$, and 4-percent) were considered, and drainage area was the only significant explanatory variable used in the regional regression equations.

The Arizona regional regression equations currently in use were developed by Thomas and others (1997 [referenced as WSP-2433]) for ten southwestern States on the basis of data through WY 1986. After testing several regional skew approaches recommended in $\mathrm{B} 17 \mathrm{~B}$, a constant regional skew of 0 with mean square error of 0.31 logarithm units was used to weight the station skew estimates. Drainage area was used as an explanatory variable in all of the AEP regional regression equations, elevation was used in three of the regions, and evaporation was used in Region 11 for the 10-, 4-, 2-, and 1-percent AEP regression equations. A later study updated the WSP-2433 regional regression equations for the Navajo Nation in northern Arizona (Waltemeyer, 2006). Basin slope was determined to be a significant explanatory variable in WSP-2433 regions 8 and 11 (covering southeastern Utah and far northeastern Arizona, and northeastern Arizona, respectively). Average standard error of prediction ranged from 52 to 116 percent in the two regions. Improvements over WSP2433 were reported in the accuracy of the regional regression equations for region 11 and the high elevation region (greater than 7,500 ft), and these were attributed more accurate GIS information and a longer period of peak-flow data.

\section{Flooding History in Arizona}

In the Southwest, water has always been regarded as a scarce and precious resource that is necessary for human survival. This is the reason communities and cities are commonly located near plentiful water sources such as large rivers. To the detriment of human development along large rivers in the lower Southwest region of the United States, housing and infrastructure are frequently prone to damaging floods. The location and physiography of Arizona (fig. 1) make it susceptible to multiple types of weather patterns that produce local and intense flooding events, as well as widespread, regional flooding events. The extreme nature of flooding in Arizona pose risks that are unique to the Southwest and have been recognized as such, through the documentation of paleofloods and other extreme events occurring over the last 1,000 years. The early documentation of flooding and significant precipitation events in Arizona dates back to settlement in the State around the early- to mid-1800's, when records were collected by explorers and by individuals at army posts, such as Fort Yuma (Brazel and Evans, 1983). The first systematic recording of weather observations was conducted by the Army Signal Service beginning in 1870. In the late 1800 's, documentation became the responsibility of the U.S. Department of Agriculture, until the Weather Bureau was formed. The Weather Bureau, which later became the National Oceanic and Atmospheric Administration, assumed the role of maintaining notable weather and flooding events. Systematic records of river stage were first obtained by the USGS along the Colorado River at Yuma, in 1878, but it was not until 1912 that cooperative agreements were established and the widespread systematic collection of surface-water records began (Pope and others, 1998). All historical flooding is currently documented in the USGS peak-flow records of the streamgages that were affected.

In Arizona, the first major historical floods that inundated and destroyed large sections of Yuma and downtown Phoenix were documented in 1862, 1874, 1891, and 1905 (Aldridge and Eychaner, 1984; Brazel and Evans, 1984). In 1916, intense rainfall on top of melting snow produced large floods, caused 4 deaths, and resulted in more than $\$ 300,000$ worth of damage (Brazel and Evans, 1984). In 1926, flooding on the Gila River 
and the San Pedro River caused $\$ 450,000$ worth of damage. During the same event, Bisbee recorded 10.19 inches (in.) of rain, Gillespie Dam was closed with 4 feet (ft) of water at the crest of the dam, and the Southern Pacific Railroad was extensively damaged (Brazel and Evans, 1984). Brawly and Santa Rosa Washes were flooded near Casa Grande, which resulted in one death and $\$ 3$ million in damage (Paulson and others, 1991). More than $\$ 10$ million in damage was caused by flooding in winter 1965-66 on the Salt and Gila Rivers, owing in large part to the release of water from storage reservoirs following widespread rainstorms (Aldridge, 1970; fig. 2). Conversely, storage behind reservoirs greatly reduced peak flows during flooding in March 1978, although peak flows in the region were still some of the largest on record, causing about $\$ 66$ million in damage and 3 deaths were still reported from these events (Aldridge and Eychaner, 1984). In December 1978, heavy rainfall combined with snowmelt caused flooding on the Gila and Lower Colorado Rivers, more than $\$ 150$ million in damage, and 12 deaths (Aldridge and Hales, 1984). In 1983, record floods on 18 streams, most notably on the Santa Cruz and San Francisco Rivers, caused 8 deaths and \$226 million in damage (Paulson and others, 1991). Significant flooding, causing more than $\$ 50$ million in damage, occurred statewide following winter precipitation in 1993; areas on the lower Gila River, normally protected by storage in Painted Rock Reservoir, were inundated by unprecedented releases (House, 1993). Although streamflows in Arizona were on average lower between 1999 and 2010 than in previous decades, flooding in the years 2005 and 2010 caused extensive damage. The 2010 storm resulted from a strong El Niño weather pattern and was responsible for widespread flooding in central Arizona. During that storm, the Flood Control District of Maricopa County had more than 100 rain gages register 5 inches or more of total precipitation, and 4 rain gages recorded 10 inches of total precipitation in the month of January (Flooding Control District of Maricopa County, 2010).

Flood damage has been very costly to the state of Arizona, but such damage can be difficult to quantify and analyze over the long term because of the complexities of collecting complete and accurate historical flood-damage data. The National Weather Service-Hydrologic Information Center (2014) estimates suggest an increase in flood damage costs in the United States since 1903. And since 1960, when flood damage cost-data began to be more consistently documented, an upward trend was observed in Arizona using data through 2010 (Kendall's $\tau, 0.25, p<0.02$ ). The yearly costs related to flooding in Arizona (since 1960) are shown in figure 2 (National Weather Service, 2001) and the flood damage costs presented have been adjusted to a 1995 dollar amount. Maximum (red) and median (blue) flood magnitudes for all streamgages from which data were used in this investigation are plotted in relation to losses caused by flood damage. The larger floods track similarly to losses, and while the losses have been trending upward, the maximum and median magnitudes of the largest floods between 1960 and 2010 have not significantly increased, suggesting that increasing population, sprawling housing construction, and infrastructure development in flood prone areas is contributing to increases in damage costs.

\section{Description of Study Area and Hydroclimatology}

Arizona has three prominent physiographic regions that influence climate conditions, flood hydrology, and vegetation communities: the Colorado Plateau, the Central Highlands (also known as the Transition Zone), and the Basin and Range Province (Trapp and Reynolds, 1995; fig. 3A). The Western and Southeastern Basin and Range, and the Central Highlands/ Transition Zone are informal names, only capitalized in this report for clarity. The hydrologic setting is highly influenced and complicated by the dramatic elevation gradient from the Colorado Plateau in the northeast to the Western Basin and Range in the southwest (fig. 3B). The combination of the physiography or landscape and variable seasonal atmospheric circulation patterns is responsible for the unique flooding regime in Arizona (that is, the timing, duration, frequency, and magnitude of floods) (House and Hirschboeck, 1997). The resulting extremes manifest in the form of prolonged periods of drought and intense precipitation events in the form of convective storms. The highly variable nature of the extreme events even within the State makes Arizona climatologically unique in the Southwest.

Precipitation events responsible for flooding can be broadly grouped into three storm types: large-scale frontal or synoptic, convective, and tropical precipitation events. The Gulf of California is approximately 60 miles (mi) from the southwestern part of Arizona, and this spatial proximity to the Pacific Ocean can produce extreme weather features or conditions, such as an atmospheric river or a narrow moisture band, rich in water vapor, which can result in massive precipitation events. These bands of enhanced winter water vapor originating in the Pacific Ocean have been recognized as the principal contributor to major flooding in California and Arizona and identified as the cause of the extreme floods of January 2010 (Dettinger, 2013; Neiman and others, 2013).

The Colorado Plateau encompasses a large part of northern Arizona and drains the Colorado River and its major tributaries: the Green, San Juan, and Little Colorado Rivers. Considerable relief and numerous canyon drainages cause temperatures to widely vary. The average elevation on the Plateau is about 5,200 ft and average rainfall is about 10 inches per year (Foos, 1999; fig. 3C). The primary Environmental Protection Agency (EPA) Level III ecoregions in this area are the Colorado Plateaus (20) and the Arizona/New Mexico Plateau (22); the latter is a large transitional region between the drier saltbrush-greasewood vegetation of the higher relief, rugged tablelands and the lower, hotter, less vegetated Mojave Basin and Range in the western part of the State (Omernik, 1987; fig. 3D). Though precipitation is relatively low in the region, resulting in low peak-flows in many years, runoff can be rapid and powerful as a result of steep topography and sparse vegetation. In addition, peak flows in the larger basins will often be influenced by snowmelt. 


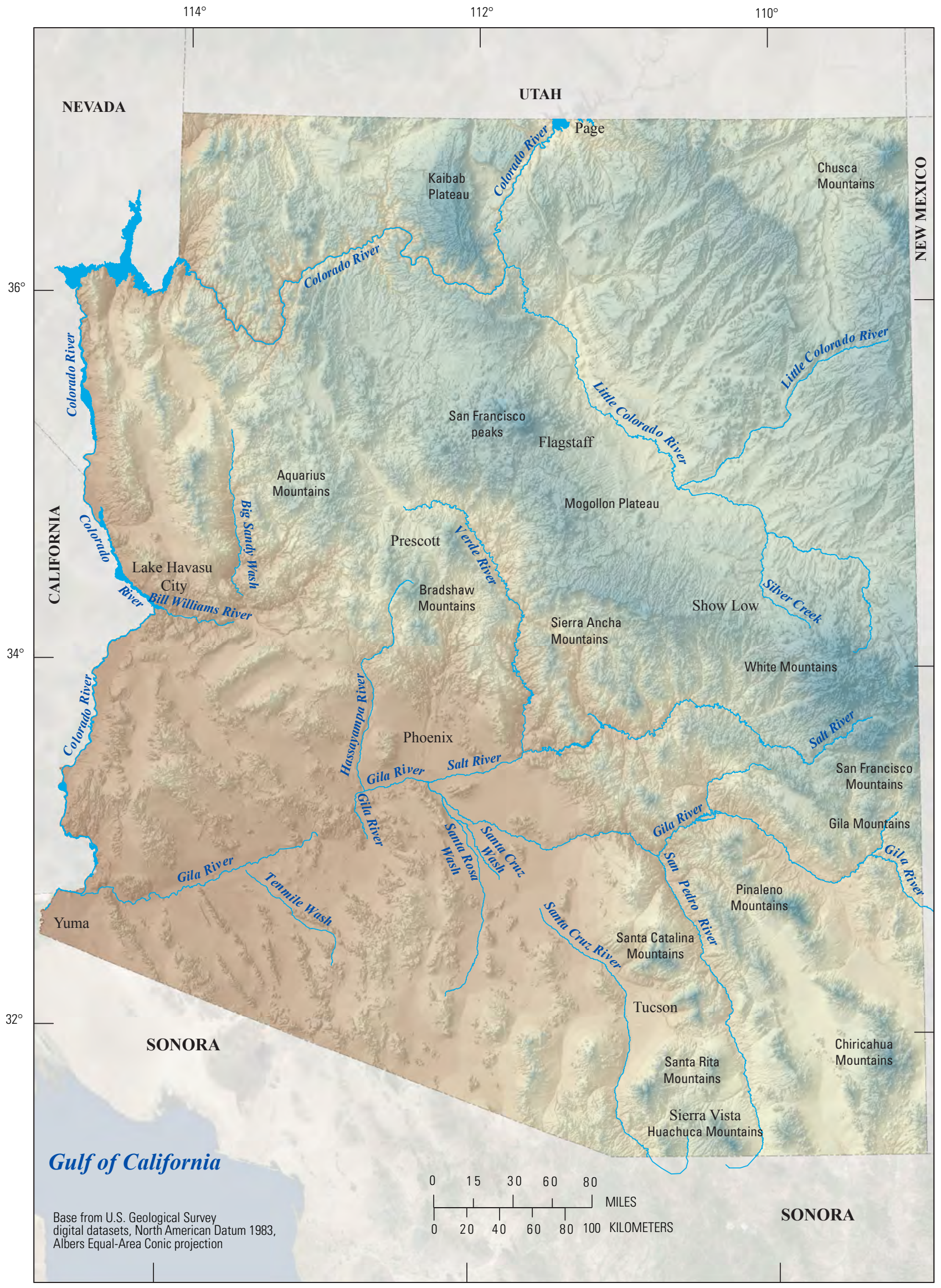

Figure 1. Map of Arizona and major physical landscape features. 
s.e||ор to suo!!|!u u! 'səssoך

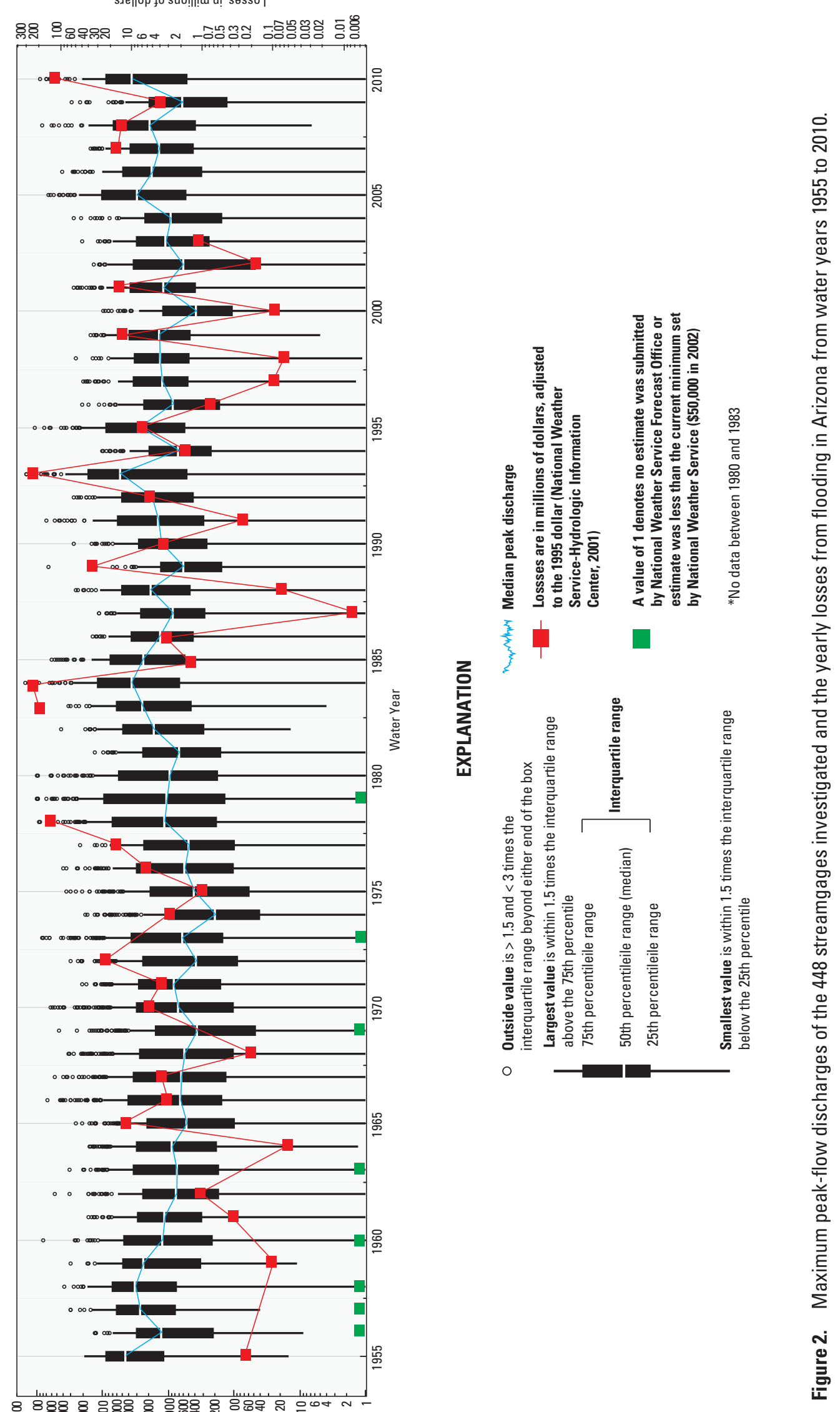

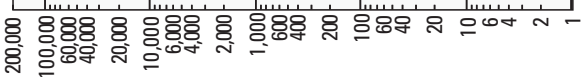

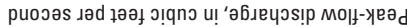


The Central Highlands, or Transition Zone, has physiographic characteristics of both the Colorado Plateau and the Basin and Range Province. This region is the primary source of water that sustains streams and rivers in the central part of the state. Land-surface elevations range from about 2,000 ft near the confluence of the Salt and Verde Rivers to about $11,400 \mathrm{ft}$ on Mount Baldy in the White Mountains. Mean annual precipitation varies widely over the region, from 38 in. in the White Mountains to 16 in. at low elevations along the Salt River (Parameter-elevation Regressions on Independent Slopes Model [PRISM] Climate Group, 2008). This region drains most of the surface water from the Mogollon Rim and several mountain ranges, including the Bradshaw, San Francisco, White, Mazatzal, Santa Maria, and Sierra Anchas Mountains (fig. 1). The headwaters of many of the large rivers in Arizona, including the Salt, Verde, Agua Fria, and Hassayampa Rivers, begin in the Central Highlands. Between July and August, the Central Highlands are affected by a seasonal weather phenomenon referred to as the North American monsoon (Adams and Comrie, 1997). Tropical moisture is pulled northward by a pressure gradient, and localized, intense precipitation can quickly cause increased runoff and flash flooding. The most damaging (costly to property and infrastructure) precipitation events, however, are typically winter synoptic events during which moisture is slowly and continuously drawn inland and rainfall causes saturated soil conditions, leading to longer duration and larger magnitude flooding events. One of the most catastrophic flooding mechanisms occurs when antecedent snow accumulation is followed by a rainfall precipitation event (House and Hirschboeck, 1997). The climate of this region also sustains a unique ecoregion (Arizona/New Mexico Mountains [23]) of mostly chaparral, pinyon-juniper and oak woodlands at lower and middle elevations; at higher elevations the mountains are mostly covered with open to dense ponderosa pine forests (Omernik, 1987).

The Basin and Range Province is a series of alternating mountain and valley features that were formed by tectonic extension (Dickinson, 2002). This dramatic topography has land-surface elevations ranging from $100 \mathrm{ft}$ along the Lower Colorado River to more than $10,000 \mathrm{ft}$ in some mountain ranges; basin floor elevations are generally between 1,000 and $5,000 \mathrm{ft}$. Mean annual precipitation ranges from less than 3 in. in the Yuma area to greater than 30 in. in the Chiricahua Mountains (PRISM Climate Group, 2012). In many years, peak flows in the lower elevation areas are very small or even zero. Throughout the summer months at low elevations, extended periods of temperatures above 100 degrees Fahrenheit are common. Perennial rivers and streams in the Basin and Range Province are relatively rare because of the aridity of the region, dams and impoundments upstream that capture streamflow, and channel infiltration due to groundwater pumping. Like the Central Highlands, this region can experience intense convective thunderstorms from the North American monsoon. The hydroclimatology of the Basin and Range Province is distinctly different between the southeastern and southwestern parts of the State. The southeastern part is higher in elevation, and on average receives more moisture than the western part (fig. $3 C$ ). Winter moisture patterns are more influential in the southeast, where scattered mountain ranges, or "sky islands", will accumulate snow during winter. Native vegetation in the southeastern Madrean Archipelago (79) ecoregion is mostly grama-tobosa shrubsteppe in the basins and oak-juniper woodlands on the mountain ranges, except at higher elevations, where ponderosa pine is most common (Omernik, 1987). The Sonoran Basin and Range (81) ecoregion is more arid than the southwestern Mojave Basin and Range (14) ecoregion, and vegetation is mostly cactus, mesquite, and palo verde. The natural vegetation is predominantly creosote bush in the Mojave ecoregion.

\section{Data Compilation}

\section{Peak-Flow Data}

All streamgages within the 2-digit Hydrologic Unit Code (HUC) of the Lower Colorado (15) and the 4-digit HUCs 1407 and 1408 of the Upper Colorado (14) were initially selected (including gages in California, Colorado, Nevada, Utah, and New Mexico) for inclusion in the flood frequency analysis. Criteria for inclusion in the analysis were that the streamgages must have 10 or more years of annual peak-flow record and that the flow be unregulated and relatively unaffected by urbanization (less than 10 percent of the drainage area covered by an impervious surface). Peak-flow data for 413 streamgages were retrieved from the USGS National Water Information System (NWIS) database at http://nwis.waterdata.usgs.gov/usa/ nwis/peak. In addition, the Maricopa and Pima County Flood Control Districts (FCD) supplied peak-flow information from 14 and 9 county-operated streamgages, respectively. Stagedischarge rating curves maintained by each FCD were used to calculate discharge. In certain instances, FCD streamgaging locations are co-occurring or discontinued USGS streamgages; where available, concurrent data were checked and compared for quality assurance. The FCD of Maricopa County data are available at: $h t t p: / / w w w . f c d . m a r i c o p a . g o v / R a i n f a l l /$ Streamflow/streamflow.aspx, and Pima County FCD data were acquired via electronic request. Peak-flow data from the Walnut Gulch Experimental Watershed and the Santa Rita Experimental Range in southeastern Arizona were collected from the U.S. Department of Agriculture, Agricultural Research Service (ARS), Southwest Watershed Research Center webpage http:// www.tucson.ars.ag.gov/dap/Default.htm. In previous USGS flood frequency analysis reports, several of the Walnut Gulch streamgages were presented with 9-digit USGS station identifications, some of which were retained for this investigation. Twelve ARS streamgages were used in the analysis.

The peak-flow data were reviewed to assure the quality of the records, and longer peak-flow records (30 years or more) were analyzed for the presence of a trend. A standardized data-check review process was completed using the PFReports computer program (Ryberg, 2008) to identify any anomalies or errors, and corrections were documented and changed in NWIS. Streamgage locations, study area boundary, and regional regression regions are shown in figure 4 , and streamgage attributes are listed in table 1. 
$\boldsymbol{A}$

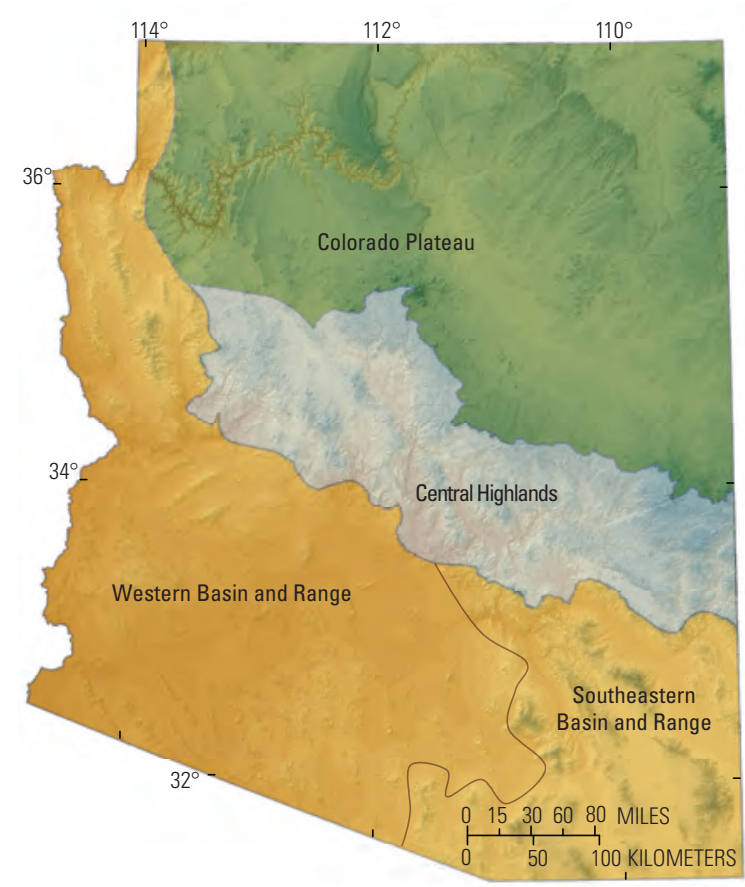

\section{EXPLANATION}

Colorado Plateau

Central Highlands Base from U.S. Geological Survey

Basin and Range digital datasets, North American Datum 1983,

\section{C}

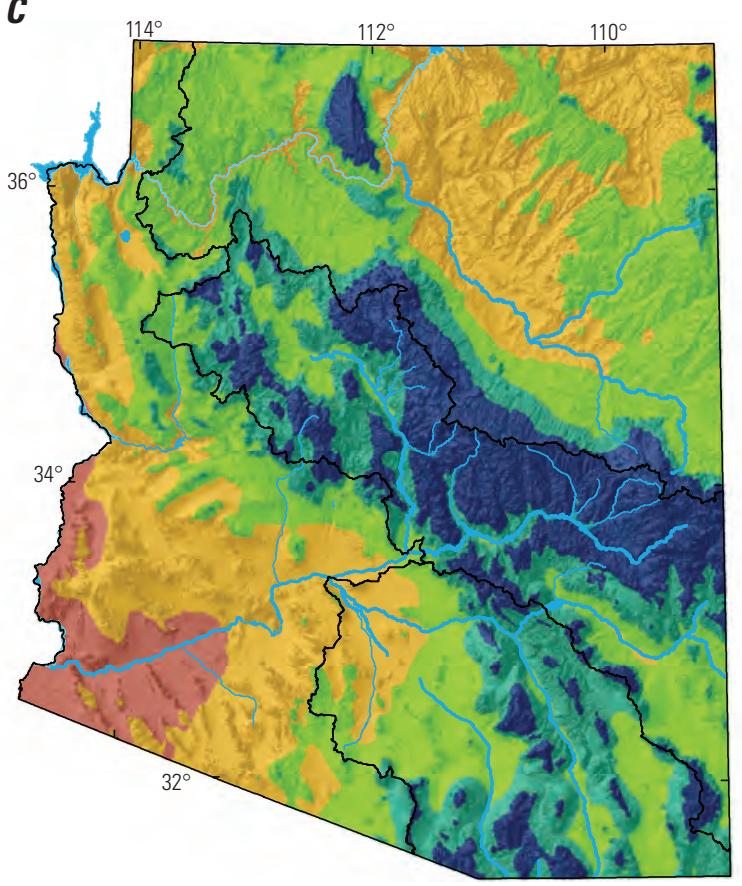

EXPLANATION

0-130 mm (0-5 in)

$131-250 \mathrm{~mm}$ (5.1-10 in)

251-375 mm (10.1-15 in)
B

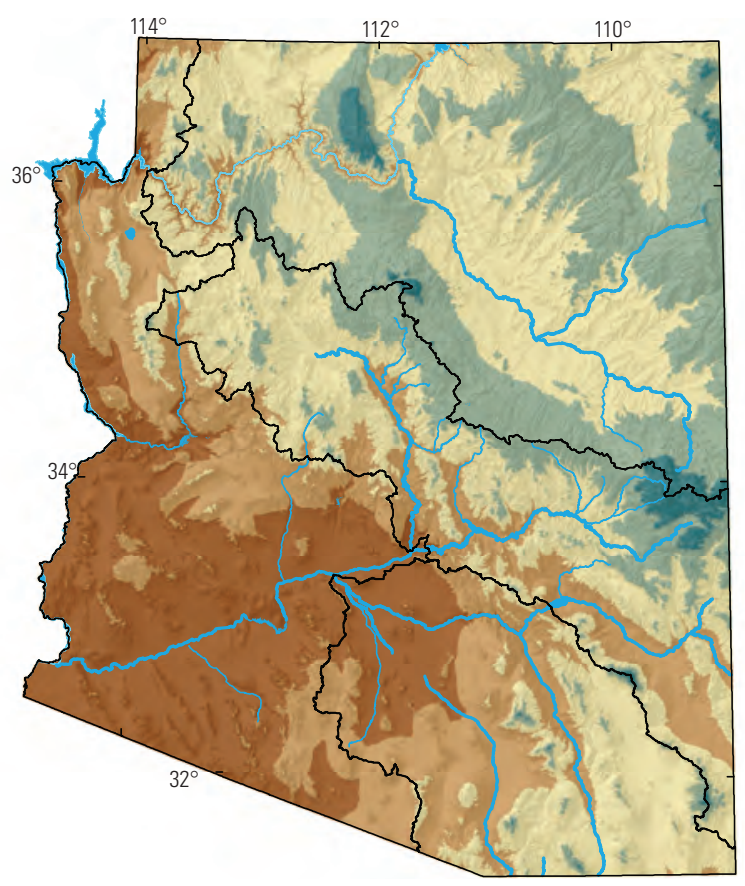

\section{EXPLANATION}

$0-605 \mathrm{~m}(0-2,000 \mathrm{ft})$ $606-1,210 \mathrm{~m}(2,001-4,000 \mathrm{ft})$ $1,211-1,820 \mathrm{~m}(4,001-6,000 \mathrm{ft})$

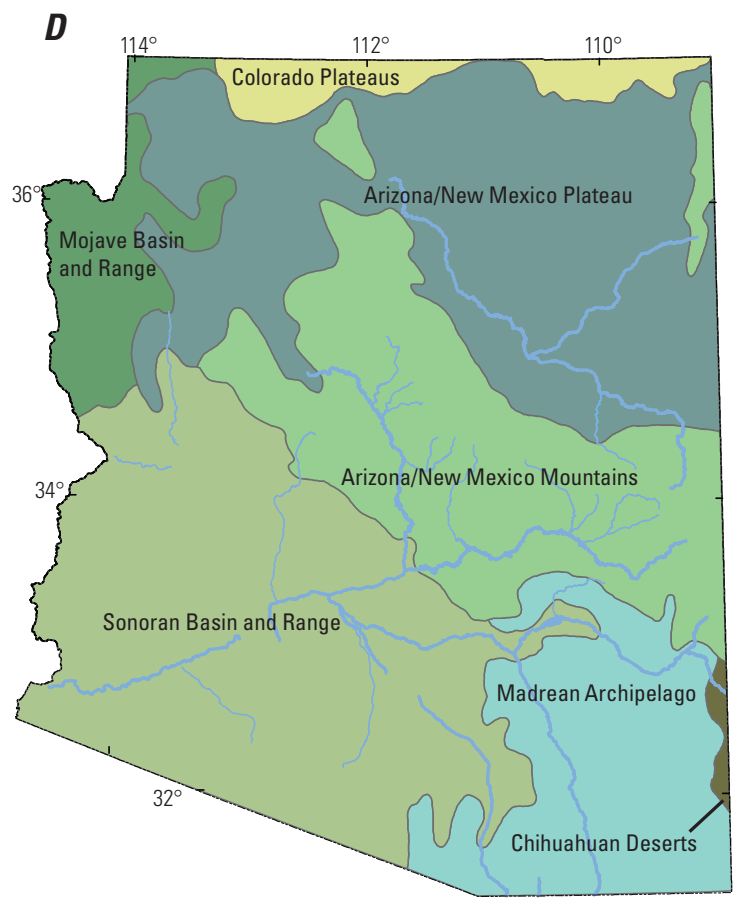

EXPLANATION

Arizona/New Mexico Mountains $\square$ Madrean Archipelago Arizona/New Mexico Plateau $\square$ Mojave Basin and Range Chihuahuan Deserts Colorado Plateaus

$1,821-2,425 \mathrm{~m}(6,001-8,000 \mathrm{ft})$ $2,426 \mathrm{~m}(8,001 \mathrm{ft})$ and above

\section{(1)}




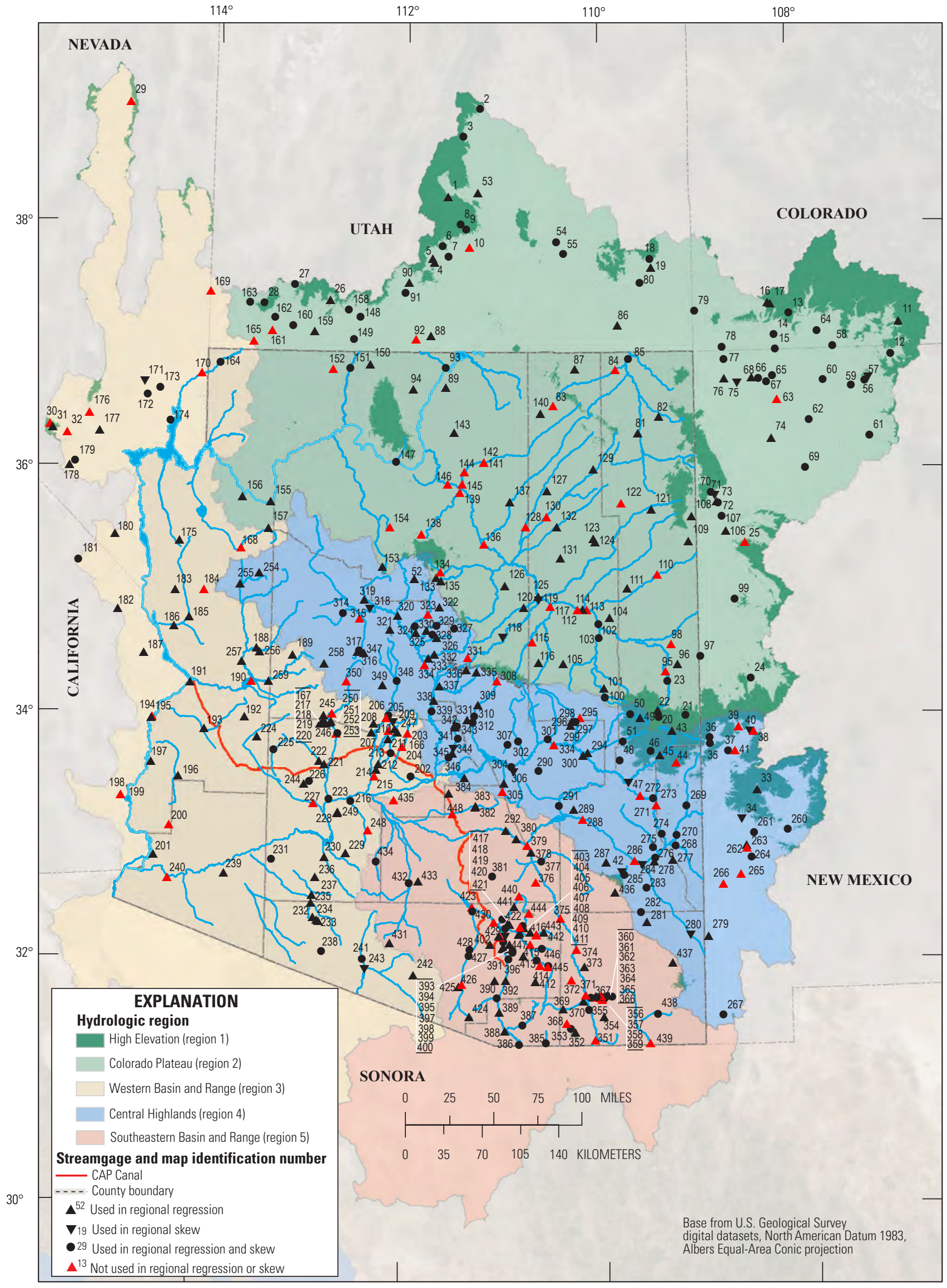

Figure 4. Location of hydrologic regions and streamgages evaluated for use in the regional skew analysis and annual exceedance-probability regional regression analysis. 


\section{Streamgage Peak-Flow Data Spatial and Temporal Representation}

The Southwestern United States has been shown to have sparse spatial coverage of streamgages and a low number of long-term gages operating in comparison to other regions of the country (Kiang and others, 2013). Regions that have low numbers of streamgages are less likely to represent a range of physical and hydrologic conditions that might occur and a limited statistical representation is likely to result in uncertain peak-flow predictions. Establishing a statistically sound streamgage network however may not always be possible or practical given political realities and short-term need for gages. Evolving agency mandates, water accountability requirements, and short-term flood warning networks will result in variable record length and uneven spatial distribution, which can complicate statistical flood frequency and regional analyses. Since the early 1900 's, the overall number of streamgages operating in the State has increased and the spatial coverage has expanded, but also fluctuated as well. About half of the streamgages used in this analysis have 20 years or less of peak-flow record (fig. 5) and Kiang and others (2013) reported the national median as 42 years of record. About 25 percent of the streamgages in Arizona have been collecting peak-flow data for more than 40 years. Many of those streamgages are found in the Central Highlands. The Colorado Plateau has lowest number of streamgages operating longer than 10 years and has the least coverage in the gaging network. Streamgages operating for more than 40 years are useful in developing robust statistical relations between peak flows and basin characteristics. The uncertainty of peak-flow statistics at a streamgage with less years of record can be reduced by combining information from longer operating gages to obtain a weighted estimate of flow statistics at the gage.

The purpose of presenting the changes in streamgage representation over time is to inform the reader of the variability in the gage network that ultimately determines the effectiveness of regional regression equations used to predict peak-flows. This presentation uses only nonregulated and nonurbanized basins (less than 10 percent impervious surface). The number of streamgages in operation for each water year (fig. 6A), the median drainage area of gaged basins (fig. 6B), and the median and coefficient of variation (ratio of the standard deviation to the mean) of peak flow for each water year (fig. 6C) are discussed for the three prominent physiographic regions (Colorado Plateau, Central Highlands, and the Basin and Range Province) of Arizona.

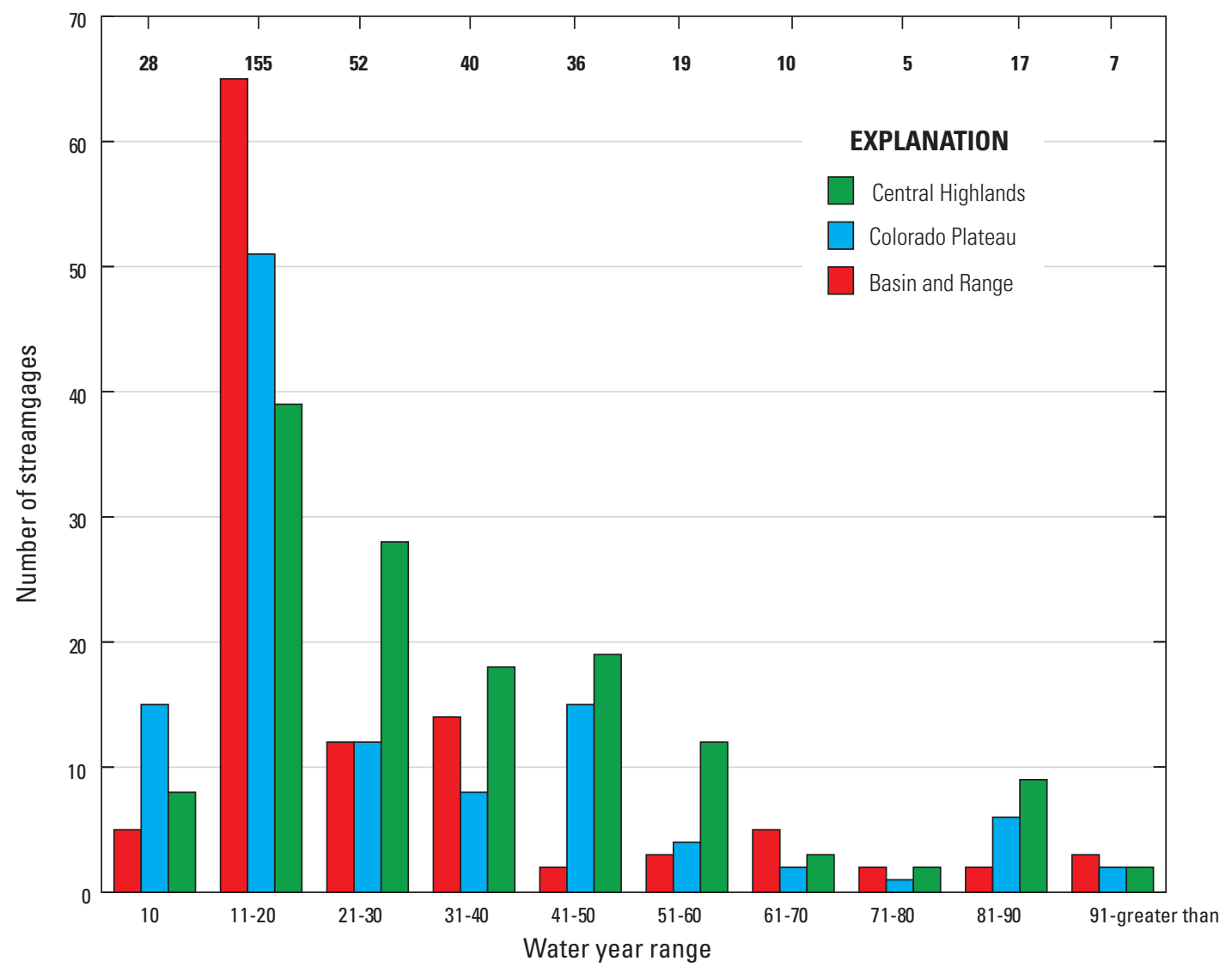

Figure 5. Number of streamgages classified by number of years operating (period of record) grouped by physiographic region. Bold numbers at top of figure indicate total number of streamgages for all regions in a given water year range. 

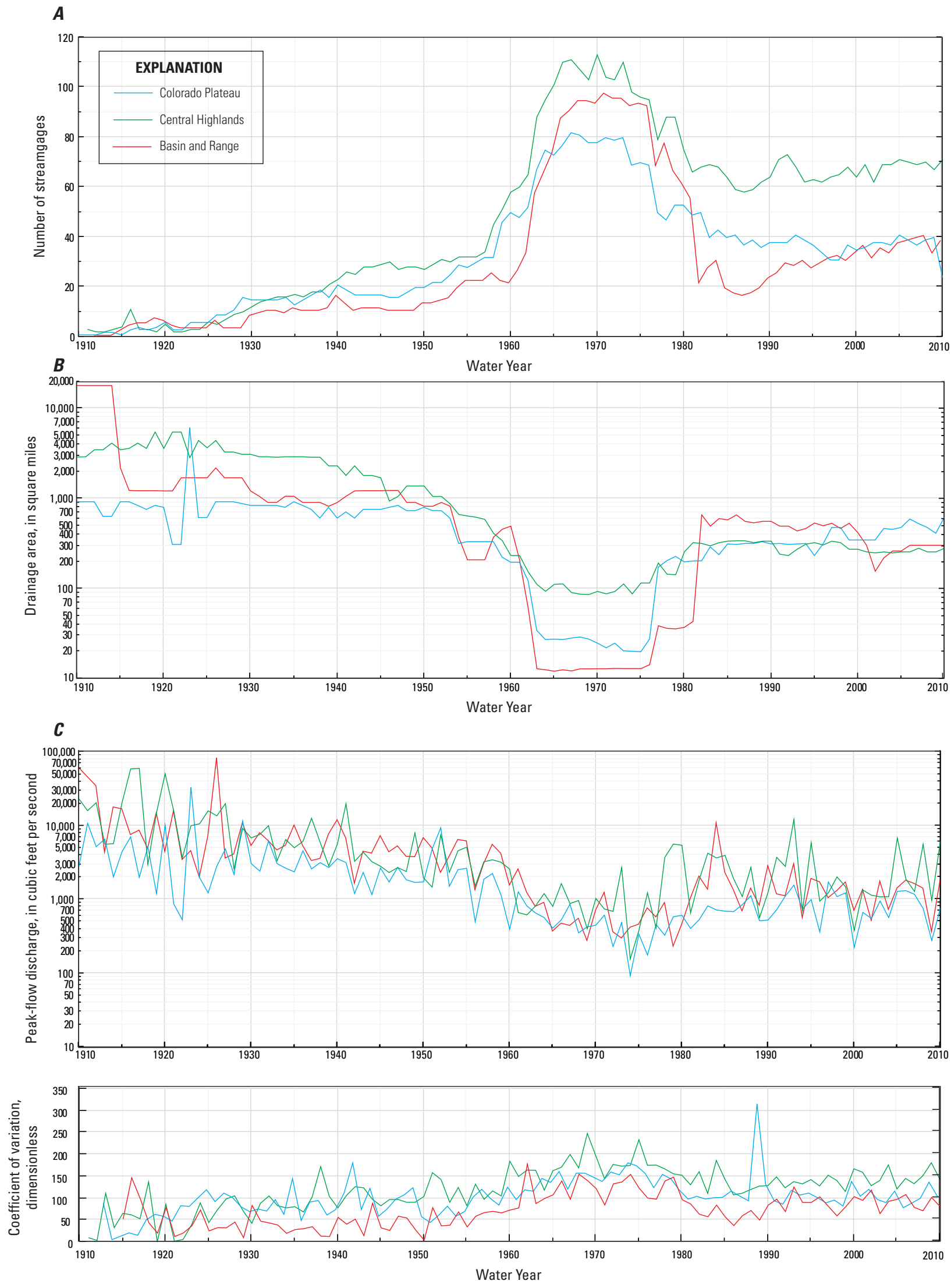

Figure 6. The $A$, number of streamgages operating; $B$, median drainage area; $C$, median and coefficient of variation of peak flows between water years 1910 and 2010. 
Prior to 1960 , thirty streamgages or less were in operation and these gages mostly represented basins greater than 1,000 sq. mi (fig. $6 A, B$ ). There was dramatic shift in the number of streamgages operating between 1957 and 1967. The number of streamgages more than tripled and the locations were more widely distributed, resulting in representation of basin sizes ranging from less than $1 \mathrm{mi}^{2}$ to greater than $20,000 \mathrm{mi}^{2}$ (note that this does not include the regulated Colorado River which exceeds $180,000 \mathrm{mi}^{2}$ in the lower basin). This increase in the number of streamgages was likely related to a national streamgage network expansion, when most states began to maintain a constant number of gages. The number of streamgages operating reached a maximum in 1970 (297 gages) with the greatest number occurring in the Central Highlands. The number of streamgages declined markedly starting in the mid-1970's, with the greatest decrease occurring in the Basin and Range Province where numbers declined by more than 75 percent. Differences between the number of streamgages in operation in each province was greatest after 1980. In the Colorado Plateau and the Basin and Range, fewer streamgages were operating than in the Central Highlands for many years, but spatially these provinces represent a land surface area that is more than twice the area of the Central Highlands. Compared to the Central Highlands, the Colorado Plateau and Basin and Range Province had many more streamgages with drainage areas less than $100 \mathrm{mi}^{2}$ In addition, those small basin streamgages were operated for only a relatively short (10-20 year) period, and depending on the climatic conditions, such as a drought or wet period, the peak-flow data representation could be biased.

The long-term patterns in peak flows were mostly similar among the three major physiographic provinces of Arizona (figs. 6C). The median peak flows decreased during the period of the expansion of the streamgage network and the coefficient of variance increased suggesting that the increase in gages was representing different range of peak flows likely originating from different basin attributes and climate conditions. Peakflow variability is associated with the number of gages in operation and has remained fairly constant since the 1980's.

Statistical approaches and modeling procedures were used to minimize the bias and redundant information used in this investigation. Users of this report should be aware of the spatial and temporal variability of peak-flow data from the streamgages used in the regional regression regions. In addition, users need to understand the limitations and appropriate application of the regional regression equations. Certain regions for specific $P$-percent AEP will provide better estimates than others, because of the number of streamgages and length of record of those gages. A re-evaluation of the streamgage network should be considered in future studies for improving regional regression equations.

\section{Peak-Flow Record Combination and Estimation}

Many large rivers in Arizona have multiple streamgages along the same main-stem river reach, but operation of the gages varies in both time and location. Data from streamgages along the same river reach and within 50 river-miles of another gage were checked for overlapping or discontinued/continued records. In a few instances, a streamgage had been moved slightly upstream or downstream from the original location to improve data collection or accessibility. In these situations, peak-flow datasets were combined because the period of record is mostly continuous and the independent reporting of records in NWIS is related to a USGS convention of station identification and not the actual peak-flow data collected along the stream. If a concurrent record was available between adjacent streamgages, an ordinary-least-squares regression (OLS) relation between peak-flow records was developed. The maintenance of variance-extension or the line of organic correlation (LOC) was considered but not used because of the relatively few pairs of nearby streamgages that had single value peakflows estimated with an OLS equation. Without robust index gages, the authors decided that minimal information would be gained by using the LOC over the OLS estimation approach. Diagnostics explained in the Regional Regression Analysis section were used to assess the peak-flow relation, and data from streamgage pairs that had a significantly strong relation (adjusted coefficient of determination values $\geq 0.80$ ) were used to estimate peak ranges that could be used to develop a composite record. Records were composited using either a non-exceedance perception threshold or a range of flow estimates, represented as an interval (described in The Expected Moments Algorithm section). Interval estimates were usually represented using the 95-percent confidence interval of the regression relation. The largest peaks were typically not estimated with the linear regression, but represented using a conservative perception threshold (that is, not exceeding the peak of record or two times the peak of record). Only the composited period of record of the adjacent streamgages was considered in the regional regression analysis, but $P$-percent frequency statistics are also presented for the individual gages.

The compositing procedure helped to resolve differences between nearby streamgages (same river) operating at different times. The differences in the flood frequency results can be large in situations where only one of two nearby streamgages collects peak-flow data from a wet or dry period. The effect of this situation can also result in non-physically based upstream/ downstream relations, where downstream estimates are less than upstream estimates, because the linear properties of the regional regression relation assumes that as drainage area increases (move downstream) the flood magnitude estimates will also increase.

All or some part of the peak-flow records from seventeen streamgage pairs were composited. Streamgage identification numbers ending with 99 denote that the record is compiled from more than one peak-flow record along the same reach (table 1). For forty-six streamgages, one or more peak flows were estimated using a perception threshold or interval. This includes information related to another gage through OLS regression, or information associated with an NWIS qualification code that indicates some type of uncertain flood information (codes 1, 4, 7, and 8). A detailed discussion about 
peak-flow qualification codes and the treatment of coded data by the EMA can be found in Paretti and others (2013). Of the 46 streamgages with perception thresholds or intervals, 39 had 5 or fewer peaks that were estimated with an interval or threshold, and 13 gages had more than 5 peaks estimated with an interval or threshold. It should be noted that 19 of the 46 streamgages that had one or more peak flows estimated using a perception threshold or interval were identified as redundant and not used in the regional regression analysis. Details of the specific peak-flow estimation at streamgages and composited records can be found in table 2 .

\section{Temporal Trends in Streamflow}

An underlying assumption of most flood frequency analyses is stationarity, meaning that the moments of the distribution (in this case, the LPIII distribution) do not substantially change over time and that there is no trend to the observed series of annual peak flows. The Kendall tau $(\tau)$ test, a nonparametric test that measures the monotonic dependence of predicted variables, is a common method for trend-testing in hydrology (Helsel and Hirsch, 2002). The test statistic, $S$, is the difference between the number of years when the peak flow is greater than the year before and the number of years when peak flow is less. The test statistic can be compared to a table of values or approximated by a normal distribution to either accept or reject the null hypothesis that there is no temporal trend in the series of annual peak flows.

Using the Kendall $\tau$ test at streamgages with 30 years or more of systematic record, the null hypothesis was rejected at the 5-percent significance level $(\alpha=0.05)$ at 42 of the 448 streamgages, or 8.9 percent (table 2). Records from seven of the streamgages were correlated with records from one or more other gages and considered redundant. Taking this into account, the nonredundant streamgages with significant trends were 7.5 percent of the total number. The strength of the correlation was low to moderate, with a median $\tau$ of -0.27 , maximum of 0.26 , and minimum of $-0.50(n=34)$. Of the streamgages with significant trends, records from 4 nonredundant streamgages had slight upward positive trends $(\tau \min =0.16, \tau \max =0.26)$ and the remaining trends were downward (negative). Within Arizona, streamgages with significant trends fall generally into two clusters, those on the Little Colorado River and its tributaries in northeastern Arizona, and those on the Gila River and its tributaries in southeastern Arizona (fig. 7). Another cluster of sites with possible trends in peak flows occurs on the San Juan River and its tributaries in northwestern New Mexico and southwestern Colorado. In comparison, the Kendall $\tau$ analysis used in WSP2433 reported a rejection of the null hypothesis at 18 percent of streamgages across the ten-state study area. States with the highest number of streamgages with possible trends were New Mexico, Colorado, and Utah; Arizona had relatively few ( 2 out of 31 streamgages with an upward trend and 3 out of 31 streamgages with a downward trend).
Although the number of streamgages that may have a trend in annual peak flows is not insignificant, the records are not adjusted for trend in the present analysis. The underlying cause of any trend unrelated to urbanization is unknown and streamgage records are still relatively short compared to longterm climate fluctuations (Hirsch, 2011), and the continuation of any such trend into the future is very uncertain. Adjustments to compensate flood frequency estimates downward because of a negative trend may result in a spurious correction when the underlying cause is not well understood. One outcome of keeping the original flood frequency estimate is the potential bias of overestimation, because most of the trends observed were negative, if in fact the frequency estimates should be adjusted downward. There is no consensus, however, about when or how a trend adjustment should be applied, so the potential for overestimation is the preferred bias to underestimating and this would be considered to be a more conservative approach in the flood frequency analysis process.

\section{StreamStats and Basin Characteristics}

StreamStats is an interactive web-based tool developed by the USGS for retrieving flood frequency and basin characteristic statistics for individual state applications ( $h t t p: / /$ water.usgs.gov/osw/streamstats/). StreamStats allows users to select a location, create a delineated watershed upstream of the selected location, and compute a variety of basin characteristic statistics. These characteristics can then be used to determine flood statistics at ungaged locations. Layers used to define watershed boundaries in StreamStats for Arizona were the 10-meter digital elevation model (DEM) from the National Elevation Dataset ([NED]; Gesch, 2007), 1:24,000 USGS National Hydrography Dataset ([NHD]; Simley and Carswell, 2009), and the 1:24,000 National Watershed Boundary Dataset ([WBD]; U.S. Department of Agriculture, Natural Resources Conservation Service, 2011). Scripts and toolboxes used by StreamStats were developed by ESRI (ArcToolboxes and ArcHydro9 tools), Bureau of Reclamation, U.S. Environmental Protection Agency, USGS StreamStats Team (StreamStats Tools), USGS [Hydrography Event Tools (HEM)], and the USGS Utah Water Science Center (NHD/WBD intersect tool).

Seventy-one basin characteristics were computed at 448 streamgages, including mean annual and monthly precipitation and temperature (PRISM), precipitation intensity (NOAA Atlas 14), physical basin properties, such as drainage area, slope, perimeter, and length (10-meter DEM, 1:24,000 NHD, WBD), land-cover (NLCD), and soil properties (STATSGO) (table 3). Of the 71 variables, 30 were selected as basin characteristics to be computed for watersheds delineated in StreamStats. Streamgage statistics for all 71 variables can be found in table AP2-1 of Appendix 2 of the report where a detailed description of the StreamStats development can be found.

As a quality control check, drainage areas computed by StreamStats were plotted against the published drainage areas 


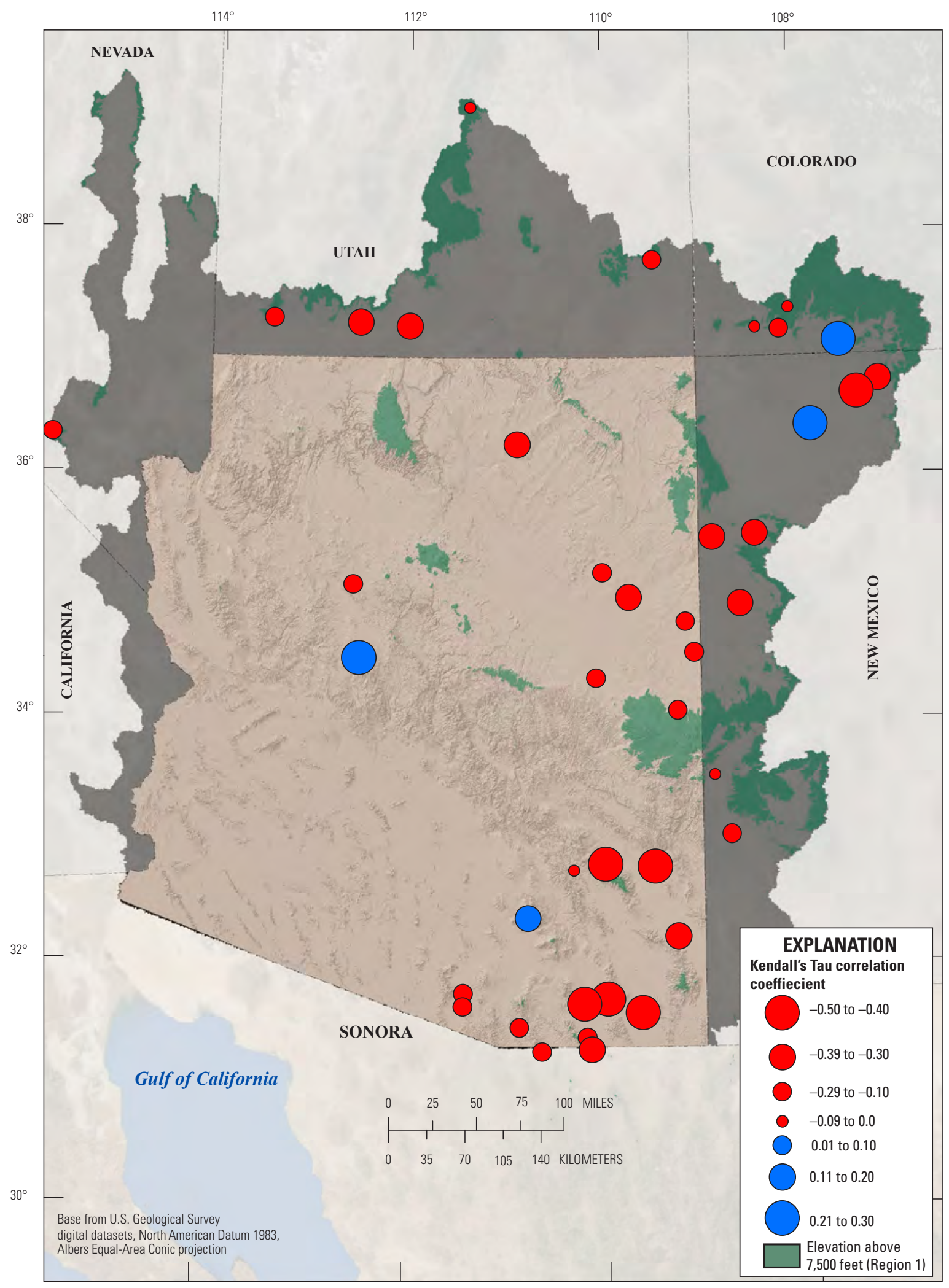

Figure 7. Map of Arizona showing streamgages with 30 or more years of record that have significant trends in annual peak flows determined using a Kendall's tau trend test. 
to find any errors that may have occurred in the StreamStats process through the identification of outliers, and to document published drainages that differed by 10 percent or more.

Records for these streamgages were checked and later corrected in the NWIS database.

\section{Methods of Flood Frequency and Magnitude Analysis at Streamgages}

A flood frequency analysis determines the magnitude of flow that can be expected with a given probability in any given year. Early USGS flood frequency publications describe flood frequency using the T-year recurrence interval (Dinicola, 1996) rather than as a probability of occurrence. Since the mid-2000's federal agencies that work with flood data have suggested moving away from this terminology because it confuses the public. Expressing flood frequencies in terms of recurrence intervals can be misleading by implying that a specified magnitude flood will be observed or exceeded once in each interval (for example, once every 100 years), when in fact this represents the probability that a flood of the specified magnitude will be equaled or exceeded in any given year. For example, the 100-year flood has a 1-percent probability of occurring every year, and the occurrence of a 1-percent flood in a given year has no effect on the probability of an equally large flood occurring in the following year. For these reasons, the USGS has recommended the use of more precise terminology, so in this report we express flood frequency in terms of annual exceedance probability - hereafter AEP — rather than recurrence interval. The $P$-percent AEP is equal to the reciprocal of the recurrence interval T multiplied by 100 (Gotvald and others, 2012). For example, the reciprocal of the 50 -year flood is $1 / 50$; multiplying by 100 shows that the 50 -year flood is equivalent to the 2-percent AEP flood. The recurrence interval equivalents for the $P$-percent AEP are shown in table 4 .

Table 4. T-year recurrence intervals with corresponding $P$-percent annual exceedance probabilities for flood frequency flow estimates.

\begin{tabular}{cc}
\hline T-Year recurrence interval & $\begin{array}{c}\boldsymbol{P} \text {-percent annual exceedance } \\
\text { probability (AEP) }\end{array}$ \\
\hline 2 & 50 \\
5 & 20 \\
10 & 10 \\
25 & 4 \\
50 & 2 \\
100 & 1 \\
200 & 0.5 \\
500 & 0.2 \\
\hline
\end{tabular}

\section{Log-Pearson Type III Frequency Analysis}

The Pearson Type III distribution with a log transformation (LPIII) of the annual peaks is the standard floodfrequency distribution as recommended in Bulletin 17B ([B17B]; Interagency Advisory Committee on Water Data [IACWD], 1982). The method of moments is typically used to determine the statistical parameters, or moments: the mean, variance, and skew coefficient. On a plot of peak flows versus probability, the mean value determines the position of the line along the y-axis, the standard deviation determines the slope of the line, and the skew coefficient describes the curvature of the line (fig. $8 A$ ). Estimates of the $P$-percent annual exceedance probability (AEP) flows are computed by inserting the three population moment estimators into the following equation:

where

$$
\log Q_{P}=\bar{X}+K_{P} S
$$

$Q_{P} \quad$ is the $P$-percent annual exceedance probability flow, in cubic feet per second $\left(\mathrm{ft}^{3} / \mathrm{s}\right)$;

$\bar{X} \quad$ is the mean of the logarithms of the annual peak flows;

$K_{P} \quad$ is a factor based on the skew coefficient and the given percent annual exceedance probability and is obtained from appendix 3 in $\mathrm{B} 17 \mathrm{~B}$; and

$S \quad$ is the standard deviation of the logarithms of the annual peak flows, which is a measure of the degree of variation of the annual values about the mean value.

\section{Regional Skew Analysis}

The skew coefficient of the LPIII distribution is sensitive to extreme events, making it an unreliable estimator of the population skew for streamgages with a short period of record. The B17B guidelines recommend weighting the station skew with a generalized or regional skew to improve the accuracy of the station skew estimator. This is calculated using the weighting equation:

$$
G_{w}=\frac{M S E_{r}\left(G_{s}\right)+M S E_{s}\left(G_{r}\right)}{M S E_{r}+M S E_{s}},
$$

where

$G_{w} \quad$ is the weighted skew,

$G_{s} \quad$ is the station skew,

$\mathrm{Gr} \quad$ is the regional skew, and

$M S E_{r}$ and $M S E_{s}$ are the mean square error of the regional and station skew, respectively. 
It is assumed that the regional skew is unbiased and independent of the station skew, and by weighting the station skew with the regional skew, the uncertainty of the flood frequency estimates at a streamgage is minimized for that given set of data.

The generalized skew map provided in Plate 1 of B17B is more than 30 years old and studies have documented potential problems with the reported MSE of 0.302 (Griffis and Stedinger, 2007), which corresponds to a record length of 17 years. It has been suggested that the MSE should be closer to 0.1 for most regions in the US, which would correspond to a record length of approximately 60 years (Stedinger and Griffis, 2008). Three alternative methods are described in B17B for developing a generalized skew using data from at least 40 streamgages, or using all streamgages within a $100 \mathrm{mi}$ radius that have at least 25 years of record. These are (1) constructing isolines on a map and interpolating; (2) performing a regression analysis relating a physical explanatory variable(s) to the skew; or (3) calculating an arithmetic mean and variance of the skew coefficients of all or a group of sites in a homogenous region. Methods 1 and 3 can be subjective, which limits the accuracy of the MSE so that the estimates may not be reproducible, similar to the B17B Plate 1 map. Regression analysis (Method 2) provides a means to separate error sources and accurately estimate the MSE. Recent work by Reis and others (2005) and Gruber and Stedinger (2008) developed a robust Bayesian Generalized Least Squares (BGLS) procedure for calculating a more accurate generalized skew. This approach was used in several states to more accurately determine the MSE of the skew coefficient (Gotvald and others, 2009; Parrett and others, 2011; Eash and others, 2013). An underlying cross-correlation model is created in the BGLS process that gives greater weight to streamgages with longer records and accounts for the correlation of peak flows between streamgages. A description of the model development and analysis for this study can be found in appendix 1 .

\section{The Expected Moments Algorithm and the Multiple Grubbs-Beck Test}

The Hydrologic Frequency Analysis Work Group (HFAWG), under the Subcommittee on Hydrology of the Advisory Committee on Water Information, consists of federal agencies, members of academia, interest groups, and private citizens. Formed to recommend and evaluate procedures for the frequency analysis of floods, the work group has put forth several recommendations and potential revisions to B17B that are related to the derivation of regional skew, identification and treatment of potentially influential low flows (PILFs), treatment of zero flow and historical information, plotting positions, and confidence intervals. These recommendations and revisions can be seen at (http:// acwi.gov/hydrology/Frequency/minutes/Minutes_HFAWG_ meeting_mar19_2012_040212.pdf). To address several of these potential revisions, the HFAWG recommended the use of the Expected Moments Algorithm with a multiple
Grubbs-Beck test (EMA-MGB) as an alternative method to the traditional B17B-standard Grubbs-Beck (B17B-GB) test moment-estimation methods (Cohn and others, 1997; Cohn and others, 2001; England and others, 2003; Cohn and others, 2013). As with B17B-GB, EMA-MGB assumes that the LPIII distribution represents the probability distribution function of annual maximum peak flows. But when historical, lowoutlier, or censored information is present (Cohn and others, 1997; Griffis and others, 2004), EMA-MGB more accurately uses this information in the flood frequency analysis. Without this additional information, estimates between B17B-GB and EMA-MGB are almost identical (fig. $8 A$ ).

Paretti and others (2013) investigated the differences between estimates from B17B-GB and EMA-MGB and their influence on predicted peak flows in Arizona. Statistical comparisons and Monte Carlo simulations indicated that EMA-MGB performed better than B17B-GB, both in visually fitting the frequency curve to the observed data and statistically in the simulations. EMA-MGB also allowed more flexibility to include uncertain or estimated flood information, which is common in Arizona. Based on the comparison investigation, the flood-frequency analysis described in this report uses EMA-MGB methods. To maintain consistency between the regional skew analysis and the regional regression analysis, version 0.974 of the PeakfqSA software was used in this report. PeakfqSA software is a beta software package that performs the EMA-MGB analysis and version testing (http:// www.timcohn.com/TAC_Software/PeakfqSA/). An updated USGS "Peak flow FreQuency analysis" program that incorporates the PeakfqSA software and implement both the B17BGB and EMA-MGB procedures for flood frequency analysis can be found at: http://water.usgs.gov/software/PeakFQ/.

The Expected Moments Algorithm (EMA) is a momentsbased approach that expands on the B17B framework. The B17B method for addressing historical peaks, by which the systematic record is weighted to represent unobserved values (years where no streamgage data were collected), fails to completely utilize the information that the historical discharge was not exceeded during the historical period. The EMA was developed specifically to incorporate this non-exceedance, or "threshold" data (Cohn and others, 1997). Furthermore, EMA-MGB identifies PILFs and uses regional skew information simultaneously with historical information. The B17B incorporates these types of data sequentially, and the predicted flood quantiles are dependent on the order in which they are performed (Griffis, 2008). Five types of peak streamflow data relevant to EMA can be identified:

1. Peak flows recorded at a streamgage during the systematic record;

2. Peak flows occurring during a historical period before the start of the systematic record collection (or outside of the systematic record), flows that are commonly estimated on the basis of high-water marks or other indirect evidence; 
3. Peak flows of undetermined discharge during the period of systematic record, but known to be above some threshold (for example, the only discharge measurement recorded by a streamgage prior to the peak discharge because of flood damage.);

4. Peak flows of undetermined discharge during the period of systematic record, but known to be below some threshold (for example, at a streamgage that does not record below a gage base-discharge, such as a crest-stage gage mounted above the bottom of the stream channel); and

5. Peak flows during the historical period that were not recorded but are known to be below some threshold (for example, in the form of information about historical magnitude non-exceedances, such as paleofloods).

Furthermore, data types 1 and 2 can be defined as lying within some interval rather than as exact quantities. The EMA-MGB represents each of these data types as a perception threshold, or interval-range of values.

A significant difference between the B17B and EMA methods arises from the assumptions made about non-exceedance observations during the historical period. The B17B method assumes that the moments of the non-exceedance observations are equal to the moments of the systematic record, calculated for all peaks below the non-exceedance threshold. The EMA, in contrast, assumes that the moments of the non-exceedance observations are equal to the moments of the overall distribution, truncated at the non-exceedance threshold. That is, EMA identifies the moments of one distribution that fits both nonexceedance observations and the systematic record, whereas the B17B method determines individual distributions for each and combines them in a weighted average.

The authors of B17B acknowledged that zero flows and outliers needed to be addressed using a conditional probability adjustment. The B17B defines outliers as data points that depart significantly from the distribution of the remaining data. While high outliers can depart from the assumed distribution, these peaks are rarely removed unless there is hydrologic evidence of a separate peak-flow distribution. Low outliers in the left-hand tail of the distribution are more problematic because these peaks can have significant influence on the fit of the distribution to the right-hand tail (that is, the largest flood events or lower AEPs). In flood-frequency analysis, the general objective is to predict the largest floods as accurately as possible, and thus it is undesirable for low-magnitude peaks to have significant influence on the frequency curve. Therefore, B17B recommends applying a Grubbs-Beck (Grubbs and Beck, 1972) statistical test to determine if the smallest (or largest, in the case of high outliers) observation is unusually small (or large) compared to the rest of the population distribution. The Grubbs-Beck test uses the logarithms of the peak-flow data to calculate a one-sided, 10-percent significance-level critical value for a normally distributed sample, but rarely is more than a single low outlier removed. However, visual inspection of the AEP frequency curves shows that many streamgages in Arizona have a distinct "dogleg" or break in the fitted frequency curve, possibly indicating that the low peak flows may not fit the same assumed distribution that is being used to fit the larger peak flows (fig. 8B). Further complicating the flood frequency analysis is the occurrence of zero-flow years, which are common in southern Arizona (the logarithm of zero is undefined). Also common to Arizona is the occurrence of many PILFs in a peak-flow record because floods are not only affected by the flood-generating mechanism, but also by the landscape. For example, channel-infiltration losses can greatly attenuate peak flows between two streamgages. Or rainfall in a given year may be low and evapotranspiration demand high, so that no measurable runoff occurs. The result is that the series of annual peaks appear to be generated from a mixed distribution, whereby small and large flood events appear to be generated by different processes.

To prevent zero- and low-flow events from influencing the distribution fit for large events, PILFs should be addressed. The B17B method suggests that procedures for treating outliers ultimately require judgment involving both mathematical and hydrologic considerations (Interagency Committee on Water Data, 1982) and allows PILFs to be removed subjectively, but no objective quantitative method for removing multiple low outliers is presented. A generalization of the Grubbs-Beck test called the Multiple Grubbs-Beck test was developed by Cohn and others (2013) to identify PILFs systematically. Similar to B17B, the MGB test calculates a one-sided, 10-percent significance-level critical value based on a log-normal distribution of the data, and operates by systematically testing the hypothesis that $k$ samples in the left-hand tail are from the same sample of normally-distributed observations in the remaining population. The number of samples $k$ is increased until the test statistic indicates the largest possible group of low outliers has been identified. The MGB test can identify PILFs for as much as 50 percent (arbitrary threshold) of the annual peak-discharge record. A detailed description of the MGB test can be found in Cohn and others (2013) and the results of using this over a standard Grubbs-Beck test for streamgages in Arizona can be found in Paretti and others (2013).

The EMA-MGB flood frequency analysis was conducted on records for 448 streamgages and on an additional 21 composited peak-flow records. Flood frequency and magnitude estimates of the 50-, 20-, 10, 4-, 2-, 1-, 0.5-, and 0.2-percent AEP can be found in table 5. Streamgage AEP frequency curves were visually assessed to determine how well the LPIII curve fit the observed data. The fit for streamgages that displayed slight breaks in the probability distribution or had one or two influential peaks (high or low) was designated as "moderate" and analyzed in the preliminary regional ordinary-leastsquares regression analysis (fig. $8 \mathrm{C}$ ). The streamgages received further scrutiny if they had high influence and (or) leverage, possibly resulting in exclusion from the regression model. Peak-flow flood frequency plots that visually displayed a "dog leg" effect or still had a significant break in the frequency plot after the MGB test were identified as "frequency fit undefined," and the data from those streamgages were not used in the regional regression analysis (fig. $8 D$ ). 

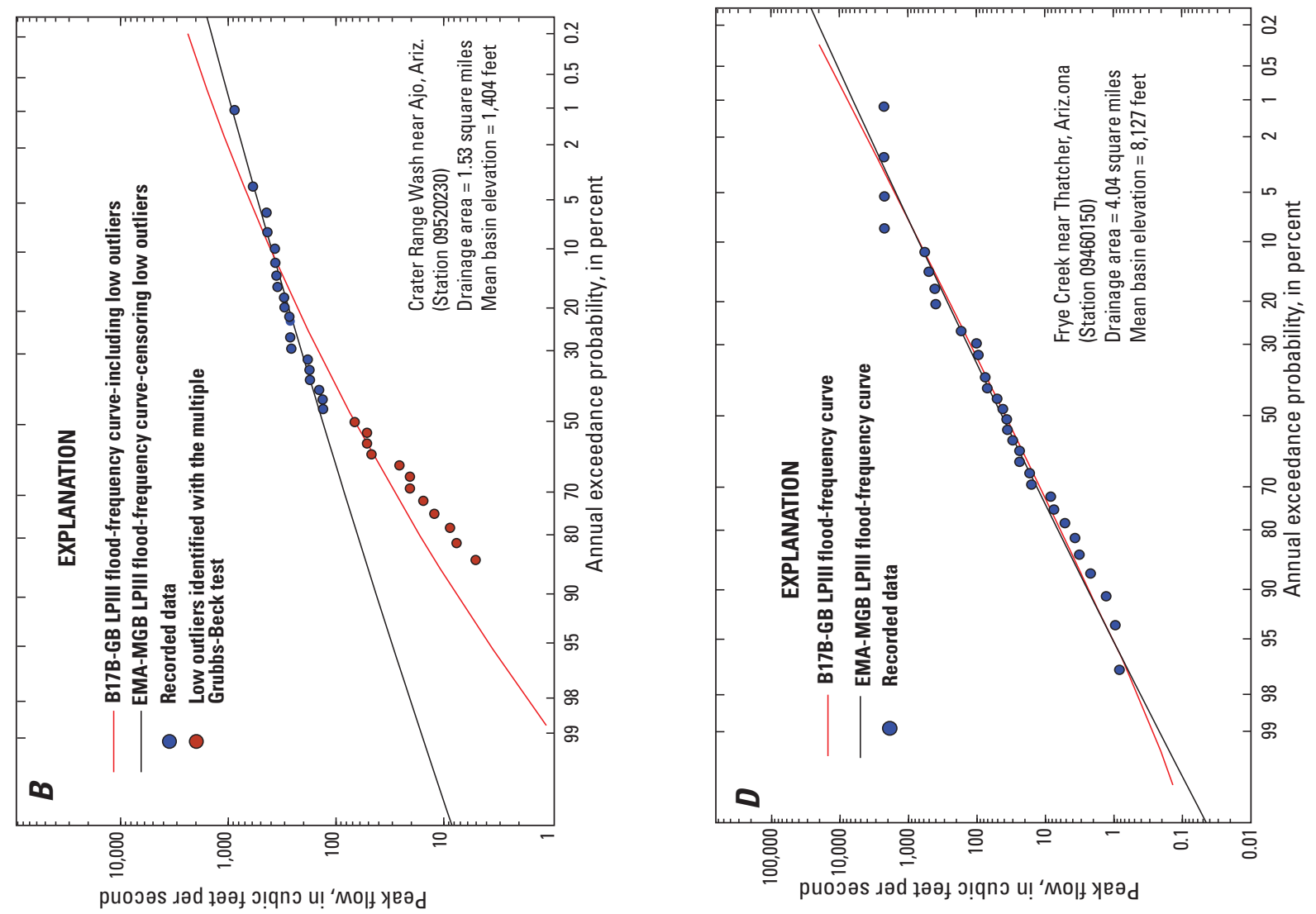

可

妾竞 离

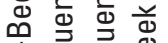

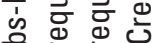

을

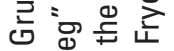

을

을 응 든 인

它《焉

ธळ

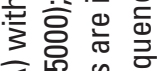

这究

을 寄

हᄃ

흠을응 흥

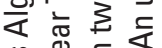

舟

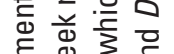

है

$\sum_{0}=$

엉 응

这

离

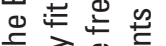

웡휴

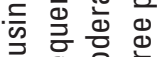

ه

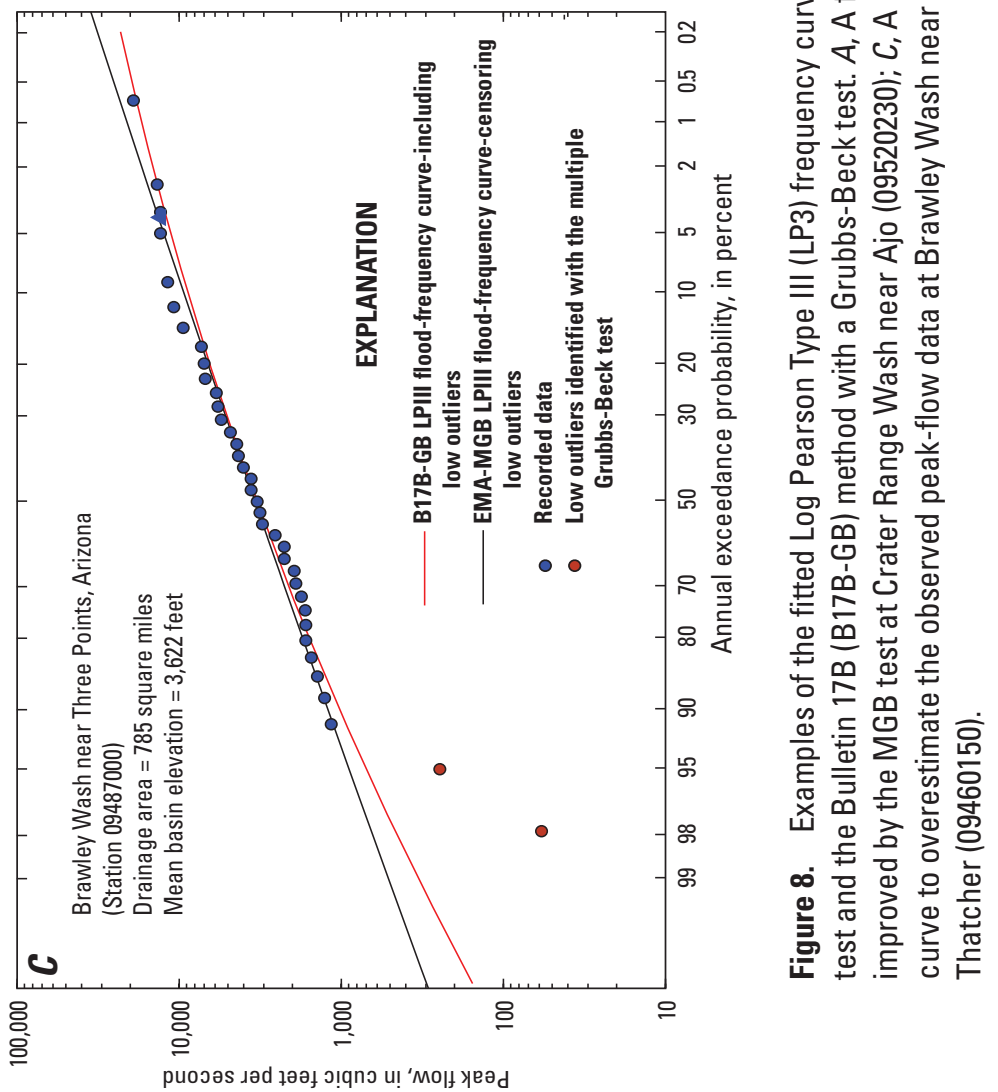

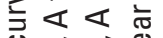

ن心

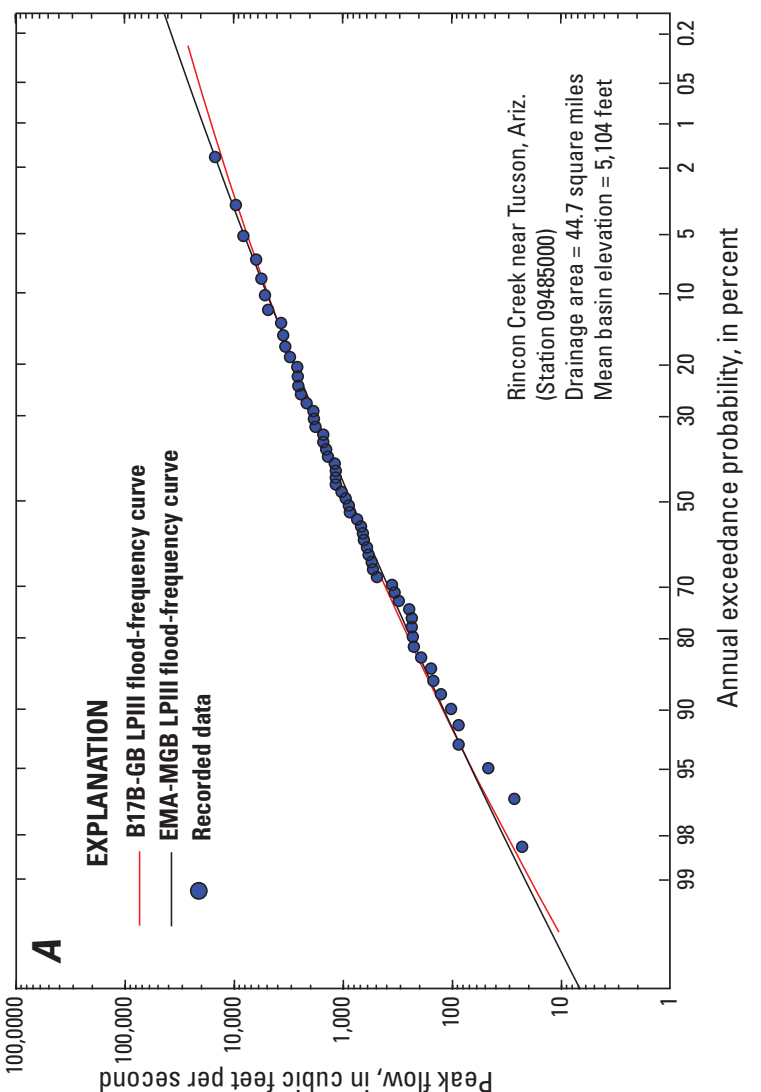




\section{Comparison with Previous Flood Frequency Estimates}

The previous comprehensive flood frequency analysis in Arizona was based on data collected through water year 1986 (in WSP-2433, by Thomas and others, 1997). The analysis on which this report is based includes an additional 24 years of data collected from 1987 to 2010 . The 24 -year period includes mostly drought years, though it contains periodic wet years during which many floods-of-record were recorded at streamgages throughout the State. Using data for 192 streamgages that were common to the two analyses, the 1-percent AEP relative percent difference (RPD) was calculated between the streamgage estimates from WSP-2433 and the present estimates, using both B17B-GB and EMA-MGB. The RPD is calculated as:

$$
\operatorname{RPD}\left(Q_{1 \%}\right)=\left(\frac{Q_{1 \%}^{\text {updated }}-Q_{1 \%}^{\text {prior }}}{Q_{1 \%}^{\text {prior }}}\right) * 100,
$$

where

$$
\begin{array}{cc}
R P D\left(Q_{1 \%}\right) \quad \text { is the 1-percent AEP flow relative percent } \\
\text { difference between the prior analysis } \\
\text { (in WSP-2433) and an updated flood } \\
\text { frequency analysis using B17B or EMA, } \\
\text { is the 1-percent AEP flow from the prior } \\
Q_{1 \%}^{\text {prior }} \quad \text { estimates in WSP-2433, and } \\
Q_{1 \%}^{\text {updated }} \\
\text { is the 1-percent AEP flow using a possible } 24 \\
\text { years of additional record in a B17B-GB or } \\
\text { EMA-MGB analysis. }
\end{array}
$$

The $R P D\left(Q_{1 \%}\right)$ values that are positive indicate that the 1-percent AEP flows are greater than the updated estimates made by using either B17B-GB or EMA-MGB, and negative values indicate that the prior 1-percent AEP flows estimated in WSP-2433 are greater. The RPDs calculated for the prior and updated B17B-GB analysis were normally distributed around the median of -6.2 percent (fig. $9 A$ ). Nine streamgages that exceeded a \pm 50 RPD had very different estimates for the 1-percent AEP, supporting the need for an updated analysis, because the addition of more data generally reduces the standard deviation and skew, and visually, the frequency curves better fit the observed data. The RPDs calculated for the prior B17B-GB and updated EMA-MGB analysis were similar to those determined from the prior and updated B17B-GB analysis. The EMA-MGB RPDs were normally distributed around the median of -7.7 percent, again indicating larger magnitude 1-percent AEP peak-flows for the prior WSP-2433 estimates (fig. $9 B$ ). This comparison showed more streamgages that exceeded a \pm 50 percent RPD than did the updated B17B-GB analysis, and most of these RPDs were negative. The RPD values suggest that differences observed between WSP-2433 and the new estimates are more closely related to the additional 24 years of peak-flow record rather than are the differences between the B17B-GB and EMA-MGB methods alone. Most of the \pm 50 percent RPD streamgages can be described as having one or more of the following characteristics when first computed in WSP-2433: a period of record less than 20 years, 3 or more PILFS, and (or) a visually less accurate frequency fit to largest observed peak flows. The occurrence of many drought years during the 24 years results in the addition of multiple years with low or moderate peak-flow magnitudes into the peak-flow data distribution. The effect on the updated analysis, of the incorporation of these types of flows into the peak-flow data distribution, will be a reduction in the magnitude and frequency of the 1-percent AEP flow, because the odds of observing a certain size flood or larger are reduced with inclusion of more low-flow peak years. This phenomenon explains the negative median RPDs observed between the prior and updated flood frequency 1-percent AEP.

\section{Regionalization and Regression Analysis to Estimate Flood Magnitude and Frequency at Ungaged Sites}

Prior to beginning the regression analysis, streamgages were grouped by similar physical and climatic basin characteristics, a process referred to as regionalization. Five regions in Arizona were designated for purposes of the analysis by comparing several existing regional delineations and adjusting boundaries to minimize error and maximize the coefficient of determination in an ordinary-least-squares regression approach. After defining these regions, streamgage flood statistics were used in a regression analysis to develop equations that predict flood statistics for ungaged basins. For each region, equations were developed to estimate the 50-, 20-, 10-, 4-, 2-, 1-, 0.5-, and 0.2-percent AEP flows.

\section{Regionalization}

Regionalization is a necessary step in developing flood regression equations for Arizona because physiographic and climatic characteristics that influence flood hydrology vary significantly from the northern Colorado Plateau to the southern Basin and Range physiographic province, and relying on a single set of regression equations for the entire State would result in estimates with poor accuracy and precision. Two previously published and three newly proposed regionalization schemes were tested. Roeske (1978) completed one of the first regionalization efforts for Arizona based largely on physiographic provinces, and delineated five flood regions (fig. 10A). The second regionalization process for Arizona was published in WSP-2433 (Thomas and others, 1997). The regions were defined primarily on watershed divides, and delineated on the basis of general flood magnitudes, the meteorologic cause of the floods, elevation, and geographic patterns in regression residuals. Of the sixteen regions developed for the Southwest, Arizona contained six $(8,10,11,12,13$, and 14; fig. 10B). 

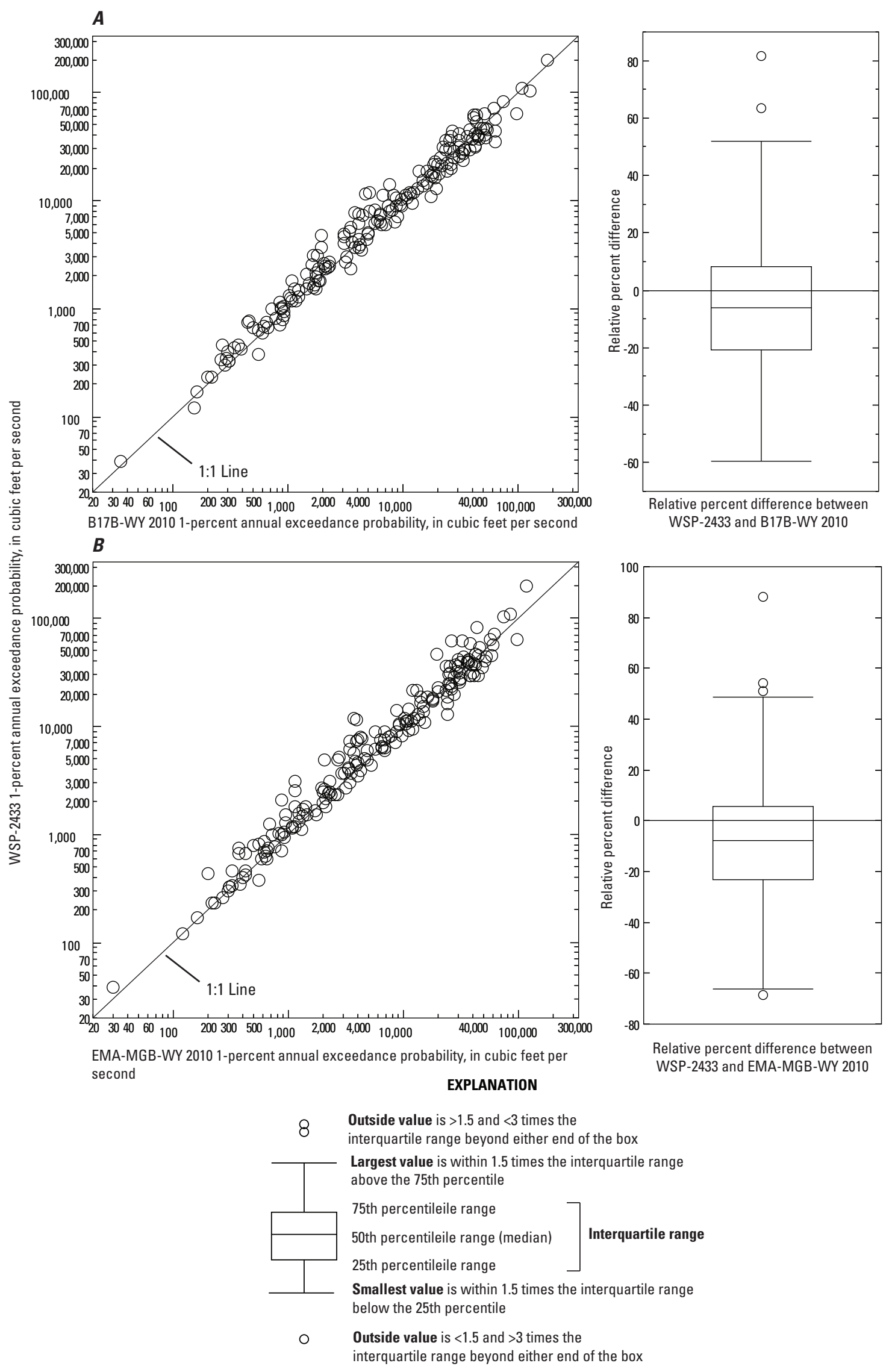

Figure 9. Relation of 1-percent annual exceedance probability flood and boxplot of the relative percent difference between updated estimates through water year 2010 and WSP-2433 estimates. Comparisons include exceedances recomputed with A, Bulletin 17B-Grubbs-Beck test (B17B-GB); and $B$, with the Expected Moments Algorithm-Multiple Grubbs-Beck test (EMA-MGB). 
$\boldsymbol{A}$

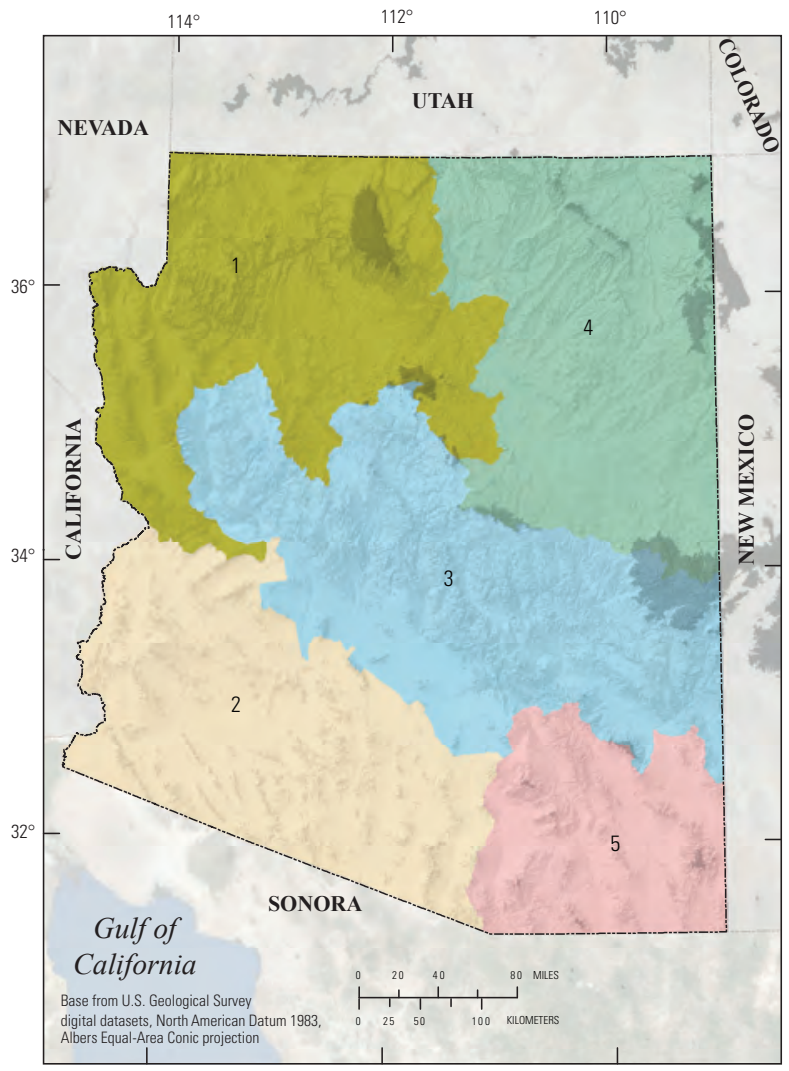

C

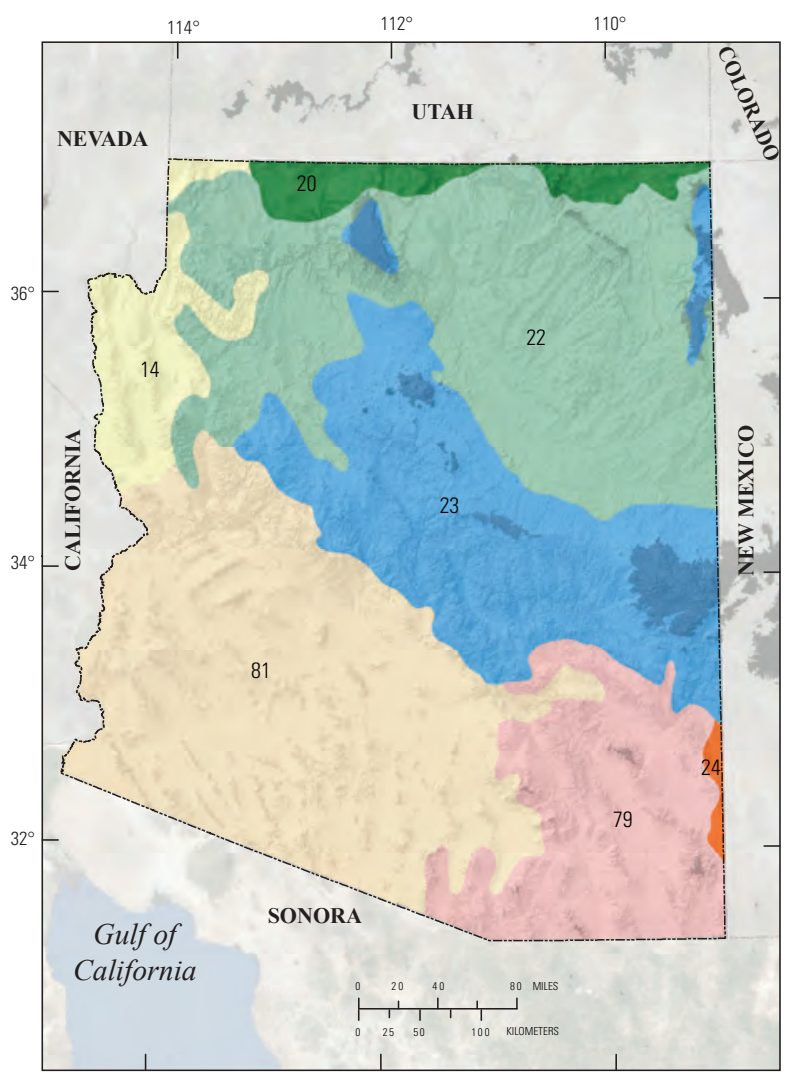

B

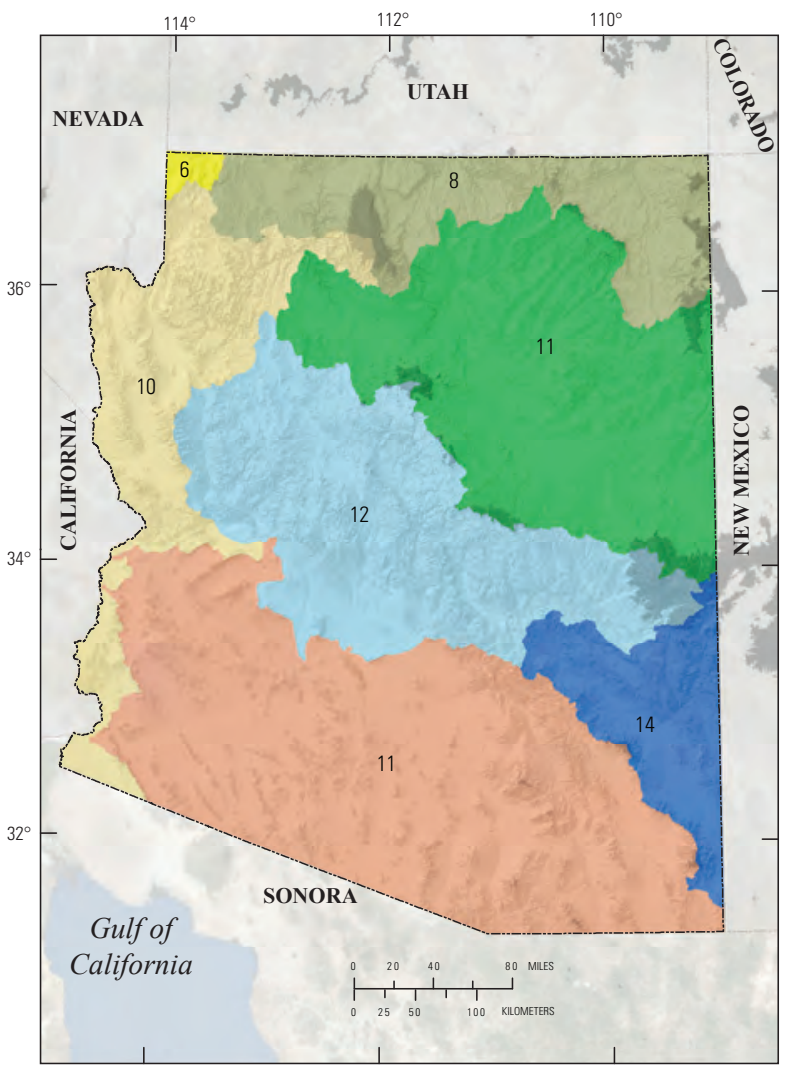

D

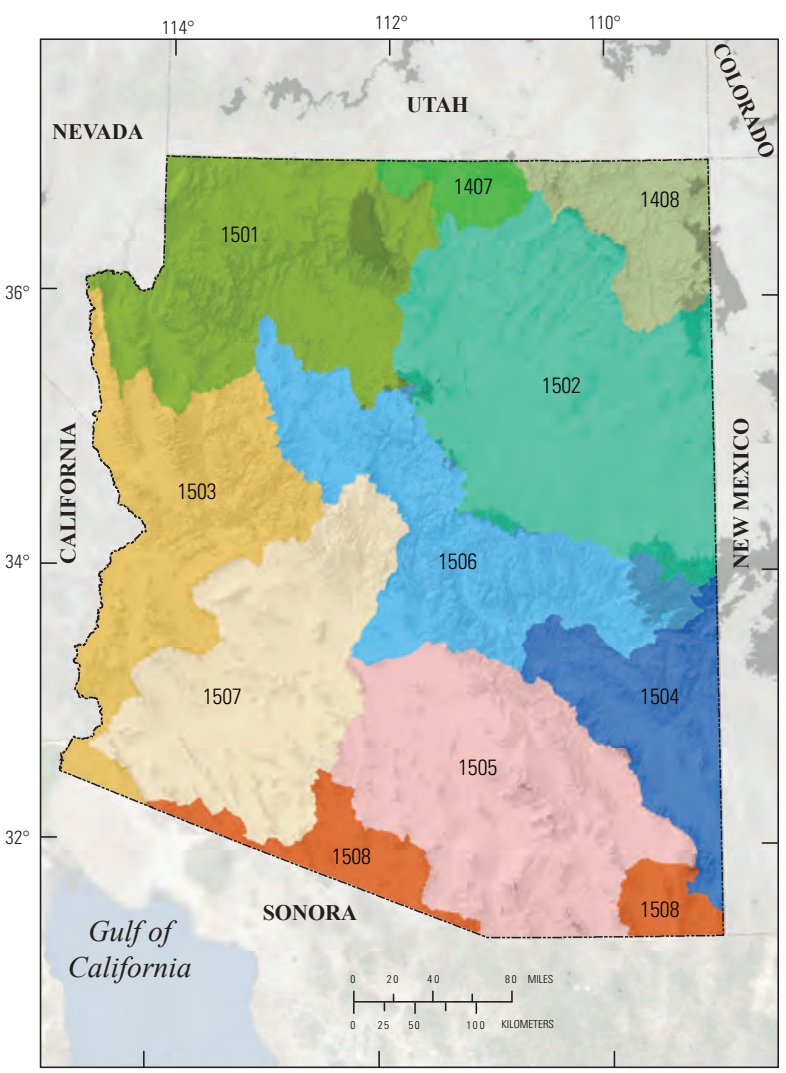

Figure 10. Maps of Arizona showing regionalization schemes. $A$, Arizona Department of Transportation (Roeske, 1978); $B$, Water supply; paper 2433 (Thomas and others, 1997); C, Level III ecoregions (Omernik, 1987); and D, Four-digit hydrologic unit codes. 
In addition to re-analyzing the two past regionalization schemes, three additional flood region approaches were developed and compared in this analysis. The first approach was grouping streamgages by an aggregated Level III ecoregion (fig. 10C). Developed by the Environmental Protection Agency (EPA), ecoregions are based on similar geology, physiography, vegetation, climate, soils, land use, wildlife, and hydrology attributes (Omernik, 1987). Some of the ecoregions contained very few streamgages and as a result were combined with similar, nearby ecoregions to increase the sample size for the analysis. Streamgages were separated into six Level III ecoregion flood regions (13 and 14 combined; 19, 20, and 21 combined; 22; 23; 24 and 79 combined; 81; http://www.epa.gov/wed/pages/ecoregions/level_iii_iv.htm). The second regionalization approach used hydrologic basins to group streamgages. The approach looked at the hydrologic basins within Arizona and grouped streamgages based on the 4-digit HUC subregions (Seaber and others, 1987; fig. 10D). Like the ecoregions, several of the HUCs contained too few streamgages to be use in a regionalization analysis and similar, nearby HUCs were combined. There were eight HUC flood regions used in the regionalization comparison (1408, 1407 combined; 1501; 1502; 1503; 1504; 1505, 1508 combined; $1506 ; 1507)$. The third regionalization approach was developed using a statistical multivariate ordination process. Instead of using only the geographical or ecological landscape delineations, the physical and climatic characteristic information from the streamgage basins were used to define flood regions.

The multivariate process began with a visual assessment of the basin characteristic variable distributions, and if distributions were skewed then data were transformed (log base-10 for most variables) to normalize the data distribution. Drainage area was excluded because it is not a unique regional characteristic. Highly correlated variables were removed using a Kendall Tau correlation scatter plot (Kendall Tau coefficient $\geq 0.6$ or $\leq-0.6$ ). This was followed by preliminary principal components analysis (PCA) to further reduce the number of variables to a nonredundant and parsimonious set of basin characteristics. For the nonredundant PCA process, the data were first normalized (subtracting the mean and dividing by the variance) and a Euclidean distance matrix was computed. Euclidean distance is the implicit matrix underlying PCA analysis (Clarke and Warwick, 2001), which was then used to generate linear combinations of variables that are represented with principal component vectors. The multivariate analysis program PRIMER-E automatically applies a varimax rotation to maximize the sum of the variance of the squared loadings (Clarke and Gorley, 2006). The first principal component accounts for the greatest proportion of variance (minimizes the sum of squares) in the data, and each successive orthogonal component accounts for the next greatest proportion of the variance. Contributions from the variables are expressed as loadings, whereby the highest loadings (largest eigenvectors) are interpreted as the most significant. Directionality (positive or negative) of the loadings is also interpretable, indicating increasing or decreasing variable values along the PCA axes.
Variables with similar eigenvector coefficients were further evaluated for redundancy and removed if two variables were providing similar information within the multivariate analysis.

Mean basin elevation, mean annual precipitation, and soil permeability were the final variables selected as most discriminating with regard to defining unique groupings of streamgages (fig. 11A). The first two principal components explained 88.2 percent of variation in the dataset. A cluster analysis was used to identify significant regional groups by evaluating minimal within-group differences and maximum differences among groups. Similar to the PCA, a Euclidean matrix of the three variables was used in the cluster analysis. The cluster analysis used a simple agglomerative, hierarchical clustering technique with a group average linkage option. A similarity profile (SIMPROF) test was used to statistically evaluate whether or not a specified set of samples, which are not a priori assigned into groups, do not differ from each other in multivariate data structure (Clarke and Gorley, 2006). SIMPROF is a permutation test that statistically tests different groups $(p \leq 0.05)$ by computing the likelihood that individual groups were not generated purely by chance alone. Sites were assigned a group, overlaid on a second PCA ordination for visualization, and plotted in ArcGIS to spatially assess regional patterns (fig. 11B). Boundary adjustments were necessary to align the streamgages with regions that followed major hydrologic divides. There were 4 regions determined in the multivariate regionalization process.

Each of the 5 regionalization schemes were tested with and without a separate, noncontiguous high-elevation region for sites above 7,500 ft mean elevation, a threshold used by both Thomas and others (1997) and Roeske (1978) to separate higher elevation streamgages from those at lower elevations. Streamgages in the high-elevation region often have peak flows generated by snowmelt, a different flood-generating mechanism than lower elevation sites. The effectiveness of the different regionalization schemes was evaluated using regression statistics from ordinary-least-squares (OLS) regression that relates the 1-percent AEP to the basin characteristics drainage area, mean elevation, and mean annual precipitation. Significant basin characteristics $(p \leq 0.05)$ were selected using the minimum Bayesian Information Criterion (BIC) as a stopping rule. The BIC is related to the Akaike information criterion (AIC) and used for optimizing variable selection for regression development, but unlike the AIC, BIC is based on the likelihood function (Schwarz, 1978). Details about the equation are described in the Regional Regression Analysis section.

For each regionalization scheme, the root mean-squareerror (RMSE) of the residuals and the adjusted coefficient of determination $\left(R^{2}\right)$ was compared. While it can be difficult to compare regional schemes directly because each consists of a different area with a different selection of streamgages, the general assessment of each scheme focused on (1) the accuracy of regression models between basin characteristics and the 1-percent AEP flow; (2) minimizing the number of regions but maintaining a sample size within each region 
for developing robust regression models; and (3) identifying distinct (or discriminating) basin characteristic boundaries that justify the need for independent regional regression equations. In general, all of the regionalization schemes produced similar results, and from a statistical standpoint, none were significantly better than the others. All of the schemes produced relatively poor results in the northwestern part of the State. Very few streamgages exist in this area and many of the streamgages used in the regional regression analysis are in Nevada and Utah. The 4-digit HUCs on average had a greater adjusted $R^{2}$ (mean $R^{2}, 0.76$; mean RMSE, 0.34), but several of the HUC equations predicted redundant information and many of the models were not significantly different than would result from using a single model for the entire state (table 6). The "best" statistics for all schemes were for the central part of the state. The use of HUCs, ecoregions, and the newly proposed regions produced slightly better relations than existing published regionalization schemes, especially in the southern part of the State. The authors used best professional judgment to select the multivariate regionalization scheme because the method takes a more statically objective approach than previously published studies in Arizona and unlike the ecoregion and HUC regions the newly proposed regions maintain large area boundaries that align with physical and climatic boundaries that affect peak-flow processes.

The five regions determined in the multivariate regionalization process (fig. 11B) are defined as: the High Elevation (region 1), the Colorado Plateau (region 2), the Western Basin and Range (region 3), the Central Highlands (region 4), and the Southeastern Basin and Range (region 5). The newly proposed regions share similar boundaries to those in WSP-2433 and Roeske (1978). The primary differences between the modified regions and the WSP-2433 regions can be summarized as (1) WSP-2433 regions 12 and 14 are combined; (2) region 13 is divided into a western and southeastern Basin and Range Province; and (3) region 11 is extended to include streamgages from the northern part of the Colorado Plateau (WSP-2433 region 8). There are some advantages to the newly-defined regions to those defined in WSP-2433; dividing the Basin and Range Province into an eastern and western region results in an overall reduction of the regression model error; and by combining two similar regions, the increase in sample size reduces the uncertainty in the flood frequency estimation.

To ensure that the newly proposed regions are independent from one another and each represents unique flood processes, a final PCA was conducted to create new principal components that represent a gradient of the normalized drainage area, mean annual precipitation, and mean basin elevation. These three variables are most commonly used to explain or predict flood frequency and magnitude. A graphical presentation (with density contours) of the 1-percent AEP flow as a function of the first principal component (PC 1), representing a gradient in the three basin attributes, was used to demonstrate the new regionalization scheme as a represented by the differences in regional effects on peak flows (fig. 12). The density contours are useful for visualizing the degree to which the region 1-percent AEP flows overlap or discriminate based on the most consistently used basin characteristics in the development of past Arizona regression equations. The densest contours of regions 1, 2, and 3 were most discriminated from regions 4 and 5, because of the differences in elevation and precipitation. Although regions 4 and 5 had some overlap, the densest part of the region contours was less so. Combining the two regions would result in a loss of explanatory power, because precipitation and elevation are not adequate predictors of $P$-percent AEP flows in region 5. Regression lines were added to show the mean response of the 1-percent AEP (maximizing the variation explained by the PC 1). The regression lines help to show the directionality and slope of the 1-percent AEP response to the basin attributes of the different regions.

\section{Regional Regression Analysis}

Following the regionalization step-assigning streamgages to separate groups, or regions, within which physical and climatic basin characteristics were similar - a multiple-linear regression analysis is used within each region to develop equations that relate specific AEP flood-frequency flows, such as the 1-percent AEP flow, to physical basin characteristics, such as drainage area. The regression equations can then be used to make predictions at ungaged sites where no peak-flow data are available. The general form of a multiplelinear regression equation is:

$$
y_{i}=\beta_{0}+\beta_{1} x_{1}+\beta_{2} x+\cdots+\beta_{n} x_{n}+\delta_{i},
$$

where

$$
\begin{aligned}
& y_{i} \quad \text { is the response variable (annual exceedance } \\
& \text { probability flow; for example, 1-percent AEP) } \\
& \text { for streamgage } i \text {, } \\
& x_{1} \text { to } x_{n} \quad \text { are the } n \text { explanatory variables (basin } \\
& \text { characteristics; for example, drainage area) } \\
& \text { for streamgage } i \text {, } \\
& \beta_{0} \text { to } \beta_{n} \quad \text { are the } n+1 \text { regression model coefficients, } \\
& \text { and } \\
& \delta_{i} \quad \text { is the model error (difference between the } \\
& \text { observed AEP and the predicted AEP) for } \\
& \text { streamgage } i \text {. }
\end{aligned}
$$

Ordinary-least-squares (OLS) regression assumes that the peak-flow data between streamgages are independent and that each record has similar variance, as indicated by similar lengths of record. Although these assumptions are generally not satisfied in peak-flow data, OLS is useful for identifying the important explanatory variables, testing different combinations of variables, and determining the general form of the equations. After the exploratory analysis is conducted with OLS, more sophisticated regression techniques, such as weighted-least-squares (WLS) or generalized-least-squares (GLS) analysis, can be used to address the issue of different 
$\boldsymbol{A}$

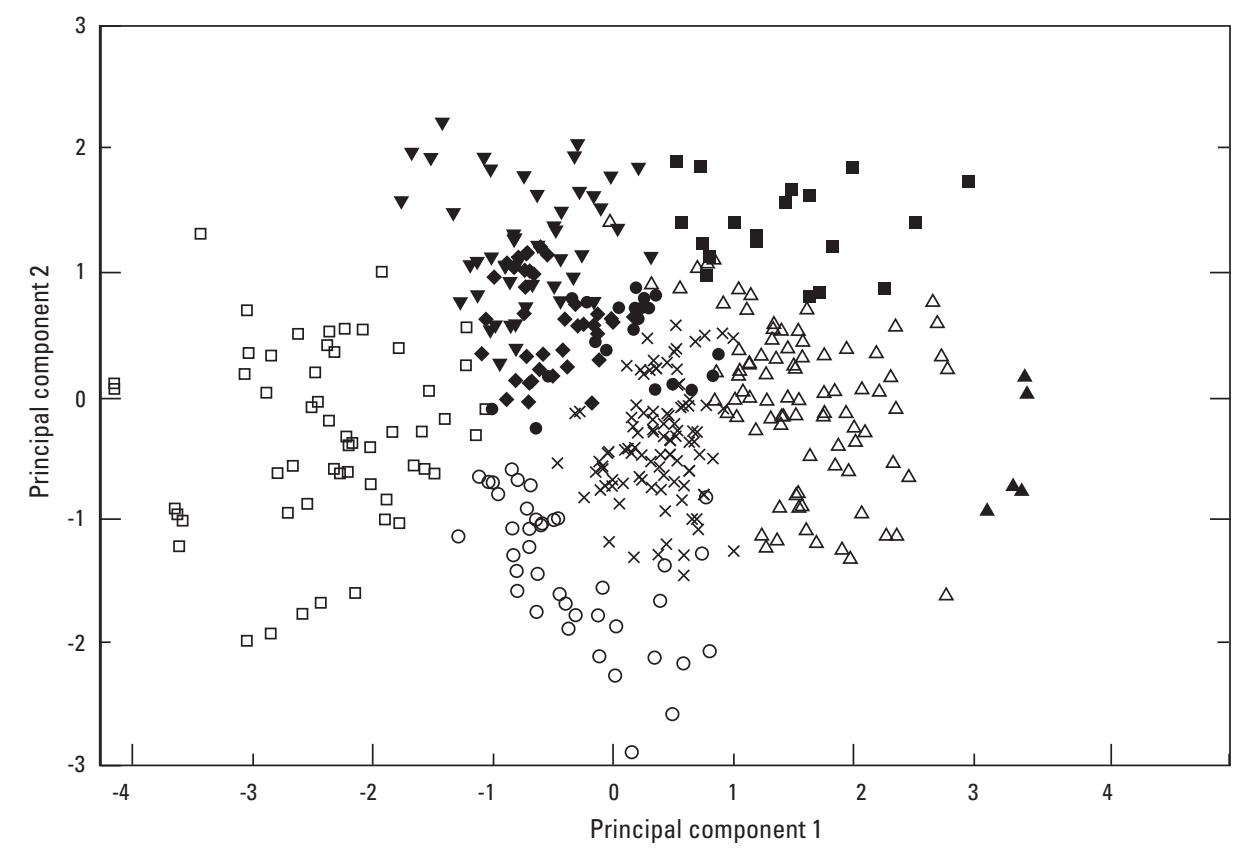

B

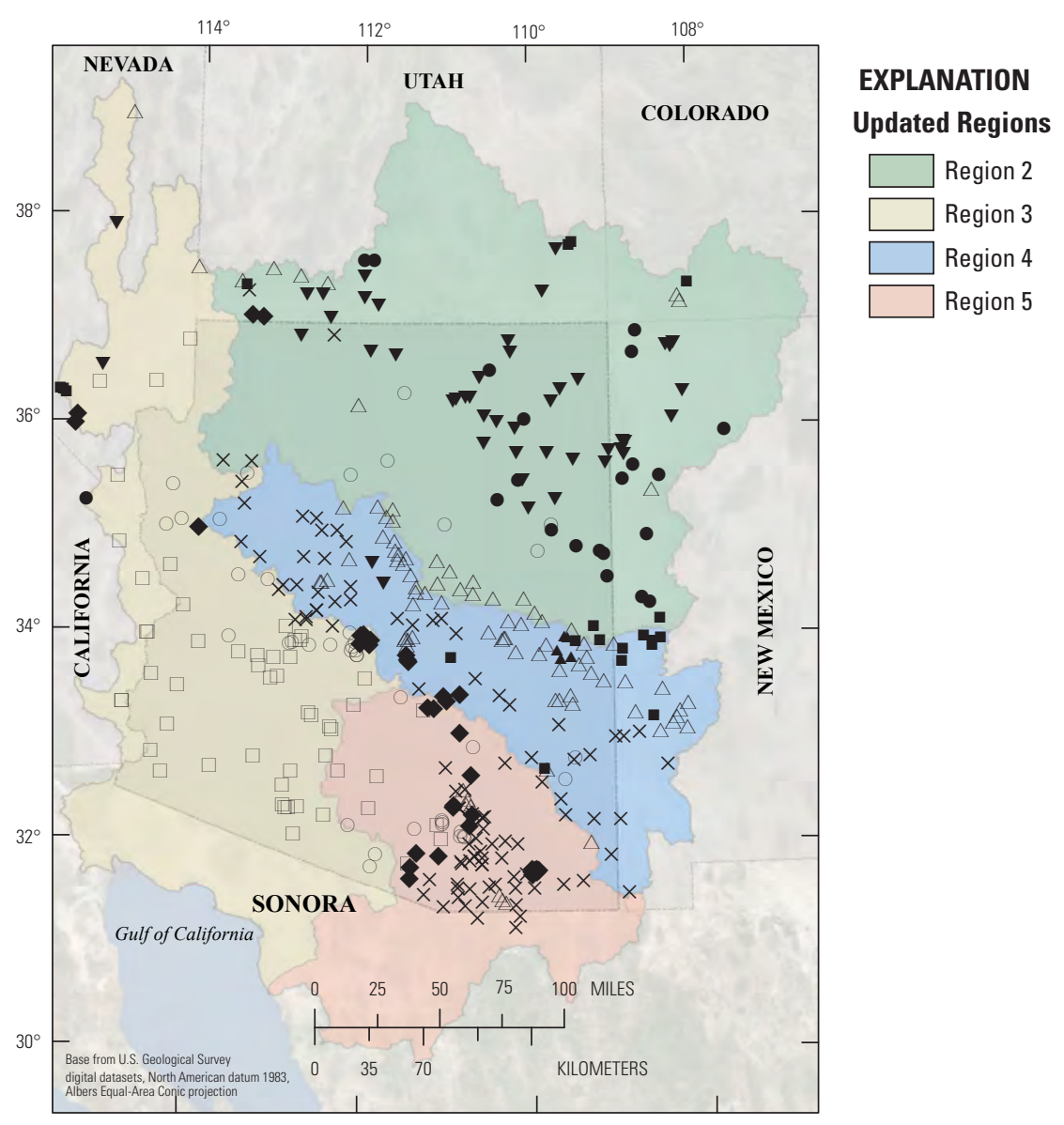

Figure 11. A principal components analysis ordination plot. $A$, Streamgages are overlaid with cluster analysis groupings. $B$, Streamgages mapped by basin centroid coordinates by 4-digit hydrologic units with cluster analysis groups overlaid (each symbol type represents a unique cluster). 


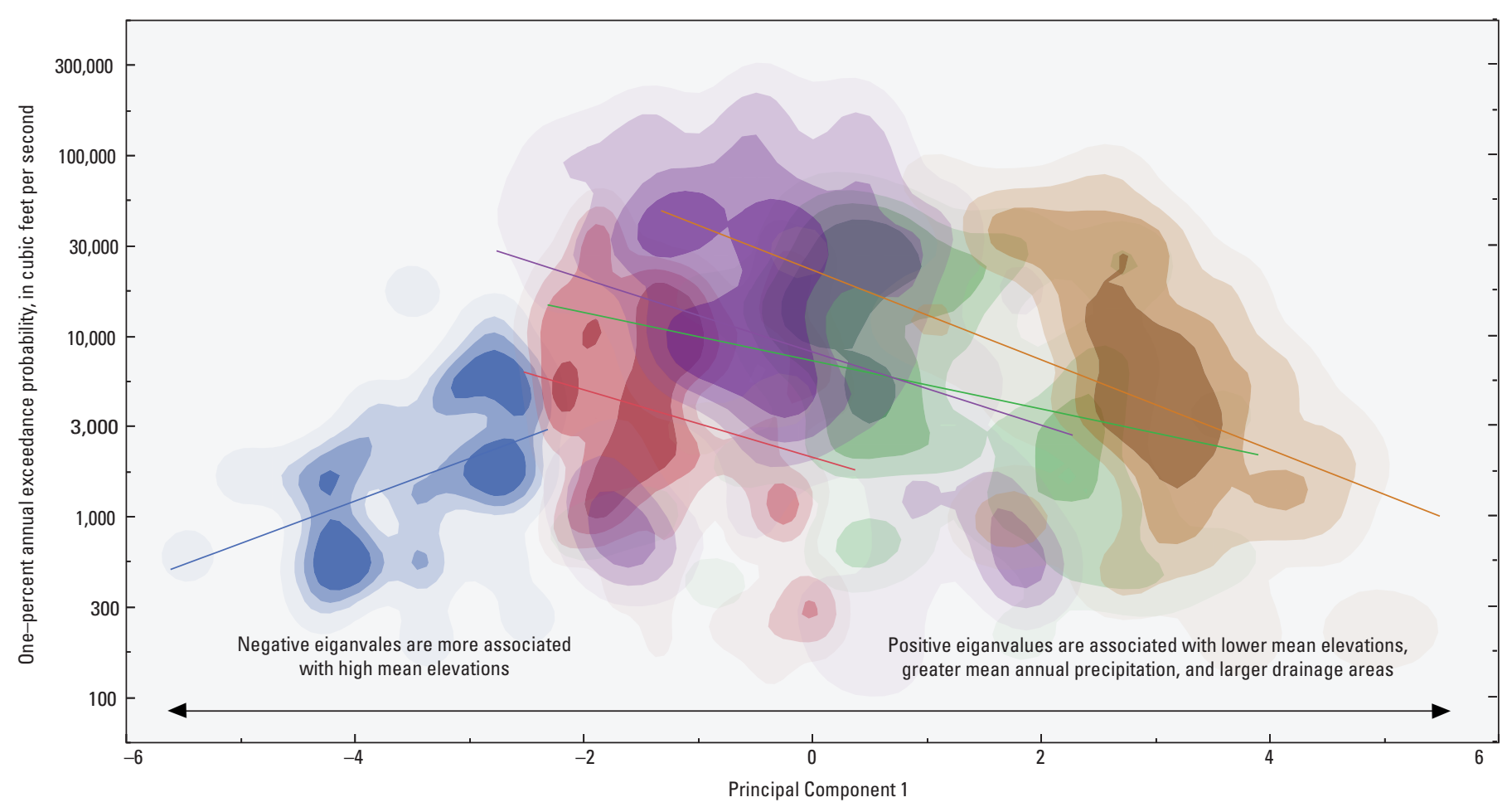

EXPLANATION

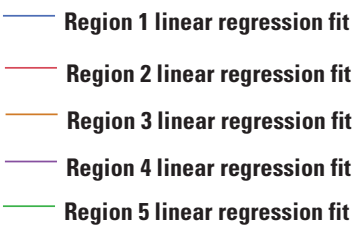

Region 1 density contour

Region 2 density contour

Region 3 density contour

Region 4 density contour

Region 5 desity contour

Figure 12. Density contour plot of the 1-percent annual exceedance probability (AEP) plotted as a function of the first principal component (PC) from the $\mathrm{PC}$ analysis of the normalized drainage, mean annual precipitation, and mean basin elevation. Linear regression lines are shown to emphasize direction and magnitude.

record lengths and correlation between sites with similar peakflow occurrences to better identify and quantify the variation in the precision of the estimated $P$-percent AEP flows.

Prior to conducting the regression analysis, steps were taken to remove redundant information in both the peakflow and explanatory (basin characteristics) datasets. Similar streamgage records may incorrectly weight a watershed in the regional dataset and basin characteristics explaining similar variability in the flow may cause mulitcollinearity in the model development. As part of the regional skew determination, an analysis was performed to determine if any two sites represented the same hydrologic events and were therefore redundant. Two factors were considered in the redundant site analysis: (1) whether two watersheds were nested, and (2) the ratio of the basin drainage areas. The drainage area ratio metric is used to determine if the two nested basins are sufficiently similar in size to conclude that they are essentially, or are at least in large part, the same watershed for the purposes of developing a regional hydrologic model (equations and details are in appendix 1). After the initial screening, streamgage locations and peak-flow magnitude and date of occurrence were checked to verify that sites were in fact providing redundant information. If streamgage peak-flow records were not correlated and (or) overlapping in period of record, then they were retained in the analysis. If two streamgages were considered redundant, the one with the longer record was retained. A list of streamgages removed from the regional regression analysis is included in table 7 .

The use of redundant basin characteristics in the regression equations will increase the risk of multicollinearity, and highly correlated variables can create erroneous regression coefficients, inflate the coefficient of determination, or unduly decrease the model error. Basin characteristics were first log-transformed (base-10) to more closely achieve the statistical inference of the Gaussian distribution assumptions. Exceptions were soil permeability, for which a square root transform was used, and mean elevation, which was divided by 1,000 so that regression coefficients were smaller and more 
easily calculated (Eng and others, 2009). Next, the correlation between explanatory variables was assessed using visual scatter plots and correlation analysis. A non-parametric Kendall's Tau $\left(\tau_{b}\right)$ correlation test was used because the procedure makes no assumptions about the normality of the data distribution. The main advantages of using $\tau_{b}$ is that the distribution of this statistic has slightly better statistical properties than the Spearman rank correlation coefficient and there is a direct interpretation in terms of probabilities of observing concordant and discordant pairs (Conover, 1999). For any two variable pairs, $\tau_{b}$ coefficients greater than or equal to \pm 0.6 were considered to indicate high correlation and the variables were not used in the same regression analysis. This was again checked after the regression models were developed with the variance inflation factor (VIF) diagnostic to further avoid multicollinearity (Johnston, 1972). Culling the explanatory variables to a list of relevant, nonredundant variables required some best professional judgment practices. For example, because the mean monthly precipitation and temperature variables are all highly correlated, a decision was made to keep months that were best at explaining the variability in the 1-percent AEP peak-flow. Highly correlated groups of variables include, mean monthly precipitation for each month, mean monthly temperature for each month, land cover (percent-forest, -herbaceous shrub, -developed, and -barren lands), precipitation intensity (5-, 10-, 25-, 50-, 100-, and 500-annual exceedance probabilities for the 24-hour duration), and elevation (minimum, mean, maximum) variables. Of the 71 basin characteristics computed, the list was reduced to 30 variables as a result of the redundancy checking.

After the redundancy analysis, a preliminary OLS was used to explore AEP peak-flow and basin characteristic relations. Explanatory variables were evaluated in a forward stepwise regression procedure. Significant parameters that most improved the model were selected by using the minimum $\mathrm{BIC}$ as a stopping rule to choose the best model. The BIC criterion introduces a penalty term for the number of parameters in the model; the penalty term is larger in BIC than in AIC (Schwarz, 1978). The JMP (version 10) statistical software (SAS Institute Inc., 2007) used in the analysis selects the minimum BIC to decide the best model. The diagnostic statistics root mean square error, VIF, coefficient of determination, t-statistics with significance $p \leq 0.05$, and prediction sum of square error were used to verify that the most effective basin characteristics were selected. The effect of individual streamgages used in the regression analysis were evaluated using the diagnostic statistics Cook's D statistic, leverage statistic, and the distribution of the residuals. Streamgages with high influence or leverage statistics were reevaluated by visually assessing the fitted frequency curve to the observed data and basin delineations checked for inconsistences or potential land-use operations that may affect normal flooding. Eleven streamgages were identified as having high influence or leverage and physical site conditions that may alter normal flow conditions. These streamgages were reevaluated and ultimately removed from the regional regression analysis because flows at several of the gages were affected by mining operations and (or) the fitted frequency curve was not fitting the observed data, likely related to physical conditions in the basin that could not be readily identified, such as effects from distributary flow (Hjalmarson and Kemna,1991). Many of the flood frequency fits appeared to have mixed flood types, possibly related to the presence of high-infiltration soils, such as those in sandy washes.

Results from the preliminary OLS regression analysis for 344 sites located in 5 newly proposed regions indicated that the base-10 logarithm of drainage area, in square miles (DRNAREA); the base-10 logarithm of mean annual precipitation, in inches (PRECIP); and mean basin elevation divided by 1,000 , in feet (ELEV); were the most significant explanatory variables for predicting the $P$-percent AEP flows. The Western Basin and Range (region 3) and Central Highlands (region 4) regions used DRNAREA, PRECIP, and ELEV in one or more the $P$-percent AEP flow equations. The High Elevation (region 1), Colorado Plateau (region 2), and Southeastern Basin and Range (region 5) regions only used the single explanatory variable: DRNAREA. Regression equation coefficients for DRNAREA and PRECIP are positive, indicating that as DRNAREA and PRECIP increase the peak-flow magnitude increases. While PRECIP mostly increases with increasing ELEV, the coefficient is negative because smaller watersheds are associated with higher elevations (DRNAREA decreases as ELEV increases) and as a result, DRNAREA is the more influential covariable in the multiple linear regression models.

\section{Generalized-Least-Squares and Final Regression Equations}

Ordinary least-squares-regression provides equal weight to the data from all of the streamgages, whereas weightedleast-squares and generalized-least-squares (GLS) regression considers the record length at each gage and gives greater weight to those with longer records. Furthermore, GLS considers the cross-correlation of annual peak flows between streamgages - if two gages are in close proximity and flooding is caused by relatively widespread storms, the annual series of peak flow will be largely similar at both gages and thus do not provide independent information for the purpose of the regression. The cross correlation matrix used in the regional skew analysis (appendix 1) was also used as the cross-correlation matrix in the GLS regional regression analysis. The USGS weighted-multiple-linear regression program (WREG; Eng and others, 2009) was used to perform GLS regression to develop the final $P$-percent AEP regression equations. The basin characteristics determined significant in the OLS stepwise procedure were tested for significance in WREG by evaluating the $T$ value statistic,

$$
\text { T value }=\frac{\beta_{k}}{\left(\operatorname{Var} \beta_{k}\right)^{1 / 2}}
$$


where

$\beta_{k} \quad$ is the predicted coefficient of the basin characteristic (Eng and others, 2009). The $T$ value statistic is assumed to follow a Student's t distribution, and gives the probability, or $p$-value, that the null hypothesis $\left(\mathrm{H}_{0}\right.$, the model parameter is equal to zero) should be rejected. Regression parameters with $p$-values less than 0.05 are deemed to be significant and included in the regression equation.

The WREG calculates leverage and influence statistics in the GLS analysis, which serve as a regression diagnostic for the effects of an individual streamgage on the regional models. Equations for the leverage and influence statistics are provided in the WREG manual (Eng and others, 2009). The leverage metric measures how dissimilar the independent variables are at a single streamgage relative to the values of the same independent variables of the other gages used in the regression model. If basin characteristic variables (that is drainage area, precipitation, or elevation) at a streamgage differ considerably from those at other gages, it can potentially, but not necessarily, have a dominant effect on the regression relation and such a gage is said to have high leverage. Alternatively, the influence metric measures the effect that the independent estimates of a streamgage have on the regression parameter values or constants (Eng and others, 2009). An influential observation is one with an unusually large residual that has a disproportionate effect on the fitted regression relations. Influential observations often have high leverage, but streamgages may have high leverage and low influence, or low leverage and high influence (table 8). In WREG, influence is calculated using a generalized Cook's D value (Eng and others, 2009). High influence may indicate an error in either the streamgage record or basin characteristics at a gage, but if no such errors exist, it alone is not sufficient justification for removing a gage from the regression analysis. Streamgages that exceeded the thresholds of the influence and leverage limits calculated by WREG were evaluated, but not removed, to reduce the effect of over calibrating the regression models. Streamgages with AEP flows that exceeded the high influence or leverage thresholds are shown in table 8 . The final regional regression equations for the 50-, 20-, 10-, 4-, 2-, 1-, 0.5-, and 0.2-percent AEP flows for the 5 hydrologic regions are shown in table 9 .

\section{Performance Metrics, Accuracy, and Limitations}

The regression equations presented are models that represent predictive relations between $P$-percent AEP peak flows and physical basin attributes. As with all models, each has an associated measure of quality, indicated by how well the predicted values represent the true values, and a reported uncertainty, represented by the model and sampling error. Users should be cautious in reporting an exact magnitude of a $P$-percent AEP flow estimate determined from a regression equation without also reporting the uncertainty. Differences in regional regression equation uncertainty arise because streamgages are disproportionately distributed within the state for a variety of reasons (see Streamgage Peak-Flow Data Spatial and Temporal Representation section). Higher density streamgage networks usually contain more perennial streamgages with longer records, thereby reducing error in the regional estimates. Regions in which many streams are characterized as ephemeral and intermittent tend to have shorter records and more variability in flow because of distributary flood-flow and attenuation. Understanding the sources of variability and error in the peak-flow data is one the most important aspects of regional analyses.

Three statistics were used to describe the performance and accuracy of the regression model equations: average variance of prediction $(A V P)$, average standard error of prediction $\left(S E_{p, a v e}\right)$, and the pseudo coefficient of determination (pseudo- $R^{2}$ ). The $A V P$ is a diagnostic statistic that reflects the underlying model error variance, $\sigma_{\delta}^{2}$, and the sampling variance:

$$
A V P=\sigma_{\delta}^{2}+\frac{1}{n} \sum_{p=1}^{n} \mathbf{x}_{p}\left(\mathbf{X}^{T} \Lambda^{-1} \mathbf{X}\right)^{-1} \mathbf{x}_{p}^{T},(6)
$$

where

$$
\begin{gathered}
\mathbf{x}_{p} \quad \text { is a vector of independent variables at the } \\
p^{\text {th }} \text { gage, and } \mathbf{X} \text { and } \Lambda^{-1} \text { are the design } \\
\text { matrix and covariance matrix from the } \\
\text { regression analysis, respectively. }
\end{gathered}
$$

The $A V P$ combines the model error, which relates to the number of explanatory variables used in the regression and the ability of those variables to predict peak flows; and the timesampling error, which accounts for the number of streamgages used in the analysis and the length of each streamgage record. The variance of prediction can also be calculated individually for each site from the regression covariance matrix and sitespecific basin characteristics, and this site-specific variance of prediction is used to combine streamgage flood estimates with the regional regression equations, as discussed in the Application of Additional Estimation Methods section.

The average standard error of prediction for a regression, $S E_{p, a v e}$, is an alternative way to express $A V P$ as a percent of the predicted $P$-percent AEP flow, and is simply a transformation of units:

$$
S E_{p, a v e}=100\left\{e^{(l n 10)^{2} A V P}-1\right\}^{1 / 2} .
$$

$\mathrm{SE}_{\mathrm{p} \text {,ave }}$ for the regression equations ranged from 27 percent to 122 percent (table 10). The average $\mathrm{SE}_{\mathrm{p}, \text { ave }}$ for all $P$-percent AEP flows was 58 percent. The $\mathrm{SE}_{\mathrm{p}, \text { ave }}$ is generally inversely correlated with the pseudo- $R^{2}$.

The pseudo- $R^{2}$ is a measure of the percent of the variability in the dependent variable ( $P$-percent AEP flow) explained 
Table 9. Regional regression equations for predicting the 50-, 20-, 10-, 4-, 2-, 1-, 0.5-, and $0.2-$ percent annual exceedance probability flows in 5 flood regions of Arizona.

[DRNAREA, drainage area in square miles; PRECIP, mean annual precipitation in inches; ELEV, mean basin elevation in feet]

\begin{tabular}{|c|c|}
\hline $\begin{array}{c}P \text {-percent annual exceedance } \\
\text { probability }\end{array}$ & Regional regression equations \\
\hline \multicolumn{2}{|c|}{ Flood region 1 (High Elevation) regression equation } \\
\hline 50 & $17.4(D R N A R E A)^{0.655}$ \\
\hline 20 & $42.1(D R N A R E A)^{0.625}$ \\
\hline 10 & $65.5(D R N A R E A)^{0.613}$ \\
\hline 4 & $103(D R N A R E A)^{0.604}$ \\
\hline 2 & $136(D R N A R E A)^{0.601}$ \\
\hline 1 & $173(D R N A R E A)^{0.599}$ \\
\hline 0.5 & $215(D R N A R E A)^{0.599}$ \\
\hline 0.2 & $279(D R N A R E A)^{0.599}$ \\
\hline \multicolumn{2}{|c|}{ Flood region 2 (Colorado Plateau) regression equation } \\
\hline 50 & $53.2(D R N A R E A)^{0.505}$ \\
\hline 20 & $142(D R N A R E A)^{0.476}$ \\
\hline 10 & $236(D R N A R E A)^{0.460}$ \\
\hline 4 & $406(D R N A R E A)^{0.442}$ \\
\hline 2 & $573(D R N A R E A)^{0.431}$ \\
\hline 1 & $778(D R N A R E A)^{0.421}$ \\
\hline 0.5 & $1,028(D R N A R E A)^{0.413}$ \\
\hline 0.2 & $1,429(D R N A R E A)^{0.403}$ \\
\hline \multicolumn{2}{|c|}{ Flood region 3 (Western Basin and Range) regression equation } \\
\hline 50 & $2.78(D R N A R E A)^{0.462}(P R E C I P)^{2.229} 10^{\left(-0.351^{*} E L E V / 1,000\right)}$ \\
\hline 20 & $12.8(D R N A R E A)^{0.474}(P R E C I P)^{1.706} 10^{\left(-0.208^{*} E L E V / 1,000\right)}$ \\
\hline 10 & $26.7(D R N A R E A)^{0.479}(P R E C I P)^{1.447} 10^{\left(-0.132^{*} E L E V / 1,000\right)}$ \\
\hline 4 & $89.1(\text { DRNAREA })^{0.495}(P R E C I P)^{0.839}$ \\
\hline 2 & $129(D R N A R E A)^{0.505}(P R E C I P)^{0.831}$ \\
\hline 1 & $183(\text { DRNAREA })^{0.516}(\text { PRECIP })^{0.812}$ \\
\hline 0.5 & $256(D R N A R E A)^{0.527}(P R E C I P)^{0.789}$ \\
\hline 0.2 & $384(D R N A R E A)^{0.539}(P R E C I P)^{0.758}$ \\
\hline
\end{tabular}


Table 9. Regional regression equations for predicting the $50-, 20-, 10-, 4-, 2-, 1-, 0.5-$, and $0.2-$ percent annual exceedance probability flows in 5 flood regions of Arizona.-Continued

[DRNAREA, drainage area in square miles; PRECIP, mean annual precipitation in inches; ELEV, mean basin elevation in feet]

\begin{tabular}{|c|c|}
\hline $\begin{array}{c}P \text {-percent annual exceedance } \\
\text { probability }\end{array}$ & Regional regression equations \\
\hline \multicolumn{2}{|c|}{ Flood region 4 (Central Highlands) regression equation } \\
\hline 50 & $54.7(D R N A R E A)^{0.664}$ \\
\hline 20 & $51.2(D R N A R E A)^{0.658}(P R E C I P)^{0.903} 10^{\left(-0.135^{*} E L E V / 1,000\right)}$ \\
\hline 10 & $43.2(D R N A R E A)^{0.643}(P R E C I P)^{1.204} 10^{\left(-0.150^{*} E L E V / 1,000\right)}$ \\
\hline 4 & $33.6(D R N A R E A)^{0.624}(P R E C I P)^{1.528} 10^{\left(-0.160^{*} E L E V / 1,000\right)}$ \\
\hline 2 & $30.8(D R N A R E A)^{0.614}(P R E C I P)^{1.687} 10^{\left(-0.161^{*} E L E V / 1,000\right)}$ \\
\hline 1 & $30.0(D R N A R E A)^{0.605}(P R E C I P)^{1.805} 10^{\left(-0.161^{*} E L E V / 1,000\right)}$ \\
\hline 0.5 & $30.6(D R N A R E A)^{0.598}(P R E C I P)^{1.893} 10^{\left(-0.161^{*} E L E V / 1,000\right)}$ \\
\hline 0.2 & $33.3(\text { DRNAREA })^{0.591}(P R E C I P)^{1.976} 10^{\left(-0.160^{*} E L E V / 1,000\right)}$ \\
\hline \multicolumn{2}{|c|}{ Flood region 5 (Southeastern Basin and Range) regression equation } \\
\hline 50 & $10^{\left(6.363-4.386 D R N A R E A^{-0.060}\right)}$ \\
\hline 20 & $\left.10^{(5.868-3.506 \text { DRNAREA }}{ }^{-0.080}\right)$ \\
\hline 10 & $10^{\left(5.778-3.218 D_{\text {DRNAREA- }}^{-0.090}\right)}$ \\
\hline 4 & $10^{(5.757-2.988 \text { DRNAREA-0.100) }}$ \\
\hline 2 & $\left.10^{(5.696-2.795 \text { DRNAREA- }}-0.110\right)$ \\
\hline 1 & $10^{(5.651-2.634 \text { DRNAREA-0.120) }}$ \\
\hline 0.5 & $\left.10^{(5.761-2.638 \text { DRNAREA- }}{ }^{-0.120}\right)$ \\
\hline 0.2 & $10^{\left(5.750-2.502 D_{D R N A R E A^{-0.130}}\right)}$ \\
\hline
\end{tabular}


Table 10. Average variance of prediction, standard error of prediction, and pseudo- $\mathrm{R}^{2}$ for the regional regression equations.

[MSE, mean square error; SEP, standard error of prediction; pseudo- $\mathrm{R}^{2}$, pseudo coefficient of determination; SEM, standard error of model; AVP, average variance of prediction]

\begin{tabular}{|c|c|c|c|c|c|}
\hline $\begin{array}{c}P \text {-percent annual } \\
\text { exceedance } \\
\text { probability }\end{array}$ & MSE (log units) & SEP (percent) & Pseudo-R (percent) & SEM (in percent) & AVP ( $\log$ units) \\
\hline 50 & 0.106 & 86.1 & 63.5 & 83.1 & 0.105 \\
\hline 20 & 0.071 & 64.4 & 72.0 & 62.2 & 0.065 \\
\hline 2 & 0.066 & 55.1 & 75.5 & 53.0 & 0.050 \\
\hline 1 & 0.072 & 56.3 & 74.6 & 54.0 & 0.052 \\
\hline 0.5 & 0.080 & 58.5 & 73.3 & 56.1 & 0.056 \\
\hline 0.2 & 0.092 & 62.7 & 70.7 & 60.0 & 0.063 \\
\hline 20 & 0.117 & 87.2 & 75.8 & 85.4 & 0.107 \\
\hline 10 & 0.100 & 75.7 & 78.7 & 74.1 & 0.085 \\
\hline 4 & 0.093 & 68.6 & 80.2 & 67.1 & 0.073 \\
\hline 2 & 0.094 & 66.6 & 80.3 & 65.0 & 0.069 \\
\hline 1 & 0.100 & 67.3 & 79.4 & 65.6 & 0.070 \\
\hline 0.5 & 0.107 & 68.8 & 78.2 & 67.1 & 0.073 \\
\hline 0.2 & 0.121 & 72.9 & 75.6 & 71.0 & 0.080 \\
\hline \multicolumn{6}{|c|}{ Region 3 (Western Basin and Range) regression equation } \\
\hline 50 & 0.156 & 108.5 & 74.3 & 103.2 & 0.147 \\
\hline 0.5 & 0.097 & 52.9 & 90.1 & 49.4 & 0.046 \\
\hline 0.2 & 0.139 & 72.2 & 84.1 & 68.1 & 0.079 \\
\hline
\end{tabular}


Table 10. Average variance of prediction, standard error of prediction, and pseudo- $\mathrm{R}^{2}$ for the regional regression equations.-Continued

[MSE, mean square error; SEP, standard error of prediction; pseudo- $\mathrm{R}^{2}$, pseudo coefficient of determination; SEM, standard error of model; AVP, average variance of prediction]

\begin{tabular}{|c|c|c|c|c|c|}
\hline $\begin{array}{l}P \text {-percent annual } \\
\text { exceedance } \\
\text { probability }\end{array}$ & MSE (log units) & SEP (percent) & Pseudo-R² (percent) & SEM (in percent) & AVP (log units) \\
\hline 50 & 0.143 & 101.4 & 85.2 & 99.2 & 0.133 \\
\hline 20 & 0.067 & 57.0 & 93.4 & 54.7 & 0.053 \\
\hline 2 & 0.032 & 27.1 & 98.2 & 24.6 & 0.013 \\
\hline 1 & 0.034 & 27.1 & 98.2 & 24.4 & 0.013 \\
\hline 0.5 & 0.038 & 28.9 & 98.0 & 25.9 & 0.015 \\
\hline 0.2 & 0.048 & 35.0 & 96.9 & 31.9 & 0.022 \\
\hline \multicolumn{6}{|c|}{ Region 5 (Southeastern Basin and Range) regression equation } \\
\hline 20 & 0.073 & 61.5 & 84.0 & 60.0 & 0.060 \\
\hline 10 & 0.061 & 52.4 & 87.6 & 51.0 & 0.046 \\
\hline 4 & 0.056 & 45.8 & 90.2 & 44.3 & 0.036 \\
\hline 2 & 0.057 & 43.5 & 91.1 & 41.9 & 0.033 \\
\hline 1 & 0.060 & 42.6 & 91.5 & 40.9 & 0.031 \\
\hline 0.5 & 0.064 & 42.4 & 91.6 & 40.7 & 0.031 \\
\hline 0.2 & 0.071 & 43.2 & 91.5 & 41.3 & 0.032 \\
\hline
\end{tabular}


by the regression after removing the effect of the time-sampling error, and is calculated as:

$$
\text { Pseudo }-R^{2}=1-\frac{\sigma_{\delta}^{2}(\mathrm{k})}{\sigma_{\delta}^{2}(0)}
$$

where

$$
\begin{gathered}
\sigma_{\mathrm{b}}^{2}(\mathrm{k}) \quad \text { is the model error variance from a } \\
\text { GLS regression with k independent } \\
\text { variables, and } \sigma_{\mathrm{b}}^{2}(0) \text { is the model error } \\
\text { variance from a GLS regression with no } \\
\text { independent variables. }
\end{gathered}
$$

The Pseudo- $R^{2}$ values ranged from 63 to 98 percent, with a mean of 85 percent, indicating that the regression models were explaining much of variation in the $P$-percent AEP peak flows. Models with lower pseudo- $R^{2}$ values were associated with drier regions of the state that usually had more variable $P$-percent AEP peak flows. Lower pseudo- $R^{2}$ values were also common for models predicting the higher $P$-percent AEP peak flows (that is, the 50-, 20-, 10-percent flows). Model performance was best in predicting $P$-percent AEP peak flows for mid to low $P$-percent AEP flows (4-, 2-, 1-percent AEP flows), as indicated by lower $S E_{p, a v e}$ and higher Pseudo- $R^{2}$ values, than for high and very low $P$-percent AEP flows (50-, 20-, 10-, 0.5-, and 0.2-percent AEP flows). The $A V P, S E_{p, a v e}$, and pseudo- $R^{2}$ statistics for the final set of regional regression equations are provided in table 10 . The relation between observed and predicted flood discharges for 1-percent AEP for each of the flood regions can be seen in figure $13 A-E$. The uncertainty of regression estimates can be seen graphically as a greater scatter of plotted observed to predicted points along the $1: 1$ line.

In comparison, the standard error of prediction for the regression equations in WSP-2433 for the 50-, 20-, 10-, 4-, 2-, and 1-percent AEP flows in regions 8 and 12-14 ranges from 37 to 105 percent; the average standard error of prediction is 56 percent. The standard error of prediction was not reported in WSP-2433 for the 0.5- and 0-.2 percent AEP flows, which typically have a higher standard error of prediction.

Some limitations should be recognized when using the final regional regression equations. First, the regional regression equations were developed using data from rural streamgages and these can only be used to predict $P$-percent AEP flows at rural locations. The methods are not appropriate (or applicable) for sites where the peak-flow magnitudes are affected substantially by flow regulation, nor are these appropriate (or applicable) for streams in urban areas (impervious area greater than 10 percent) unless the effects of urbanization are deemed insignificant. A separate analysis of the frequency and magnitude of flooding in urban watersheds is presented in Kennedy and Paretti (2014). Second, there is a specified range of values for which the explanatory variables (basin characteristics) are applicable for predicting $P$-percent AEP flows. Applying the equations to sites on streams having explanatory variables outside of the ranges of those used to develop the regression equations may result in prediction errors that are considerably greater than those indicated by the standard error of prediction percentages listed in table 6 . The ranges of explanatory variables used to develop the regional regression equations are given in table 11 .

\section{Prediction Intervals}

In past flood frequency analysis reports, the accuracy of the regression equations was often described as equivalent years of record, or the number of years of systematic record that would be needed to provide an estimate equal in accuracy to the standard error of prediction of the regression equation. The equivalent years of record and the streamgage period of record would be used to weight the flow estimates determined by the regression analysis and the flood frequency AEP estimated flows. Flow estimation accuracy usually follows the general assumption that more years of peak-flow data minimize error; however, this fails to account for the true variance of the streamgage flood frequency estimates (Gotvald and others, 2009). For example, the predictive properties may still be highly variable for long-record streamgages in small tributary watersheds in southeastern Arizona, because floods at these gages are often strongly affected by convective-type storm processes and commonly have high channel infiltration rates. For this reason, record length alone fails to capture the physical and hydroclimatic processes affecting streamflow, and the variance of the streamgage and regional estimators will provide a better estimate of the accuracy than the traditional proxy of record length alone.

A regional regression equation provides an estimate of the $P$-percent AEP flow at an ungaged location, but with that ungaged estimate, no measure of uncertainty is provided. Although $A V P$ and $S E_{p, a v e}$, and pseudo- $R^{2}$ provide useful information about the average performance of the regression equation itself, the uncertainty of a predicted $P$-percent AEP peak-flow for a specific basin depends in part on the basin characteristics. That is, basins that are well-represented by conditions and characteristics in other basins in the regression equations will have lower uncertainty than do basins in which those conditions and characteristics are less common. A procedure developed originally by Tasker and Driver (1988) for determining the uncertainty for chemical loading has been used by several states to identify the uncertainty around a specific streamgages $P$-percent AEP flow, rather than using an average uncertainty based on all the streamgages used in the regression analysis (Gotvald and others, 2009; Gotvald and others, 2012; Eash and others, 2013). A prediction interval can be calculated to provide the confidence bounds of error associated with a probability that the true value of the estimated $P$-percent AEP flow will be within the stated interval percentile (Helsel and Hirsch, 2002). The 90-percent prediction interval, a commonly reported metric, effectively states that there is a 90 -percent probability that the true $P$-percent AEP flow lies within the margin of error that represents 
Table 11. Applicable ranges of explanatory variables used to develop the regional regression equations.

[GIS, geographical information system; $\mathrm{mi}^{2}$, square miles; -, not applicable]

\begin{tabular}{|c|c|c|c|}
\hline Statistic description & GIS drainage area, $\left(\mathrm{mi}^{2}\right)$ & Elevation (feet) & $\begin{array}{c}\text { Mean Annual } \\
\text { Precipitation (inches) }\end{array}$ \\
\hline \multicolumn{4}{|c|}{ Flood region 1 (High Elevation) } \\
\hline Minimum & 1.26 & - & - \\
\hline Maximum & 711 & - & - \\
\hline Mean & 100 & - & - \\
\hline Median & 39.8 & - & - \\
\hline Number of sites & 41 & - & - \\
\hline \multicolumn{4}{|c|}{ Flood region 2 (Colorado Plateau) } \\
\hline Minimum & 0.103 & - & - \\
\hline Maximum & 1,6017 & - & - \\
\hline Mean & 610 & - & - \\
\hline Median & 56.3 & - & - \\
\hline Number of sites & 85 & - & - \\
\hline \multicolumn{4}{|c|}{ Hydrologic region $3^{\mathrm{a}}$ (Western Basin and Range) } \\
\hline Minimum & 0.082 & 283 & 3.7 \\
\hline Maximum & 1,725 & 6,404 & 22.2 \\
\hline Mean & 152 & 2,419 & 10.5 \\
\hline Median & 12.51 & 2,271 & 10.2 \\
\hline Number of sites & 68 & 68 & 68 \\
\hline \multicolumn{4}{|c|}{ Hydrologic region $4^{\text {b }}$ (Central Highlands) } \\
\hline Minimum & 0.059 & 3,274 & 10.8 \\
\hline Maximum & 18,044 & 7,451 & 33.5 \\
\hline Mean & 804 & 5,443 & 21.9 \\
\hline Median & 77.8 & 5,441 & 21.3 \\
\hline Number of sites & 77 & 77 & 77 \\
\hline \multicolumn{4}{|c|}{ Hydrologic region 5 (Southeastern Basin and Range) } \\
\hline Minimum & 0.155 & - & - \\
\hline Maximum & 2,925 & - & - \\
\hline Mean & 254 & - & - \\
\hline Median & 19.6 & - & - \\
\hline Number of sites & 73 & - & - \\
\hline
\end{tabular}


90 percent of the respective distribution. A modified equation from Tasker and Driver (1988) can be used to compute the 90 -percent prediction interval at a streamgage. A $100(1-\alpha)$ or (90-percent, $\alpha=0.10$ ) prediction interval for the true mean can be computed as follows:

$$
\frac{Q}{T}<Q<Q T
$$

where $Q$ is the $P$-percent AEP flow computed from the regional regression equation, and

$T$ is computed as

$$
T=10^{\left[t_{(a / 2, n-p)} S E_{p, i}\right]}
$$

where

$$
\begin{gathered}
t_{(a / 2, n-p)} \quad \begin{array}{c}
\text { is the critical value form the Student's } \\
\text { t-distribution at alpha level } \alpha=0.10 \text { for } \\
90 \text {-percent prediction interval; }
\end{array} \\
n-p \quad \text { is the degrees of freedom with } n \text { streamgages } \\
\text { included in the regression analysis and } p \\
\text { parameters in the equation; and } \\
S E_{p, i} \quad \begin{array}{l}
\text { is the standard error of the prediction for site } i \\
\text { and is computed as }
\end{array}
\end{gathered}
$$

$$
S E_{p, i}=\left[\sigma_{\delta}^{2}+\mathbf{X}_{i}\left(\mathbf{X}^{T} \Lambda^{-1} \mathbf{X}\right)^{-1} \mathbf{X}_{i}^{T}\right]^{0.5}
$$

where

$$
\begin{aligned}
& \sigma_{\delta}^{2} \quad \text { is the model error variance, } \\
& \mathbf{X}_{i} \quad \text { is a row vector of the explanatory variables } \\
& \text { for site } i \text {, augmented by a } 1 \text { as the first } \\
& \left(\mathbf{X}^{T} \Lambda^{-1} \mathbf{X}\right)^{-1} \quad \text { is the covariance matrix for the regression } \\
& \text { coefficients (computed using WREG and } \\
& \text { presented in table 12), and } \\
& \mathbf{X}_{i}^{T} \quad \text { is the transpose of } \mathrm{X}_{i} \text { (Ludwig and } \\
& \text { Tasker, 1993). }
\end{aligned}
$$

To demonstrate the application of equation 9 to calculate 90-percent prediction intervals, the following example is given for streamgaging station 09508500 (Verde River Below Tangle Creek, above Horseshoe Dam), located in region 4. Using the basin characteristics calculated by StreamStats (note that StreamStats is not capable of implementing USGS rounding standards and basin characteristic statistics may include more significant figures than shown in table 1), the contributing drainage area (DRNAREA) for this station is 5,499 $\mathrm{mi}^{2}$, mean annual precipitation (PRECIP) is 19.6 in., and average elevation (ELEV) is $5,573 \mathrm{ft}$. Using the appropriate regression equation for region 4 (table 9), the predicted 1-percent AEP flow is:

$$
\begin{aligned}
& Q_{1}=30.0^{*} \text { DRNAREA } A^{0.605} * \text { PRECIP } \\
& 10^{1.805 * 161 * \frac{E L E V}{1000}}=149,714 \mathrm{ft}^{3} / \mathrm{s} ; \text { rounded to three } \\
& \text { significant figures } 150,000 \mathrm{ft}^{3} / \mathrm{s}
\end{aligned}
$$

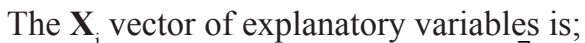
$\left[1 ; \log _{10}(5,499) ; \log _{10}(19.6) ; 5,573 / 1000\right]$, and the model error variance is 0.0109 (table 12). The covariance matrix $\boldsymbol{U}=\left(\mathbf{X}^{T} \Lambda^{-1} \mathbf{X}\right)^{-1}$ can be retrieved from table 12 ; region 4 , 1-percent AEP which was determined using WREG. The product $\mathbf{X}_{i}\left(\mathbf{X}^{T} \Lambda^{-1} \mathbf{X}\right)^{-1} \mathbf{X}_{i}^{T}$ is 0.0013066 . From equation 11 , the standard error of prediction is 0.1105 . The critical value $t_{(a / 2, n-p)}$ for the regression equation for region 4 with 73 degrees of freedom, (77 streamgages used to develop the regression equation with 4 parameters) is 1.67 (table 12). Therefore, $T$ (equation 10) equals 1.5279 and the 90-percent prediction interval is $97,960<Q_{1}<228,687$ (rounded to $\left.98,000 \mathrm{ft}^{3} / \mathrm{sec}<\mathrm{Q} 1<229,000 \mathrm{ft}^{3} / \mathrm{sec}\right)$.

\section{Application and Additional Estimation Methods}

Estimates of flood frequency can be improved through the use of additional or nearby streamgage information. Information along the same stream reach may enable more localized and relevant estimates than a larger regional approach. The application of alternative flood frequency estimation methods should be evaluated and used on a case by case basis. The application of additional flood frequency estimation methods should be supported by user knowledge of the hydrologic system of the area of interest. The estimation uncertainty will be very dependent on the number of streamgages located in the area and the length of record for which those gages have been operating.

\section{Weighting Estimates at Streamgages}

Flood frequency estimates at streamgages, particularly those with short records (less than 10 years of record), can be improved by computing a weighted average of the streamgage estimate and the estimate from the regional regression equations (Cohn and others, 2012). The estimate from the regression equation is considered an independent estimate, and if the uncertainty of the two independent estimates is known, then an optimal weighted average can be determined (Berenbrock and Cohn, 2008). The weighting is inversely proportional to the variance of the regression and streamgage estimates ( $V P$ and $V P_{s}$, respectively, in log units; table 13) so that estimates with greater uncertainty have less weight in the weighted average. The variance of the regression estimate is calculated differently depending on whether the site was used to develop the regional regression equations. For sites not used in the regional regression equations, $V P_{r}$ is equivalent to $A V P$ and calculated using equation 6 . For individual sites that are used in the regional regression equations, $V P_{\mathrm{r}}$ is;

$$
V P_{r}=\sigma_{\delta}^{2}+\mathbf{x}_{i}\left(\mathbf{X}^{T} \boldsymbol{\Lambda}^{-1} \mathbf{X}\right)^{-1} \mathbf{x}_{i}^{T}
$$


The $\mathbf{X}^{T} \boldsymbol{\Lambda}^{-1} \mathbf{X}$ covariance matrix is provided as output from WREG (Eng and others, 2009). A first-order approximation of $V P_{s}$ is output for each AEP from the PeakfqSA EMA-MGB software used to fit the LPIII distribution (Cohn and others, 2001). The weighted average for a particular AEP is then:

$$
\log (\hat{Q})=\frac{V P_{r} * \log \left(Q_{s}\right)+V P_{s} * \log \left(Q_{r}\right)}{V P_{r}+V P_{s}} .
$$

The station, regression, and weighted estimates of discharge are presented in table 14 . The variance of prediction associated with the weighted estimate, $V P_{w}$, is computed as:

$$
V P_{w}=\frac{V P_{s} V P_{r}}{V P_{s}+V P_{r}}
$$

$V P$ estimates are presented in table 13 for the station, regression, and weighted estimate of $P$-percent AEP flows.

\section{Maximum Floods and Envelope Curves}

An estimate of the potential maximum flood for a geographical region is often the purpose of estimating flood frequency at an ungaged site. An alternative to the statistical distribution approach taken in this report is to simply evaluate the largest recorded peaks for basins of similar size. An "envelope curve" can be drawn that encompasses the maximum peaks, representing the largest flood that can be expected in a period comparable to the period of record at the streamgages used in the analysis (on the order of 100 years in Arizona). This method requires many of the same assumptions as the statistical distribution approach, most importantly that flood peaks are stationary and do not trend larger or smaller over time. Because the regression equations in the Central Highlands (region 4) and Southwest Basin and Range (region 3) depend on precipitation and elevation, new regression equations relating $P$-percent AEP flows were developed using drainage area only for the express purpose of generating envelope curves.

Various equations have been proposed for representing the envelope curve (Malvick, 1980; Crippen, 1982; Boughton and Renard, 1984) and often the envelope curve is drawn graphically and no equation given (Thomas and others, 1997). The curves published by Crippen and shown in figure 14 are given by

$$
Q_{C}=10^{\beta_{0}} * \operatorname{DRNAREA}^{\left(\beta_{1}\right)} *\left(D R N A R E A^{0.5}+0.5\right)^{\beta_{2}},
$$

where

$Q_{C} \quad$ is the potential maximum discharge based on the envelope curve analysis, in cubic feet per second;

DRNAREA is the drainage area, in square miles;

$\beta_{0} \quad$ is the regression constant for region $14,4.00$ and region 16, 4.995196;

$\beta_{1} \quad$ is the regression coefficient for region 14 , 0.710 and region $16,1.029$; and

$\beta_{2} \quad$ is the regression coefficient for region 14, -0.844 and region $16,-1.341$.

The potential maximum curves closely define the ceiling of the maximum peaks in regions 2 ; in regions 3,4 , and 5 , the Crippen envelope curves are significantly higher than any of the observed maximum peak-flows (fig. 14A-D).

\section{Estimates near Streamgages on the Same Stream}

If a study area is near an existing streamgage where flood frequency statistics have been calculated, a weighted average peak flow may be calculated that incorporates the data from that gage explicitly, rather than using only the regional regression equations (Ries, 2007). Generally, "near" is defined as having a drainage area ratio between 0.5 and 1.5 of the streamgage of interest. First, the estimated peak flow at the ungaged site is determined by comparing the drainage area to that at the gage itself:

$$
Q_{u}=\left(\frac{\log \left(A_{u}\right)}{\log \left(A_{g}\right)}\right)^{b} * Q_{s},
$$

where

$Q_{u} \quad$ is the area-weighted $P$-percent AEP flow estimate at the ungaged site,

$Q_{s} \quad$ is the estimate at the streamgage prior to weighting with the regional regression estimate (table 14), and

$A_{u}$ and $A_{g} \quad$ are the areas of the ungaged and gaged drainage areas, respectively. The exponent $b$ is the exponent of the drainage area variable in the regional regression equation (DRNAREA, table 9). 


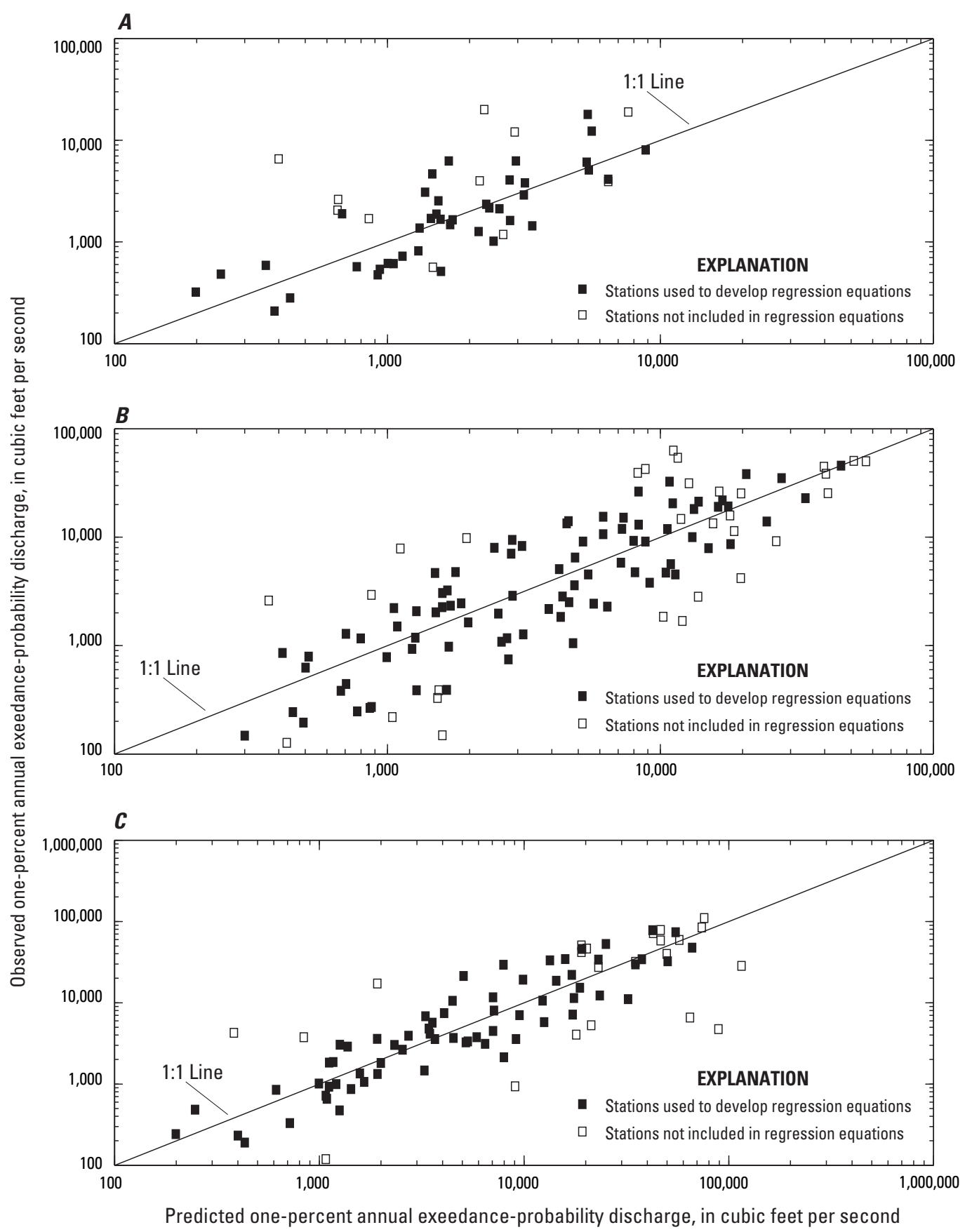

Figure 13. The relation between the observed and predicted flood discharges for 1-percent annual exceedance probability by flood region. $A$, Region 1 (High Elevation); $B$, Region 2 (Colorado Plateau); $C$, Region 3 (Western Basin and Range); $D$, Region 4 (Central Highlands); and E, Region 5 (Southeastern Basin and Range). 


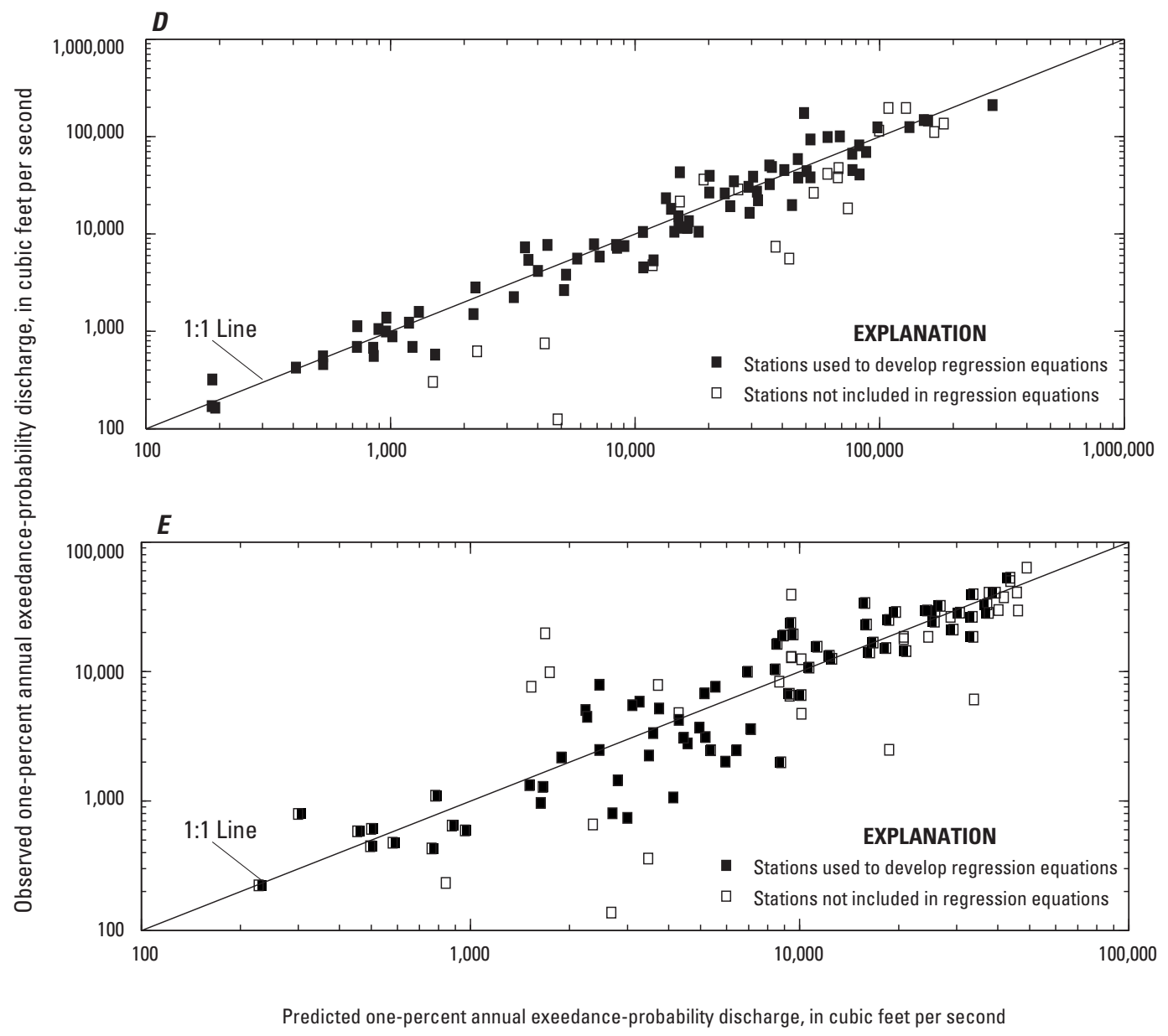

Figure 13. - Continued. The relation between the observed and predicted flood discharges for 1-percent annual exceedance probability by flood region. $A$, Region 1 (High Elevation); $B$, Region 2 (Colorado Plateau); $C$, Region 3 (Western Basin and Range); $D$, Region 4 (Central Highlands); and $E$, Region 5 (Southeastern Basin and Range). 


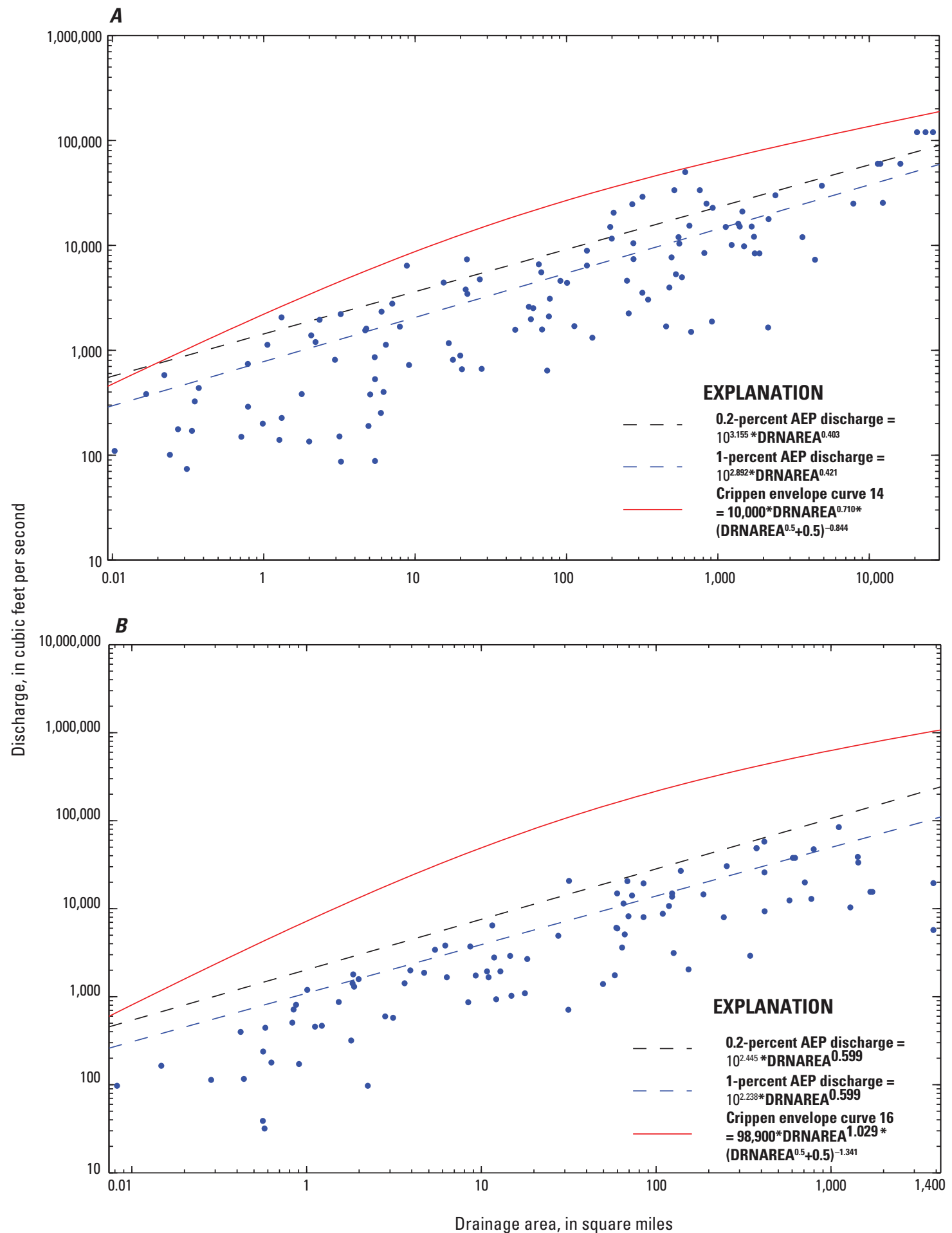

Figure 14. The maximum recorded peak-flow discharge plotted with the frequency curves for the 1- and 0.2-percent annual exceedance probability (AEP) and the Crippen (1978) envelope curve region (14 for the Colorado Plateau and 16 for all other regions), by region. $A$, Region 2 (Colorado Plateau); $B$, Region 3 (Western Basin and Range); $C$, Region 4 (Central Highlands); and $D$, Region 5 (Southeastern Basin and Range). 


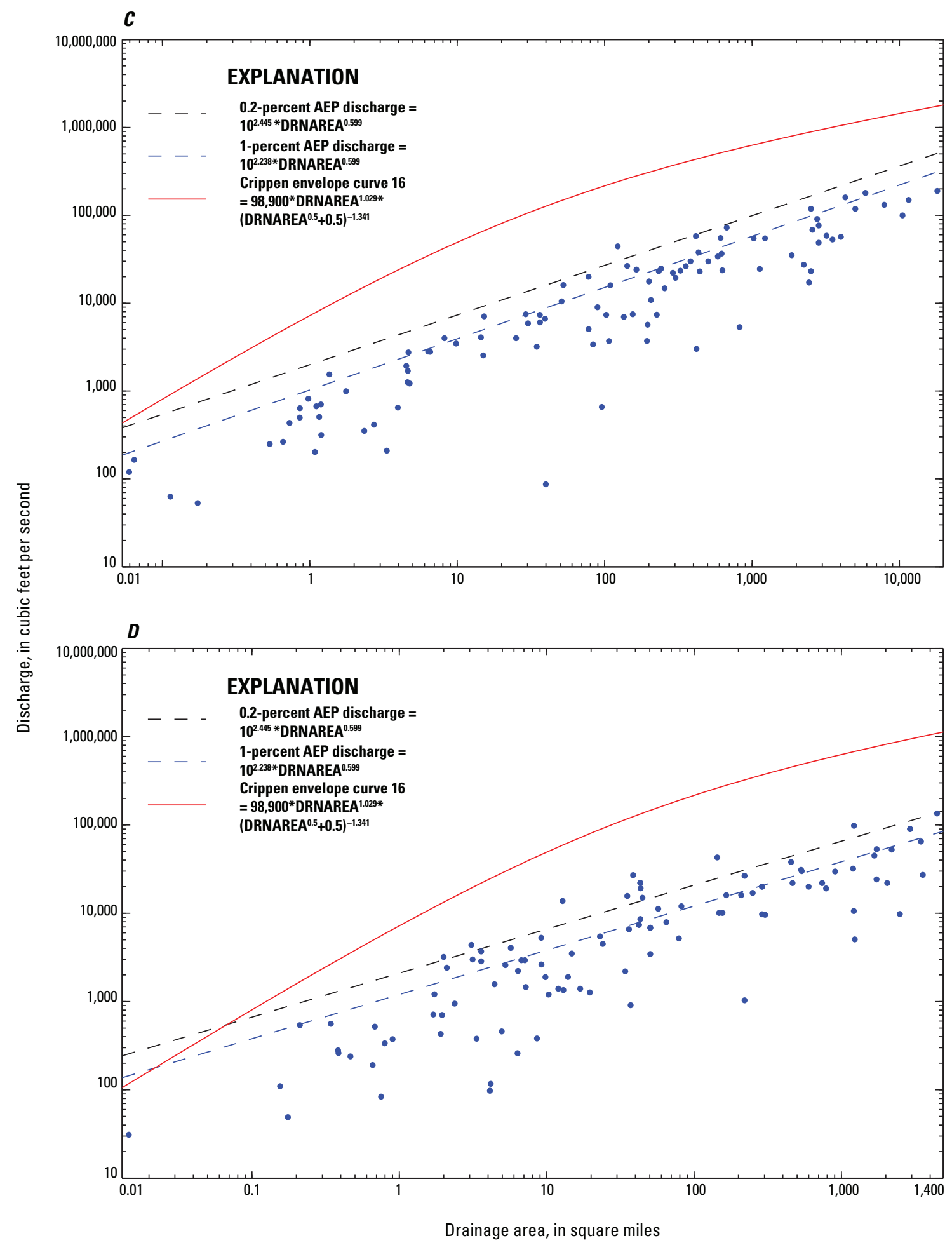

Figure 14.-Continued. The maximum recorded peak-flow discharge plotted with the frequency curves for the 1- and 0.2-percent annual exceedance probability (AEP) and the Crippen (1978) envelope curve region (14 for the Colorado Plateau and 16 for all other regions), by region. $A$, Region 2 (Colorado Plateau); $B$, Region 3 (Western Basin and Range); $C$, Region 4 (Central Highlands); and $D$, Region 5 (Southeastern Basin and Range). 
After calculating the expected $P$-percent AEP flow at the ungaged site based on the drainage area ratio, it can be combined with the regional regression equation

$$
\mathrm{Q}_{\mathrm{u}(\mathrm{w})}=\left[\left(\frac{2 \Delta \mathrm{A}}{\mathrm{A}_{\mathrm{g}}}\right) \mathrm{Q}_{\mathrm{u}(\mathrm{r})}+\left(1-\frac{2 \Delta \mathrm{A}}{\mathrm{A}_{\mathrm{g}}}\right) \mathrm{Q}_{\mathrm{u}}\right],
$$

where

$$
\begin{aligned}
& Q_{u(w)} \quad \text { is the weighted estimate of the } P \text {-percent AEP } \\
& \text { flow at the ungaged site, } \\
& \Delta \mathrm{A} \quad \text { is }\left|A_{g}-A_{u}\right| \text {, the absolute value of the } \\
& \text { difference between the drainage areas of } \\
& \text { the streamgages and the ungaged site, and } \\
& \text { is the } P \text {-percent AEP flow estimate for at the } \\
& \text { ungaged site derived from the applicable } \\
& \text { regression equation. }
\end{aligned}
$$

Unlike the procedure for calculating the weighted average at streamgages, the procedure for a gage of particular interest near another gage does not take into account the length of the streamgaging record. If the nearby streamgaging record is short (less than about 20 years) and the difference in drainage areas is large, the estimated $P$-percent AEP flow at the streamgage of interest may be excessively weighted in equation 16. In this case, the use of the regional regression method for ungaged sites may produce better estimates of $P$-percent AEP flow.

If an ungaged site lies between two streamgages on the same stream, the weighted average of the predicted $P$-percent AEP flow at the two gages may be calculated, incorporating the relative distance of the ungaged site between the two gages. Major tributaries and (or) nonlinear variation in drainage area should be accounted for, and consideration given to the length of record, and therefore uncertainty, at each streamgage. In areas of distributary flow, this method may not be appropriate.

\section{Special Considerations}

\section{Urbanization}

Sites affected by urbanization were not used in the rural flood frequency and magnitude analysis. Still, flooding in urban areas is a serious concern because of the risk to property and the potential for loss of life in densely populated settings. Many published studies indicate that flood peaks in urbanized watersheds are larger than in equivalent rural watersheds (that is similar in drainage area, precipitation, and elevation), primarily because the greater extent of impervious surface area in urban watersheds reduces rainfall infiltration so that a greater percentage of rainfall is conveyed to stream channels. Kennedy and Paretti (2014) presented a flood frequency analysis for urbanized streamgages in Phoenix and Tucson, Ariz. Flood peaks at each streamgage are predicted using the EMA-MGB to fit a log-Pearson Type III distribution. The streamgage estimates were compared to flood peaks estimated by rural-regression equations for Arizona, and to flood peaks adjusted for urbanization using the procedure outlined in Moglen and Shivers (2006). Only smaller, more common flood peaks at the 50-, 20-, 10- and 4-percent annual exceedance probabilities (AEP) demonstrated any increase in magnitude as a result of urbanization; the 1-, 0.5-, and 0.2-percent AEP flood estimates were predicted without bias by the rural-regression equations. Percent imperviousness was determined not to account for the difference in estimated flood peaks between streamgages, either when adjusting the ruralregression equations or when deriving urban-regression equations to predict flood peaks directly from basin characteristics.

\section{Mixed Population Analysis and Climate Considerations}

The Bulletin 17B (B17B) framework assumes stationarity of peak-flow occurrence and that all floods come from the same homogeneous population (Interagency Advisory Committee on Water Data, 1982). Several flood hydrologists and statisticians have recognized that the assumptions stated in B17B may not be correct and have started addressing solutions as to how flood frequency analysis might be enhanced by incorporating climate scenarios or mixed population analysis into a B17B framework (Crippen, 1978; Webb and Betancourt, 1992; Griffis and Stedinger, 2007; Sando and others, 2008; Stedinger and Griffis, 2008). Thomas and others (1997) reported that more than 80-percent of the streamgage sites in the Southwest had mixed flood populations. Flood heterogeneity and trends should be checked, and if identified as significant, the user should investigate the possibility of incorporating the atmospheric mechanisms into the analysis. Multiple flood processes or short records might complicate this analysis (Hirschboeck, 1988; Murphy, 2001). Regions in which floods actively exhibit heterogeneity may benefit from mixed population analysis when considering different climate change scenarios, because not all flood types will be affected similarly throughout the State (Todhunter, 2012). Climate influence issues have also been recognized by the Hydrologic Frequency Analysis Work Group and new rhetoric on the subject has been proposed in future updates to B17B.

Arizona's geographic location and complex terrain are associated with three types of atmospheric conditions that lead to flooding: summer convective thunderstorms, tropical cyclone-enhanced convective activity, and winter synopticscale storms. Because the magnitude and frequency of the types of floods resulting from these different atmospheric conditions are not equally distributed throughout the State, further studies are needed in order to determine if and how such information is an important determinant of regional flood frequency variations. One such approach that has been used 
in past studies is a mixed population flood frequency analysis proposed by Crippen (1978):

$$
P_{c}(\mathrm{x})=P_{A}(\mathrm{x})+P_{B}(\mathrm{x})-P_{A}(\mathrm{x}) P_{B}(\mathrm{x}),
$$

where

$$
\begin{aligned}
& P_{c}(\mathrm{x}) \quad \begin{array}{l}
\text { is the probability that the annual flood in the } \\
\text { composite population will exceed } \mathrm{x},
\end{array} \\
& P_{A}(\mathrm{x}) \quad \begin{array}{l}
\text { is the probability that the annual flood in } \\
\text { population A will exceed } \mathrm{x} \text {, and }
\end{array} \\
& P_{b}(\mathrm{x}) \quad \begin{array}{l}
\text { is the probability that the annual flood in } \\
\text { population B will exceed } \mathrm{x} .
\end{array}
\end{aligned}
$$

Several USGS scientists have applied the mixed population analysis to different statewide flood frequency analyses and have had limited success with mixed population analysis, citing small datasets (Parrett and Johnson, 2004; Waltemeyer, 2006; Gotvald and others, 2012). Others researchers have used variations on this procedure, such as weighting more common populations (Murphy, 2001; Sando, 2008). The European flood frequency scientific community has explored alternatives such as a peaks-over-threshold time series to explore the relation between flood magnitude and frequency (Clarke, 2003; Renard and others, 2006; Kyselý and others, 2010; Villarini and others, 2012). The data from several streamgages in Arizona were analyzed using the Crippen method and the results were inconclusive, often producing flood estimates less than those from the single population analysis or resulting in a visually poor frequency fit of one of the population types. For this investigation, no mixed distribution flood frequency estimates are reported, but a more in-depth analysis is planned for a future study that will also include climate effects (Zamora-Reyes and others, 2013).

Water-resource managers in Arizona forecast streamflow predictions in order to plan for water-resource projects and to operate reservoirs for water supply. Streamflow forecasts based on peak-flow analyses such as the one presented in this report are useful, but statistical assumptions, such as stationarity of flows, need to be evaluated, in particular for long-range forecasts. Relations between climatic fluctuations and streamflow are useful for understanding changes in the magnitude and periodicity of streamflow over time. Thomas (2007) developed regression equations to forecast streamflow in the Lower Colorado River Basin in Arizona by using climatic fluctuations as explanatory variables. Climatic fluctuations were represented by the Atlantic Multidecadal Oscillation, Pacific Decadal Oscillation, and Southern Oscillation Index. The multiagency Workshop on Nonstationarity, Hydrologic Frequency Analysis, and Water Management was organized to present and discuss possible operational alternatives to the assumption of stationarity in hydrologic frequency analysis. The workshop proceedings (Rolf and others, 2010) present statistical methods and serves as a good primer for the incorporation of climate information in flood frequency analysis.

\section{Sites Spanning Multiple Regions}

Although the boundaries of the flood regions delineated for this study are largely coincident with watershed divides, in some instances ungaged watersheds for which flood frequency statistics are desired straddle a flood-region boundary - either a geographic boundary or a high-elevation boundary. If a study includes several watersheds on both sides of a regional boundary, the regional regression equations could provide markedly different flood estimates, depending on the region of a particular watershed, when in fact they are all physiographically similar and should have similar flood frequency estimates. In these situations, it may be useful to calculate either a weighted average, if the watershed straddles a boundary, or simply to calculate the estimated flood frequency as if the watershed were in the adjacent region. The latter case provides an indication of the influence of regionalization on the predicted flood estimates. The weighted average for watersheds that straddle a boundary can be calculated as:

$$
Q_{T(w)}=\frac{Q_{T(a)} A_{a}+Q_{T(b)} A_{b}}{A},
$$

where

$$
\begin{aligned}
& Q_{T(w)} \quad \text { is the combined, weighted discharge for a } \\
& \text { particular AEP; } \\
& Q_{T(A)} \text { and } Q_{T(B)} \text { are the computed discharges, from the } \\
& \text { regional regression equations, for the } \\
& \text { parts of the watershed in regions A and B, } \\
& \text { respectively; } \\
& A_{A} \text { and } A_{B} \quad \text { are the drainage areas in regions } \mathrm{A} \text { and } \mathrm{B} \text {, } \\
& \text { respectively; and } \\
& A \quad \text { is the total drainage area in both regions. }
\end{aligned}
$$

StreamStats will estimate streamflow statistics for basins that span more than one hydrologic region and apply the correct regional regression equations to the appropriate portions of the delineated basin (Ries, 2007).

\section{Flood Attenuation}

In some parts of Arizona, particularly in the south, large volumes of storm runoff can infiltrate in normally dry washes underlain by coarse sediment, greatly reducing the magnitude of flood peaks in the downstream direction (Eychaner, 1984). For example, in 1962, a large flood with peak flow greater than 50,000 cubic feet per second $\left(\mathrm{ft}^{3} / \mathrm{s}\right)$ that caused widespread inundation between Tucson and Santa Cruz had nearly entirely infiltrated and (or) evaporated before reaching Gillespie Dam on the Gila River (Lewis, 1963). In some areas, the relation of peak runoff to watershed area is increasingly non-linear with increasing watershed size; a transition from a linear to non-linear relation at the critical threshold watershed area of $0.143 \mathrm{mi}^{2}$ to $0.232 \mathrm{mi}^{2}$ was postulated for Walnut Gulch in southeastern Arizona (Goodrich and others, 1997). Eychaner 
(1984) suggested adjusting predicted flood peaks by a factor of 0.5 in regions subject to attenuation. Large watersheds with extreme peak attenuation tend to be located in southcentral and southwest Arizona; many such events have been documented on Brawley Wash in Avra Valley, west of Tucson, and on the Santa Cruz River north of Tucson (Eychaner, 1984). Attenuation in smaller watersheds can occur throughout the State, particularly in those regions where annual flood peaks are generated by convective thunderstorms that cover only a portion of the watershed. Reducing the predicted flood peak for attenuation should be applied cautiously and not without strong evidence that it is an important process for the magnitude of the peaks of concern.

\section{Flow Duration Flow Frequency and Magnitude}

Estimates of peak-flow frequency and magnitude are required for managing the risk posed by floods, but floodduration flow frequency estimates are also useful for planning and assessing the adequacy of retention and conveyance structures, and for water-resource planning. Kennedy and Paretti (2014) conducted a flood-volume frequency analysis of 1-day, 3-day, 7-day, 15-day, and 30-day flood-duration flow frequency estimates for 173 streamgages throughout Arizona.

\section{StreamStats}

StreamStats is an integrated web-based geographical information system (GIS) application developed through a cooperative effort of the USGS and ESRI, Inc. (http://water. usgs.gov/osw/streamstats/index.html). StreamStats provides the public the ability to access streamflow statistics at gaged and ungaged locations in a way that is faster, more accurate, and more consistent than manual methods and without the need to access the publications from which regression equations were derived. The Arizona portal provides streamflow statistics at streamgages for the 50-, 20-, 10-, 4-, 2-, 1-, 0.5 -, and 0.2-pecent peak flows and the 1-day, 3-day, 7-day, 15-day, and 30-day flood-duration flows. For user-selected ungaged locations, the regional equations presented in this report are used to compute the $P$-percent AEP peak-flow and flood-duration flow estimates and their associated uncertainty. Although drainage area, mean basin elevation, and mean annual precipitation are the primary characteristics used in the regional regression equations, many additional basin characteristics are available for analysis, including land cover, precipitation intensity, temperature, and other watershed physical properties.

When an ungaged location is selected, StreamStats computes the drainage-basin boundary for the site and presents it to the user in the map frame. The user has the option of modifying the basin boundary using the EditBasin tool. Once the correct basin boundary has been verified, the user can compute basin-characteristic and (or) streamflow statistics. StreamStats references the USGS National Streamflow Statistics (NSS) Program, which contains all of the USGS-developed equations for estimating flood-frequency statistics in the Nation. The NSS estimates the streamflow statistics for the ungaged site and then StreamStats presents the statistics and the basin characteristics for the site in a pop-up Web-browser window (Ries and others, 2004; Ries, 2007). The NSS serves additional flow statistics computed at USGS streamgages. If the user delineates a basin that spans more than one regression region, StreamStats will first compute flow estimates using the equations for each region and then weight the regional estimates according to the proportion of the area in each region (equation 19). StreamStats will delineate transboundary basins in Sonora, Mexico, although no streamgages from Sonora were used in the regional regression analysis. There are several streams that flow north from Sonora into the United States and a few USGS streamgages near the border that record flow measurements originating from Sonora. The similarity of southern Arizona to northern Mexico enables regression equations for regions 3 and 5 to be applied to northern portions of Sonora. In addition, a limited set of basin characteristic statistics can be calculated for most of Sonora.

\section{Summary and Conclusions}

This report documents methods for determining flood frequency and magnitude at rural and unregulated gaged and ungaged locations in Arizona. Annual peak-flow data through water year 2010 were compiled from 448 unregulated streamgages having a minimum of 10 years of record. Flood frequency estimates were computed using the Expected Moments Algorithm with a multiple Grubbs-Beck test to fit a Pearson Type III distribution of the logarithms of the station peak flows. A multiple step Bayesian least-squares-regression approach was used to determine a statewide regional skew of -0.09 and it was weighted with station skew to determine the final flood frequency estimates of the 50-, 20-, 10-, 4-, 2-, 1-, $0.5-$, and 0.2 -percent annual exceedance probabilities at the streamgages used in the analysis.

Basin characteristic information was generated from the U.S. Geological Survey's StreamStats program, an integrated, web-based geographical information system (GIS) application using updated GIS data. This information was used in a multivariate regionalization analysis to determine and delineate five new regression regions in Arizona. Flood frequency estimates and basin characteristic information from 344 nonredundant gaged locations were used in an ordinary-least-squares regression followed by a generalized-least-squares analysis to account for cross correlation between streamgage locations and concurrent records. The regression equations developed for the five regions used one or more of the statistically significant explanatory variables: drainage area, mean basin elevation, and mean annual precipitation. Average standard errors 
of prediction for the regression regions for the five regions ranged from 27 to 122 percent. The pseudo coefficients of determination range from 63 to 98 percent. Regression equation statistics showed better performance in region 4 (Central Highlands), than in region 2 (Colorado Plateau), which had more variability due to the limited number of streamgages within a large area.

The regional regression equations were then integrated into StreamStats, which provides the public easy access to published flood frequency and basin characteristic statistics. StreamStats allows a user to select a point within a watershed, either at a streamgage or an ungaged location, and retrieve flood-frequency estimates derived from the current regional regression equations and GIS information within the basin selected. StreamStats provides consistent statistics, minimizes user error, and reduces the need for large datasets and costly GIS software.

\section{Acknowledgments}

The authors would like to recognize the dedicated personnel of the USGS field offices in Arizona and thank them for the high quality of the data that is collected. We also wish to thank Timothy Cohn, Robert Mason, Julie Kiang, Terry Kenny, Charles Parrett, Nancy Barth, Wilbert Thomas, and Jery Stedinger, all of the USGS, who have helped our report process and worked to develop the techniques used in flood frequency analysis. Thank you to the StreamStats Team: Alan Rea, Kernell Ries, David Stewart, Todd Koenig, and Peter Steeves. The authors would especially like to thank all the cooperators for providing data, support, and constructive comments.

\section{References Cited}

Adams, David K., and Comrie, Andrew C., 1997, The North American Monsoon: Bulletin of the American Meteorological Society, v. 78, no. 10, p. 2197-2213.

Arizona Division of Emergency Management, 2013, State Hazard Mitigation Plan, Risk Assessment, Flooding/Flash Flooding, p. 217-240, accessed September 15, 2014, at http://www.dem.azdema.gov/preparedness/docs/coop/mitplan/26_Flooding.pdf.

Aldridge, B.N., 1970, Floods of November 1965 to January 1966 in the Gila River basin, Arizona and New Mexico, and adjacent basins in Arizona: U.S. Geological Survey WaterSupply Paper 1850-C, 176 p.

Aldridge, B.N., and Eychaner, J.H., 1984, Floods of October 1977 in southern Arizona and March 1978 in central Arizona: U.S. Geological Survey Water-Supply Paper 2223, $143 \mathrm{p}$.
Aldridge, B.N., and Hales, T.A., 1984, Floods of November 1978 to March 1979 in Arizona and west-central New Mexico: U.S. Geological Survey Water-Supply Paper 2241, $154 \mathrm{p}$.

Boughton, W.C., and Renard, K.G., 1984, Flood frequency characteristics of some Arizona watersheds: Water Resources Bulletin, v. 20, no. 5, p. 761-769.

Boughton, W.C., Renard, K.G., and Stone, J.J., 1987, Flood frequency estimates in southeastern Arizona: Journal of Irrigation and Drainage Engineering, v. 113, no. 4, p. 469-478.

Brazel, A.J., and Evans, K.E., 1984: Major Storms and Floods in Arizona, 1862-1983: Tempe, Arizona, Arizona State University, Office of the State Climatologist Climatological Publications, Precipitation Series, no. 6, 63 p.

Clarke, K.R., and Gorley, R.N., 2006, Primer v6-User manual/tutorial: Plymouth, United Kingdom, PRIMER-E Ltd, $190 \mathrm{p}$.

Clarke, K.R., and Warwick, R.M., 2001, Ordination of samples by Principal Components Analysis (PCA), chap. 4 in Change in marine communities: an approach to statistical analysis and interpretation ( $2 \mathrm{~d}$ ed.): Plymouth, United Kingdom, PRIMER-E Ltd., 8 p.

Clarke, Robin T., 2003, Frequencies of future extreme events under conditions of changing hydrologic regime: Geophysical Research Letters, v. 30, no. 3, p. 1124, doi:10.1029/2002GL016214.

Cohn, T.A., England, J.F., Barenbrock, C.E., Mason, R.R., Stedinger, J.R., and Lamontagne, J.R., 2013, A generalized Grubbs-Beck Test statistic for detecting multiple potentially-influential low outliers in flood series: Water Resources Research, v. 49, p. 1-12.

Cohn, T.A., Lane, W.L., and Baier, W.G., 1997, An algorithm for computing moments-based flood quantile estimates when historical flood information is available: Water Resources Research, v. 33, p. 2089-2096.

Cohn, T.A., Lane, W.L., and Stedinger, J.R., 2001, Confidence intervals for Expected Moments Algorithm flood quantile estimates: Water Resources Research, v. 37, no. 6, p. 1695-1706, at http://timcohn.com/Publications/CohnLaneSted2001WR900016.pdf.

Conover, W.L., 1999, Practical nonparametric statistics (3d ed.): New York, John Wiley and Sons, 584 p.

Crippen, J.R., 1978. Composite log-Type III frequency magnitude curve of annual floods: U.S. Geological Survey OpenFile Report 78-352, 5 p. 
Crippen, J., 1982, Envelope curves for extreme events: Journal of the Hydraulics Division, Proceedings of the American Society of Civil Engineers, v. 108, no. HY10, p. 1208-1212.

Dettinger, Michael D., 2013, Atmospheric rivers as drought busters on the U.S. West Coast: Journal of Hydrometeorology, v. 14, no. 6, p. 1721-1732, doi: http://dx.doi. org/10.1175/JHM-D-13-02.1

Dickinson, W.R., 2002, The Basin and Range Province as a composite extensional domain: International Geology Review, v. 22, p. 1-38.

Dinicola, K., 1996, The "100-Year Flood": U.S. Geological Survey Fact Sheet 229-96, 2 p.

Eash, D.A., Barnes, K.K., and Veilleux, A.G., 2013, Methods for estimating annual exceedance-probability discharges for streams in Iowa, based on data through water year 2010: U.S. Geological Survey Scientific Investigations Report 2013-5086, 63 p. with appendix, at http://pubs.usgs.gov/ $\operatorname{sir} / 2013 / 5086 /$.

Eng, Ken, Chen, Yin-Yu, and Kiang, J.E., 2009, User's guide to the weighted-multiple-linear-regression program (WREG version 1.0): U.S. Geological Survey Techniques and Methods, book 4, chap. A8, 21 p. [Also available at http://pubs. usgs.gov/tm/tm4a8.]

England, J.F., Jr., Salas, J.D., and Jarrett, R.D., 2003, Comparisons of two moments-based estimators that utilize historical and paleoflood data for the log Pearson type III distribution: Water Resources Research, v. 39, no. 9, p. 1243.

Eychaner, J.H., 1984, Estimation of magnitude and frequency of floods in Pima County, Arizona, with comparisons of alternative methods: U.S. Geological Survey WaterResources Investigations Report 84-4142, 69 p.

Flooding Control District of Maricopa County, 2010, Storm report-January 2010: Engineering

Division, Flood Warning Branch, 73 p., at http://alert.fcd. maricopa.gov/alert/WY10/StormRpt_Jan2010_Rev_110510.pdf

Foos, A., 1999, National Park Service geology field trip guides: Geology of the Colorado Plateau, Geology Department, University of Akron, 6 p., at http://www.nature.nps. gov/geology/education/Foos/plateau.pdf.
Gesch, D.B., 2007, The national elevation dataset, in Maune, D., ed., Digital elevation model technologies and applications - The DEM users manual (2d ed.): Bethesda, Maryland, American Society for Photogrammetry and Remote Sensing, p. 99-118, accessed March 15, 2013, at http:// topotools.cr.usgs.gov/pdfs/Gesch_Chp_4_Nat_Elev_ Data_2007.pdf. [See also http://ned.usgs.gov/.]

Goodrich, D.G., Lane, L.J., Shillito, R.M., Miller, S.N., Syed, K.H., and Woolhiser, D.A., 1997, Linearity of basin response as a function of scale in a semiarid watershed: Water Resources Research, v. 33, no. 12, p. 2591-2965.

Gotvald, A.J., Barth, N.A., Veilleux, A.G., and Parrett, Charles, 2012, Methods for determining magnitude and frequency of floods in California, based on data through water year 2006: U.S. Geological Survey Scientific Investigations Report 2012-5113, 38 p. (Also available at: http://pubs. usgs.gov/sir/2012/5113/pdf/sir2012-5113.pdf.)

Gotvald, A.J., Feaster, T.D., and Weaver, J.C., 2009, Magnitude and frequency of rural floods in the southeastern United States, 2006 - Volume 1, Georgia: U.S. Geological Survey Scientific Investigations Report 2009-5156, 120 p.

Griffis, V.W., 2008, EMA with historical information, low outliers, and regional skew: American Society of Civil Engineers World Environmental and Water Resources Congress 2008, 10 p.

Griffis, V.W., and Stedinger, J.R., 2007, Incorporating climate change and variability into Bulletin 17B LPIII Model, paper 40927-2320, in Kabbes, K.C., ed., Proceedings of the World Environmental and Water Resources Congress - Restoring our natural habitat: American Society of Civil Engineers, Tampa, Fla., May 15-18.

Griffis, V.W., and Stedinger, J.R., 2009, Log-Pearson type 3 distribution and its application in flood frequency analysis, III-sample skew and weighted skew estimators: Journal of Hydrology, v. 14, no. 2, p. 121-130.

Griffis, V.W., Stedinger, J.R., and Cohn, T.A., 2004, Log Pearson type 3 quantile estimators with regional skew information and low outlier adjustments: Water Resources Research, v. 40, no. 10, W07503 17 p. [Also available at http://onlinelibrary.wiley.com/ doi/10.1029/2003WR002697/pdf.] 
Gruber, A.M., and Stedinger, J.R., 2008, Models of LPIII Regional Skew, Data Selection and Bayesian GLS Regression, paper 596, in Babcock, R.W., Jr., and Watson, R., eds., Proceedings of the World Environmental and Water Resources Congress - Ahupua'a: American Society of Civil Engineers, Honolulu, Hawai‘i, May 12-16.

Grubbs, F.E., and Beck, G., 1972, Extension of sample sizes and percentage points for significance tests of outlying observations: Technometrics, v. 14, no. 4, p. 847-854.

Helsel, D.R., and Hirsch, R.M., 2002. Statistical methods in water resources: U.S. Geological Survey Techniques of Water Resources Investigations, book 4, chap. A3, 522 p.

Hill, G.W., Hales, T.A., and Aldridge, B.N., 1987, Flood hydrology near Flagstaff, Arizona: U.S. Geological Survey Water-Resources Investigation Report 87-4210, 35 p.

Hirsch, R.M., 2011, A Perspective on nonstationarity and water management: Journal of the American Water Resources Association, v. 47, no. 3, p. 436-446.

Hirschboeck, K.K., 1988, Flood hydroclimatology, in Baker, V.R., Kochel, R.C., and Patton, P.C., eds., Flood geomorphology: New York, John Wiley and Sons, p. 27-49, at http://www.ltrr.arizona.edu/ katie/kt/pubs/Flood.Hydrocli.1988.kkh.pdf.

Hjalmarson, H.W. and Kemna, S.P., 1991,Flood hazards of distributary-flow areas in southwestern Arizona: U.S. Geological Survey Water-Resources Investigations Report 91-4171, p. 58.

Hoaglin, D.C., and Welsch, R.E., 1978, The hat matrix in regression and ANOVA: The American Statistician, v. 32, no. 1, p. 17-22.

House, P.K., 1993, The Arizona floods of January and February 1993: Arizona Geology, v. 23, no. 2, p. 5-9, at http:// www.azgs.az.gov/Hazards_ocr/Floods\%20_\%20Debris\%20 Flows/floods\%201993.pdf.

House, P.K., and Hirschboeck, K.K., 1997, Hydroclimatological and paleohydrological context of extreme winter flooding in Arizona, 1993, in Larson, R.A., and Slosson, J.E., eds., Storm-induced geologic hazards - Case histories from the 1992-1993 winter in Southern California and Arizona: Boulder, Colorado, Geological Society of America Reviews in Engineering Geology, v. XI, p. 1-24.

Interagency Advisory Committee on Water Data, 1982, Guidelines for determining flood flow frequency, Bulletin 17-B of the Hydrology Subcommittee: Reston, Virginia, U.S. Geological Survey, Office of Water Data Coordination, 183 p.
Johnston, J., 1972, Econometric Methods: New York, McGraw-Hill, 437 p.

Kennedy, J.R., and Paretti, N.V., 2014, Methods for estimating magnitude and frequency of floods in urban watersheds in Arizona: U.S. Geological Survey Scientific Investigations Report 2014-5121, 29 p., http://dx.doi.org/10.3133/ sir20145121.

Kennedy, J.R., Paretti, N.V., and Veilleux, A.G., 2014, Methods for estimating magnitude and frequency of 1-, 3-, 7-, 15-, and 30-day flood-duration flows in Arizona: U.S. Geological Survey Scientific Investigations Report 2014-5109, 35 p., http://dx.doi.org/10.3133/sir20145109.

Kiang, J.E., Stewart, D.W., Archfield, S.A., Osborne, E.B., and Eng, Ken, 2013, A national streamflow network gap analysis: U.S. Geological Survey Scientific Investigations Report 2013-5013, 79 p., accessed on March 1, 2014, at http:// pubs.usgs.gov/sir/2013/5013/

Kyselý J., Picek, J., and Beranová, R., 2010, Estimating extremes in climate change simulations using the peaksover-threshold method with a non-stationary threshold: Global and Planetary Change, v. 72, p. 55-68.

Lewis, D.D., 1963, Desert floods, A report on southern Arizona floods of September, 1962: Arizona State Land Department Water Resources Report, no. 13, 34 p.

Ludwig, A.H., and Tasker, G.D., 1993, Regionalization of low-flow characteristics of Arkansas streams: U.S. Geological Survey Water-Resources Investigations Report 93-4013, $19 \mathrm{p}$.

Malvick, A.J., 1980, A magnitude-frequency-area relation for floods in Arizona: Tucson, Ariz., Engineering Experiment Station, College of Engineering, University of Arizona, Research Report no. 2, 186 p.

Moglen, G.E., and Shivers, D.E., 2006, Methods for adjusting U.S. Geological Survey rural regression peak discharges in an urban setting: U.S. Geological Survey Scientific Investigations Report 2006-5270, 55 p.

Murphy, P., 2001, Estimating equation for mixed populations of floods in Massachusetts: Journal of Hydrologic Engineering, v. 6, no. 1, p. 72-74, at http://ascelibrary.org/doi/ abs/10.1061/(ASCE)1084-0699(2001)6:1(62)

National Oceanic and Atmospheric Administration National Climatic Data Center [2014], Annual Climatological Summary of Arizona, annual precipitation data for January 01, 1960 to January 01, 2010: National Climatic Data Center Web page, accessed July 1, 2014, at http://www.ncdc.noaa. gov/cdo-web/datasets. 
National Weather Service-Hydrologic Information Center, 2001, Flood loss data: National Weather Service-Hydrologic Information Center Web page, last accessed July 15, 2013, at $h t t p: / / w w w . n w s . n o a a . g o v / o h / h i c / f l o o d \_s t a t s / F l o o d \_l o s s$ time_series.htm.

National Weather Service-Hydrologic Information Center, 2014, Flood loss data: National Weather Service-Hydrologic Information Center Web page, last accessed February 1, 2014, at $h t t p: / / w w w . n w s . n o a a . g o v / h i c /$.

Neiman, P.J., Ralph, M.F., Moore, B.J., Hughes, M., Mahoney, K.M., Cordeira, J.M., and Dettinger, M.D., 2013, The landfall and inland penetration of a flood-producing atmospheric river in Arizona - Part I-observed synoptic-scale, orographic, and hydrometeorological characteristics: Journal of Hydrometeorology, v. 14, no. 2, p. 460-484, doi: http:// dx.doi.org/10.1175/JHM-D-12-0101.1

Omernik, J.M., 1987, Ecoregions of the conterminous United States, map: Annals of the Association of American Geographers, v. 77 , no. 1, p. 118-125, scale 1:7,500,000.

Osborn, H.B., and Laursen, E.M., 1973, Thunderstorm runoff in southeastern Arizona: Journal of the Hydraulics Division, Proceedings of the American Society of Civil Engineers, v. 99, no. 7, p. 1129-1145.

Parameter-Elevation Regressions on Independent Slopes Model Climate Group, 2008, Normal annual precipitation grid for the conterminous United States: Oregon State University Northwest Alliance for Computational Science and Engineering Web site, last accessed January 15, 2012, at $h t t p: / / w w w . p r i s m . n a c s e . o r g /$.

Paretti, N., Kennedy, J., and Cohn, T., 2014, Evaluation of the expected moments algorithm and a multiple low-outlier test for flood frequency analysis at streamgaging stations in Arizona: U.S. Geological Survey Scientific Investigations Report 2014-5026, 61 p.

Parrett, C., Veilleux, A., Stedinger, J.R., Barth, N.A., Knifong, D.L., and Ferris, J.C., 2011, Regional skew for California, and flood frequency for selected sites in the SacramentoSan Joaquin River Basin, based on data through water year 2006: U.S. Geological Survey Scientific Investigations Report 2010-5260, 94 p., [Also available at $h t t p: / / p u b s$. usgs.gov/sir/2012/5113/pdf/sir2012-5113.pdf]

Parrett, C., and Johnson, D.R., 2004, Methods for estimating flood frequency in Montana based on data through water year 1998: U.S. Geological Survey Water-Resources Investigations Report 03-430, 109 p.
Paulson, R.W., Chase, E.B, Roberts, R.S, and Moody, D.W., 1991, National Water Summary 1988-89, Hydrologic events and floods and droughts: U.S. Geological Survey WaterSupply Paper 2375, p. 181-188.

Pielke, R.A., Downton, M.W., and Barnard Miller, J.Z., 2002, Flood damage in the United States, 1926-2000; A reanalysis of National Weather Service estimates: Boulder, Colo., National Oceanic and Atmospheric Administration, 86 p., at http://www.flooddamagedata.org/flooddamagedata.pdf.

Phillips, J.V., and Thomas, B.E., 2005, Hydrologic conditions in Arizona during 1999-2004-a historical perspective: U.S. Geological Survey Fact Sheet 2005-3081, 4 p.

Pope, G.L., Rigas, P.D., and Smith, C.F., 1998, Statistical summaries of streamflow data and characteristics of drainage basins for selected streamflow-gaging stations in Arizona through water year 1996: USGS Water-Resources Investigations Report 98-4225, $907 \mathrm{p}$.

Reich, B.M., Osborn, H.B., and Baker, M.C., 1979, Tests on Arizona's new flood estimates, Proceedings of the 1979 meetings of the Arizona Section-American Water Resources Association and the Hydrology Section; ArizonaNevada Academy of Science, April 13, 1979, p. 65-74.

Reis, D.S., Stedinger, J.R., and Martins, E.S., 2005, Bayesian generalized least squares regression with application to $\log$ Pearson type 3 regional skew estimation: Water Resources Research, v. 41, W10419, 14 p.

Renard, B., Lang, M., and Bois, P., 2006, Statistical analysis of extreme events in a non-stationary context via a Bayesian framework-case study with peak-over-threshold data: Stochastic Environmental Research and Risk Assessment, v. 21, p. 97-112, doi 10.1007/s00477-006-0047-4.

Ries III, K.G., 2007, The national streamflow statistics program-A computer program for estimating streamflow statistics for ungaged sites: U.S. Geological Survey Techniques and Methods 4-A6, $37 \mathrm{p}$.

Ries III, K.G., Steeves, P.A., Coles, J.D., Rea, A.H., and Stewart, D.W., 2004, StreamStats-A U.S. Geological Survey web application for stream information: U.S. Geological Survey Fact Sheet 2004-3115, 4 p.

Rolf, O.J., Kiang, J., and Waskom, R., eds., 2010, Workshop on nonstationarity, hydrologic frequency analysis, and water management: Colorado Water Institute Information Series no. 109, 300 p., last accessed on November 1, 203, at http:// www.cwi.colostate.edu/nonstationarityworkshop/index.shtm. 
Roeske, R.H., 1978, Methods for estimating the magnitude and frequency of floods in Arizona: Arizona Department of Transportation Report ADOT-RS-15-121, 82 p.

Ryberg, K.R., 2008, PFReports-A program for systematic checking of annual peaks in NWISWeb: U.S. Geological Survey Open-File Report 2008-1284, 17 p.

Sando, S.K., Driscoll, D.G., and Parrett, Charles, 2008, Peak-flow frequency estimates based on data through water year 2001 for selected streamflow-gaging stations in South Dakota: U.S. Geological Survey Scientific Investigations Report 2008-5104, 367 p.

SAS Institute Inc., 2007, JMP statistics and graphics guide: Cary, North Carolina, SAS Institute Inc., 1048 p., at http:// www.jmp.com/support/downloads/pdf/jmp_stat_graph_ guide.pdf.

Schwarz, G.E., 1978, Estimating the dimension of a model: Annals of Statistics, v. 6, p. 461-464.

Schruben, P.G., Arndt, R.E., and Bawiec, W.J., 1998, Geology of the conterminous United States at 1:2,500,000 scale - A digital representation of the 1974 P.B. King and H.M. Beikman map: U.S. Geological Survey Digital Data Series 11, release 2, accessed March 15, 2012, at http://pubs.usgs.gov/ dds/dds11/index.html.

Seaber, P.R., Kapinos, F.P., and Knapp, G.L., 1987, Hydrologic unit maps: U.S. Geological Survey Water-Supply Paper 2294, 23 p.

Simley, J.D., and Carswell, W.J., Jr., 2009, The National Map-Hydrography: U.S. Geological Survey Fact Sheet 2009-3054, 4 p. [Also available at http://pubs.usgs.gov/ fs/2009/3054/, also see http://nhd.usgs.gov/.]

Stedinger, J.R., and Griffis, V.W., 2008, Flood frequency analysis in the United States- Time to update: Journal of Hydrologic Engineering, v. 13, p. 199-204.

Tasker, G.D., and Driver, N.E., 1988, Nationwide regression models for predicting urban runoff water quality at unmonitored sites: Water Resources Bulletin, v. 24, no. 5, p. 1091-1101.

Thomas, B.E., Hjalmarson, H.W., and Waltemeyer, S.D., 1997, Methods for estimating magnitude and frequency of floods in the Southwestern United States: U.S. Geological Survey Water-Supply Paper 2433, 205 p.
Thomas, B.E., 2007, Climatic fluctuations and forecasting of streamflow in the Lower Colorado River Basin: Journal of the American Water Resources Association, v. 43, no. 6, p. $1550-1569$.

Todhunter, P.E., 2012, Uncertainty of the assumptions required for estimating the regulatory flood; Red River of the North: Journal of Hydrologic Engineering, v. 17, no. 9, p. 1011-1020.

Trapp, R.A., and Reynolds, J.S, 1995, Map showing names and outlines of physiographic areas in Arizona used by the Arizona Geological Survey with comprehensive base map: Arizona Geological Survey Open File Report OFR-95-2a, 1 map sheet, map scale 1:1,000,000, accessed September 15, 2012, at http://repository.azgs.az.gov/category/thematickeywords/physiographic-provinces.

U.S. Department of Agriculture, Natural Resources Conservation Service [2011], Geospatial data gateway: U.S. Department of Agriculture Web page, accessed January 15, 2011, at http://datagateway.nrcs.usda.gov/.

Villarini, Gabriele, Smith, J.A., Serinaldi, Francesko, Ntelekos, A.A., and Schwarz, Ulrich, 2012, Analyses of extreme flooding in Austria over the period 1951-2006: International Journal of Climatology, v. 32, p. 1178-1192, doi: 10.1002/ joc. 2331 .

Waltemeyer, S.D., 2006, Analysis of the magnitude and frequency of peak discharges for the Navajo Nation in Arizona, Utah, Colorado, and New Mexico: U.S. Geological Survey Scientific Investigations Report 2006-5306, 42 p.

Weaver, J.C., Feaster, T.D., and Gotvald, A.J., 2009, Magnitude and frequency of rural floods in the southeastern United States, 2006-Volume 2, North Carolina: U.S. Geological Survey Scientific Investigations Report, 2009-5158, 111 p. [Also available at: http://pubs.usgs.gov/ sir/2009/5158/.]

Webb, R.H., and Betancourt, J.L., 1992, Climatic variability and flood frequency of the Santa Cruz River, Pima County, Arizona: U.S. Geological Survey Water-Supply Paper 2379, 40 p., at http://wwwpaztcn.wr.usgs.gov/julio_pdf/WebbBetancourt-WSP-2379.pdf.

Zamora-Reyes, D., Hirschboeck, K.K., and Valdes, J.B., 2013, Flood heterogeneity as a tool for exploring flood frequencyclimate linkages from a watershed perspective: American Geophysical Union Fall Meeting, San Francisco, Calif., December 9-13, 2013. 


\title{
Appendix 1. Regional Skew Regression Analysis
}

\author{
By Andrea G. Veilleux, U.S. Geological Survey
}

\section{Introduction to Statistical Analysis of Regional Skew}

For the log-transformation of annual peak flows, Bulletin 17B (Interagency Advisory Committee on Water Data, 1982) recommends using a weighted average of the station skew coefficient and a regional skew coefficient to help improve estimates of annual exceedance probability discharges (AEPs) (equation A2 in the appendix). Bulletin 17B supplies a national map, but also encourages hydrologists to develop more specific local relations. Since the first map was published in 1976, almost 40 years of additional information has been accumulated, and spatial estimation procedures have been improved (Stedinger and Griffis, 2008).

Tasker and Stedinger (1986) developed a weighted-leastsquares (WLS) procedure for estimating regional skew coefficients based on sample skew coefficients for the logarithms of annual peak-discharge data. Their method of regional analysis of skew estimators accounts for the precision of the skew-coefficient estimate for each streamgage or station, which depends on the length of record for each streamgage and the accuracy of an ordinary-least-squares (OLS) regional mean skew. More recently, Reis and others (2005), Gruber and others (2007), and Gruber and Stedinger (2008) developed a Bayesian generalized-least-squares (GLS) regression model for regional skew analyses. The Bayesian methodology allows for the computation of a posterior distribution of both the regression parameters and the model error variance. As shown in Reis and others (2005), for cases in which the model error variance is small compared to the sampling error of the station estimates, the Bayesian posterior distribution provides a more reasonable description of the model error variance than both the GLS method-of-moments and maximum likelihood point estimates (Veilleux, 2011). While WLS regression accounts for the precision of the regional model and the effect of the record length on the variance of skew-coefficient estimators, GLS regression also considers the cross-correlations among the skew-coefficient estimators. In some studies, the crosscorrelations have had a large impact on the precision attributed to different parameter estimates (Feaster and others, 2009; Gotvald and others, 2009; Weaver and others, 2009; Parrett and others, 2011).

Due to complications introduced by the use of the expected moments algorithm (EMA) with multiple GrubbsBeck censoring of low outliers (Cohn and others, 1997) and large cross-correlations between annual peak flows at pairs of streamgages, an alternative regression procedure was developed to provide both stable and defensible results for regional skew (Veilleux, 2011; Lamontange and others, 2012; Veilleux and others, 2012). Because EMA allows for the censoring of low outliers, as well as the use of estimated interval discharges for missing, censored, and historical data, it complicates the calculations of effective record length (and effective concurrent record length) used to describe the precision of sample estimators because the peak flows are no longer represented solely by single values. This alternative procedure is referred to as the Bayesian WLS/ Bayesian GLS (B-WLS/B-GLS) regression framework (Veilleux, 2011; Veilleux and others, 2011; Veilleux and others, 2012). It uses an OLS analysis to fit an initial regional skew model; that OLS model is then used to generate a stable regional skew-coefficient estimate for each site. The stable regional estimate is the basis for computing the variance of each station skew-coefficient estimator employed in the WLS analysis. Then, B-WLS is used to generate estimators of the regional skew-coefficient model parameters. Finally, B-GLS is used to estimate the precision of those WLS parameter estimators, to estimate the model error variance and the precision of that variance estimator, and to compute various diagnostic statistics.

\section{Methodology for Regional Skew Model}

This section provides a brief description of the B-WLS/BGLS methodology (as it appears in Veilleux and others, 2012). Veilleux and others (2011) and Veilleux (2011) provide a more detailed description.

\section{Ordinary Least Squares Regression Analysis}

The first step in the B-WLS/B-GLS regional skew analysis is the estimation of a regional skew model using OLS. The OLS regional regression yields parameters $\hat{\boldsymbol{a}}_{O L S}$ and a model that can be used to generate unbiased and relatively stable regional estimates of the skew for all streamgages:

$$
\tilde{\mathbf{y}}_{O L S}=\mathrm{X} \hat{\beta}_{O L S}
$$

Here $\mathrm{X}$ is an $(n \times k)$ matrix of basin characteristics, $\tilde{\mathbf{y}}_{O L S}$ are the estimated regional skew values, $n$ is the number of streamgages, and $k$ is the number of basin parameters including a column of ones to estimate the constant. The estimated 
regional skew values, $\tilde{\mathbf{y}}_{O L S}$, are then used to calculate unbiased station-regional skew variances using the equations reported in Griffis and Stedinger (2009). These station-regional skew variances are based on the regional OLS estimator of the skew coefficient instead of the station skew estimator, thus making the weights in the subsequent steps relatively independent of the station skew estimates.

\section{Weighted Least Squares Analysis}

A B-WLS analysis is used to develop estimators of the regression coefficients for each regional skew model (Veilleux, 2011; Veilleux and others, 2011). The WLS analysis explicitly reflects variations in record length, but intentionally neglects cross correlations, thereby avoiding the problems experienced with GLS parameter estimators (Veilleux, 2011; Veilleux and others, 2011).

\section{Generalized Least Squares Analysis}

After the regression model coefficients, $\hat{\beta}_{W L S}$, are determined with a WLS analysis, the precision of the fitted model and the precision of the regression coefficients are estimated using a B-GLS analysis (Veilleux, 2011; Veilleux and others, 2011). Precision metrics include the standard error of the regression parameters, $S E\left(\hat{\beta}_{W L S}\right)$, and the model error variance, $\sigma_{\delta, B-G L S}^{2}$, pseudo coefficient of determination, $R_{\delta}^{2}$, as well as the average variance of prediction at a streamgage not used the regional model, $\mathrm{AVP}_{\text {new }}$.

\section{Data Analysis}

The statistical analysis of the data requires several steps. This section describes (1) a redundant site analysis; (2) the calculations for pseudo record length for each site given the number of censored observations, and for concurrent record lengths; and (3) the development of the model of cross-correlations of concurrent annual peak flows.

\section{Data for Arizona Regional Skew Study}

This study is based on annual peak-discharge data from 307 streamgages in Arizona and the surrounding states. The streamgage dataset used in the regional skew analysis does not reflect the same dataset used in the regional regression analysis. The main reasons for the discrepancy are the timing of the regional skew analysis relative to the regional regression analysis and the record length considered for each analysis. The regional skew analysis was conducted much earlier in the study progression and considered many sites that were later determined to have visually poor frequency fits to the observed data and (or) had high influence or leverage in the regression analysis. These streamgages may have had different effects in each analysis because they were considered at a study area level (regional skew) rather than at a smaller regional level (regional equations). Secondly, record lengths of 20 years or more were considered for the regional skew analysis, whereas 10 years was the threshold for inclusion in the regional regression analysis.

\section{Redundant Site Analysis}

Redundant streamgage information occurs when the drainage basins of two streamgages are similar in size or they are nested, meaning that one is contained inside the other. Then, instead of providing two independent spatial observations, depicting how drainage basin characteristics are related to skew (or AEPs), these two basins will have the same hydrologic response to a given storm, and thus represent only one spatial observation. When sites are redundant, a statistical analysis that considers data from both streamgages incorrectly represents the information in the regional dataset (Gruber and Stedinger, 2008). In order to determine if two sites are redundant and thus represent the same hydrologic experience, two pieces of information are considered: (1) whether their watersheds are nested, and (2) the ratio of the basin drainage areas.

The standardized distance (SD), is used to determine the likelihood the basins are nested. The standardized distance between two basin centroids, SD is defined as

$$
S D_{i j}=\frac{D_{i j}}{\sqrt{0.5\left(D A_{i}+D A_{j}\right)}},
$$

where $D_{i j}$ is the distance between centroids of basin $i$ and basin $j$, and $D A_{i}$ and $D A_{j}$ are the drainage areas at sites $i$ and $j$.

The drainage area ratio, DAR, is used to determine if two nested basins are sufficiently similar in size to conclude that they are virtually, or are at least in large part, the same watershed for the purposes of developing a regional hydrologic model. The drainage area ratio of two basins, DAR, is defined as

$$
D A R=\operatorname{Max}\left[\frac{D A_{i}}{D A_{j}}, \frac{D A_{j}}{D A_{i}}\right],
$$

where $D A_{i}$ and $D A_{j}$ have already been defined in equation A2 (Veilleux, 2009).

Two basins might be expected to have possible redundancy if the basin sizes are similar and the basins are nested. Previous studies suggest that site pairs having SD less than or equal to 0.50 and DAR less than or equal to 5 were likely to have possible redundancy problems for purposes of determining regional skew (Parrett and others, 2011). If DAR is large enough, even if the sites are nested, they will reflect different hydrologic experiences because they respond differently to storms of the same size and duration. 
The results of the redundant site screening on the Arizona regional skew data are shown in table 1-1. All possible combinations of site-pairs from the 307 streamgages were considered in the redundancy analysis (including all types of streamgages: continuous-record streamgages, crest-stage streamgages, and mixed continuous-record and crest-stage streamgages). All site pairs with SD less than 0.5 and DAR less than 5 were identified as possible redundant site-pairs. All streamgages identified as redundant were then investigated to determine if, in fact, one site of the pair was nested inside the other. For site-pairs that were nested, one site from the pair was removed from the regional skew analysis. Streamgages removed from the regional skew study due to redundancy are identified in table 1-1 as "no-redundant." From the 39 identified possible redundant site-pairs, 23 were found to be redundant and those sites were removed from the analysis.

\section{Station Skew Estimators}

In order to estimate the station logarithm base 10 skew coefficient, $G$, and its mean square error, $M S E_{G}$, the analysis used the EMA-MGB (Cohn and others, 1997; Griffis and others, 2004). The EMA-MGB provides a straightforward and efficient method for the incorporation of historical information and censored data, such as those from a crest stage gage, contained in the record of annual peak flows for a streamgage. The PeakfqSA EMA software was used to generate the streamgage logarithm base 10 estimates of $G$ and its $M S E_{G}$, assuming an LPIII distribution and employing a multiple Grubbs-Beck test for low-outlier screening. The EMA-MGB estimates of $G$ and its $M S E_{G}$ based on annual peak-discharge data through water year 2010 are listed in table 1-1 for the streamgages evaluated for the Arizona regional skew study. Twelve streamgages were removed from the analysis due to poor LPIII fit (including a large percentage of zero flows) and they are identified in table 1-1 as "no-LPIII."

\section{Pseudo Record Length}

Because the dataset includes censored data and historical information, the effective record length used to compute the precision of the skew estimators is no longer simply the number of annual peak flows recorded or measured at a streamgage. Instead, a more complex calculation should be used to take into account the availability of historical information and censored values. While historical information and censored peaks provide valuable information, they often provide less information than an equal number of years with systematically recorded peaks (Stedinger and Cohn, 1986). The following calculations provide a pseudo record length $\left(\mathrm{P}_{\mathrm{RL}}\right)$, which appropriately accounts for all peak-discharge data types available for a site. The $\mathrm{P}_{\mathrm{RL}}$ equals the systematic record length if such a complete record is all that is available for a site.
The first step is to run EMA with all available information, including historical information and censored peaks (denoted $\mathrm{EMA}_{\mathrm{C}}$, for EMA complete). From the EMA run, the station skew without regional information $\hat{G}_{C}$ and the MSE of that skew estimator $\operatorname{MSE}\left(\hat{G}_{C}\right)$ are extracted, as well as the year the historical period begins, $\mathrm{YB}_{\mathrm{C}}$, the year the historical period ends, $\mathrm{YE}_{\mathrm{C}}$, and the length of the historical period, $\mathrm{H}_{\mathrm{C}}$ $\left(\mathrm{YB}_{\mathrm{C}}, \mathrm{YE}_{\mathrm{C}}\right.$, and $\mathrm{H}_{\mathrm{C}}$ are used in equation $\left.\mathrm{A} 12\right)$.

The second step is to run EMA with only the systematic peaks (denoted EMA , for EMA systematic). From the EMA analysis, the station skew without regional information $\hat{G}_{S}$ and the MSE of that skew estimator, $\operatorname{MSE}\left(\hat{G}_{S}\right)$ are extracted, as well as the number of peaks, $\mathrm{P}_{\mathrm{S}}\left(\mathrm{P}_{\mathrm{S}}\right.$ is used in equation $\left.\mathrm{A6}\right)$.

The third step is to represent, from both $\mathrm{EMA}_{\mathrm{C}}$ and $\mathrm{EMA}_{\mathrm{S}}$, the precision of the skew estimators as two record lengths, $\mathrm{RL}_{\mathrm{C}}$ and $\mathrm{RL}_{\mathrm{S}}$, based upon the estimated skew and MSE. The corresponding record lengths are calculated using equation A4 below from Griffis and others (2004) and Griffis and Stedinger (2009), where $\mathrm{RL}_{\mathrm{C}}$ uses ${ }^{\wedge}$ and $\operatorname{MSE}\left(\hat{G}_{C}\right)$, and $\mathrm{RL}_{\mathrm{S}}$ uses $\hat{G}_{S}$ and $\operatorname{MSE}\left(\hat{G}_{S}\right)^{\mathrm{C}}$.

$$
\begin{gathered}
\operatorname{MSE}(\hat{G})=\left[\frac{6}{\mathrm{RL}}+a(\mathrm{RL})\right] *\left[1+\left(\frac{9}{6}+b(\mathrm{RL})\right) \hat{G}^{2}+\right. \\
\left.\left(\frac{15}{48}+c(\mathrm{RL})\right) \hat{G}^{4}\right] \\
a(\mathrm{RL})=-\frac{17.75}{R L^{2}}+\frac{50.06}{R L^{3}} \\
b(\mathrm{RL})=\frac{3.93}{R L^{0.3}}-\frac{30.97}{R L^{0.6}}+\frac{37.1}{R L^{0.9}} \\
c(\mathrm{RL})=-\frac{6.16}{R L^{0.56}}+\frac{36.83}{R L^{1.12}}-\frac{66.9}{R L^{1.68}}
\end{gathered}
$$

Next, the difference between $\mathrm{RL}_{\mathrm{C}}$ and $\mathrm{RL}_{\mathrm{S}}$ is employed as a measure of the extra information provided by the historical and (or) censored information that was included in the EMA analysis, but not in the $\mathrm{EMA}_{\mathrm{s}}$ analysis.

$$
R L_{\text {diff }}=R L_{C}-R L_{S}
$$

The pseudo record length for the entire record at the streamgage, $\mathrm{P}_{\mathrm{RL}}$, is calculated using $R L_{\text {diff }}$ from equation $\mathrm{A} 5$ and the number of systematic peaks, $\mathrm{P}_{\mathrm{S}}$,

$$
P_{R L}=R L_{d i f f}+P_{S} .
$$

$\mathrm{P}_{\mathrm{RL}}$ must be non-negative. If $\mathrm{P}_{\mathrm{RL}}$ is greater than $\mathrm{H}_{\mathrm{C}}$, then $\mathrm{P}_{R L}$ should be set to equal $\mathrm{H}_{\mathrm{C}}$. Also if $\mathrm{P}_{\mathrm{RL}}$ is less than $\mathrm{P}_{\mathrm{S}}$, then $\mathrm{P}_{\mathrm{RL}}$ is set to $\mathrm{P}_{\mathrm{S}}$. This ensures that the pseudo record length will not be larger than the complete historical period or less than the number of systematic peaks.

As stated in Bulletin 17B, the skew coefficient of the station skew is sensitive to extreme events, and more accurate estimates can be obtained from longer records. Thus, after 
ensuring adequate special and hydrologic coverage, those gage sites that do not have a minimum of 20 years of pseudo record length were removed from the regional skew study. Another 66 streamgages were removed because their $\mathrm{P}_{\mathrm{RL}}$ is less than 20 years. The sites removed from the Arizona regional skew study due to the PRL being less than 20 are identified in table 1-1 as "no-POR".

\section{Unbiasing the Station Estimators}

The station skew estimates are unbiased by using the correction factor developed by Tasker and Stedinger (1986) and employed in Reis and others (2005). The unbiased station skew estimator using the pseudo record length is

$$
\hat{\gamma}_{i}=\left[1+\frac{6}{P_{R L, i}}\right] G_{i} .
$$

Where

$$
\begin{aligned}
& \hat{\gamma}_{i} \quad \text { is the unbiased station sample skew estimate } \\
& \text { for site } i \text {, } \\
& P_{R L, i} \quad \text { is the pseudo record length for site } i \text { as } \\
& \text { calculated in equation } \mathrm{A} 6 \text {, and } \\
& G_{i} \quad \text { is the traditional biased station skew estimator } \\
& \text { for site } i \text { from EMA. }
\end{aligned}
$$

The variance of the unbiased station skew includes the correction factor developed by Tasker and Stedinger (1986):

$$
\operatorname{Var}\left[\hat{\gamma}_{i}\right]=\left[1+\frac{6}{P_{R L, i}}\right]^{2} \operatorname{Var}\left[G_{i}\right],
$$

where $\operatorname{Var}\left[G_{i}\right]$ is calculated using (Griffis and Stedinger, 2009)

$$
\begin{gathered}
\operatorname{Var}(\hat{G})=\left[\frac{6}{P_{R L}}+a\left(P_{R L}\right)\right] *\left[1+\left(\frac{9}{6}+b\left(P_{R L}\right)\right) \hat{G}^{2}+\right. \\
\left.\left(\frac{15}{48}+c\left(P_{R L}\right)\right) \hat{G}^{4}\right] \\
a\left(P_{R L}\right)=-\frac{17.75}{P_{R L}{ }^{2}}+\frac{50.06}{P_{R L}^{3}}
\end{gathered}
$$

$$
\begin{aligned}
& b\left(P_{R L}\right)=\frac{3.92}{P_{R L}^{0.3}}-\frac{31.10}{P_{R L}^{0.6}}+\frac{34.86}{P_{R L}^{0.9}} \\
& c\left(P_{R L}\right)=-\frac{7.31}{P_{R L}^{0.59}}+\frac{45.90}{P_{R L}^{1.18}}-\frac{86.50}{P_{R L}^{1.77}}
\end{aligned}
$$

\section{Estimating the Mean Square Error of the Skew Estimator}

There are several possible ways to estimate $M S E_{G}$. The approach used by EMA (taken from equation 55 in Cohn and others [2001]) generates a first-order estimate of the $M S E_{G}$, which should perform well when interval data are present. Another option is to use the Griffis and Stedinger (2009) formula in equation A8 (the variance is equated to the MSE), employing either the systematic record length or the length of the whole historical period. However, this method does not account for censored data, and thus can lead to inaccurate and underestimated $M S E_{G}$. This issue has been addressed by using the pseudo record length instead of the length of the historical period; the pseudo record length reflects the impact of the censored data and the number of recorded systematic peaks. Thus, the unbiased Griffis and Stedinger (2009) $M S E_{G}$ is used in the regional skew model because it is more stable and relatively independent of the station skew estimator. This methodology was used in the Iowa regional skew study (Eash and others, 2013).

It is also difficult to get an accurate measure of the skew (that is, the asymmetry of the distribution) when the $\mathrm{P}_{\mathrm{RL}}$ is short and more than 30 percent of the observations are censored as low outliers. Thirty sites were removed due to the fact that greater than 30 percent of the observations in their record were identified as low outliers ( 8 sites with 31 to 39 percent low outliers, 16 sites with 40 to 49 percent low outliers, 6 sites with 50 to 61 percent low outliers). Of these 30 sites, the average $\mathrm{P}_{R L}$ was 40 years, while the average $\mathrm{P}_{R L}$ of the remaining sites was 54 years. The streamgages removed from the Arizona regional skew study due to the percent of low outliers greater than 30 percent as estimated by EMA are identified in table 1-1 as "no-PILF". After removing the streamgages from the regional skew analysis, 176 remained from which to build a regional skew model for the Arizona study area. 


\section{Cross-Correlation Models}

A critical step for a GLS analysis is estimation of the cross-correlation of the skew coefficient estimators. Martins and Stedinger (2002) used Monte Carlo experiments to derive a relation between the cross-correlation of the skew estimators at two stations $i$ and $j$ as a function of the cross-correlation of concurrent annual maximum flows, $\rho_{i j}$ :

$$
\hat{\rho}\left(\hat{\gamma}_{i}, \hat{\gamma}_{j}\right)=\operatorname{Sign}\left(\hat{\rho}_{i j}\right) c f_{i j}\left|\hat{\rho}_{i j}\right|^{k}
$$

where

$$
\begin{aligned}
& \hat{\rho}_{i j} \quad \text { is the cross-correlation of concurrent annual } \\
& \kappa \quad \text { peak flow for two streamgages, } \\
& \text { is a constant between } 2.8 \text { and } 3.3 \text {, and } \mathrm{cf}_{\mathrm{ij}} \text {, } \\
& \text { a factor that accounts for the sample } \\
& \text { size difference between stations and } \\
& \text { their concurrent record length, is defined } \\
& \text { as follows: } \\
& c f_{i j}=C Y_{i j} / \sqrt{\left(P_{R L, i}\right)\left(P_{R L, j}\right)}
\end{aligned}
$$

$C Y_{i j}=$ pseudo record length of the period of concurrent record, and $P_{R L, i}, P_{R L, j}=$ the pseudo record length corresponding to sites $i$ and $j$, respectively (see equation A6).

\section{Pseudo Concurrent Record Length}

After calculating the $\mathrm{P}_{\mathrm{RL}}$ for each streamgage in the study, the pseudo concurrent record length between pairs of sites can be calculated. Due to the use of censored data and historical data, the effective concurrent record length calculation is more complex than determining in which years the two streamgages both have recorded systematic peaks.

The years of historical record in common between the two streamgages is first determined. For the years in common, with beginning year $\mathrm{YB}_{i j}$ and ending year $\mathrm{YE}_{i j}$, the following equation is used to calculate the concurrent years of record between site $i$ and site $j$,

$$
C Y_{i j}=\left(Y E_{i j}-Y B_{i j}+1\right)\left(\frac{P_{R L, i}}{H_{C, i}}\right)\left(\frac{P_{R L, j}}{H_{C, j}}\right) .
$$

The computed pseudo concurrent record length depends upon the years of historical record in common between the two streamgages, as well as the ratios of the pseudo record length to the historical record length for each of the two streamgages.

\section{Arizona Study Area Cross-Correlation Model of Concurrent Annual Peak Flow}

A cross-correlation model for the log annual peak flows in the Arizona study area were developed using 52 sites with at least 50 years of concurrent systematic peaks (zero flows not included). Various models relating the cross-correlation of the concurrent annual peak flow at two sites, $\rho_{i j}$, to various basin characteristics were considered. A logit model, termed the Fisher $Z$ Transformation $(Z=\log [(1+r) /(1-r)])$, provided a convenient transformation of the sample correlations $r_{i j}$ from the $(-1,+1)$ range to the $(-\infty,+\infty)$ range. The adopted model for estimating the cross-correlations of concurrent annual peak flow at two stations, which used the distance between basin centroids, $D_{i j}$, as the only explanatory variable, is

$$
\rho_{\ddot{y}}=\frac{\exp \left(2 Z_{\ddot{y}}\right)-1}{\exp \left(2 Z_{\ddot{y}}\right)+1}
$$

where

$$
Z_{i j}=0.11+\exp \left(-0.67-0.0094 * D_{i j}\right) .
$$

An OLS regression analysis based on 1,032 station-pairs indicated that this model is as accurate as having 45 years of concurrent annual peaks from which to calculate crosscorrelation. Figure 1-1 shows the fitted relation between Z and distance between basin centroids together with the plotted sample data from the 1,032 station pairs of data. Figure 1-2 shows the functional relation between the untransformed cross correlation and distance between basin centroids together with the plotted sample data from the 1,032 station pairs of data. The cross correlation model was used to estimate site-to-site cross correlations for concurrent annual peak flows at all pairs of sites in the regional skew study.

\section{Arizona Regional Skew Study Results}

The results of the Arizona regional skew study using the B-WLS/B-GLS regression methodology are provided below. All of the available basin characteristics were initially considered as explanatory variables in the regression analysis for regional skew. Available basin characteristics include; mean annual precipitation, rainfall intensity, soil metrics, basin cover, basin measures, and both 4-digit hydrologic unit codes and EPA level III ecoregions. While a small number of the basin characteristics were statistically significant, none of the models produced a pseudo $R_{\delta}^{2}$ greater than 10 percent, indicating that they do not help explain the variability in the true skew or decrease the model error variance. Thus, the addition of a basin characteristic is not warranted as the increased model complexity does not result in a gain in model precision. 


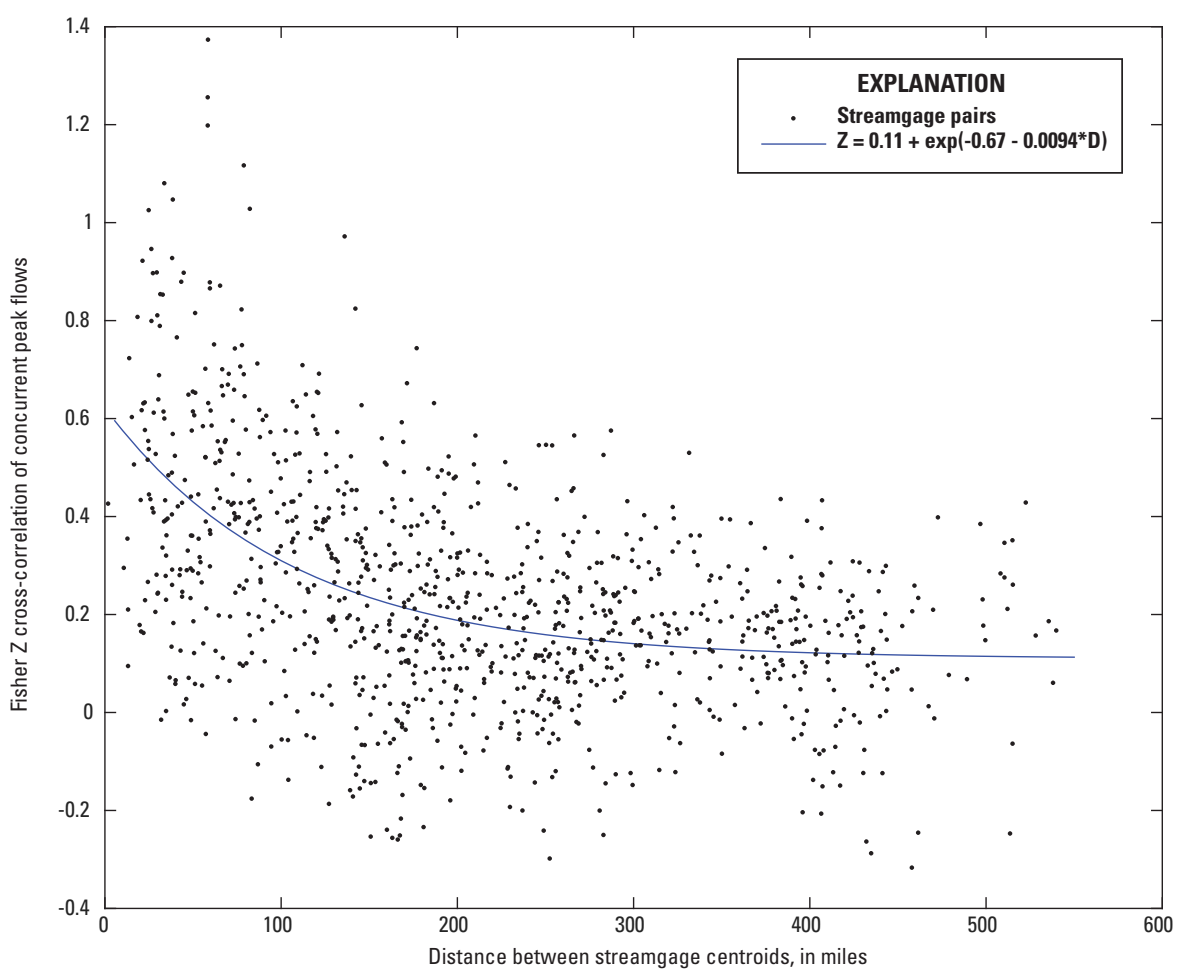

Figure 1-1. Relation between Fisher Z transformed cross-correlation of logarithm of annual peak flow and distance between basin centroids for 1,032 station-pairs with concurrent record lengths $\geq 50$ years from 52 streamgages in Arizona and neighboring states.

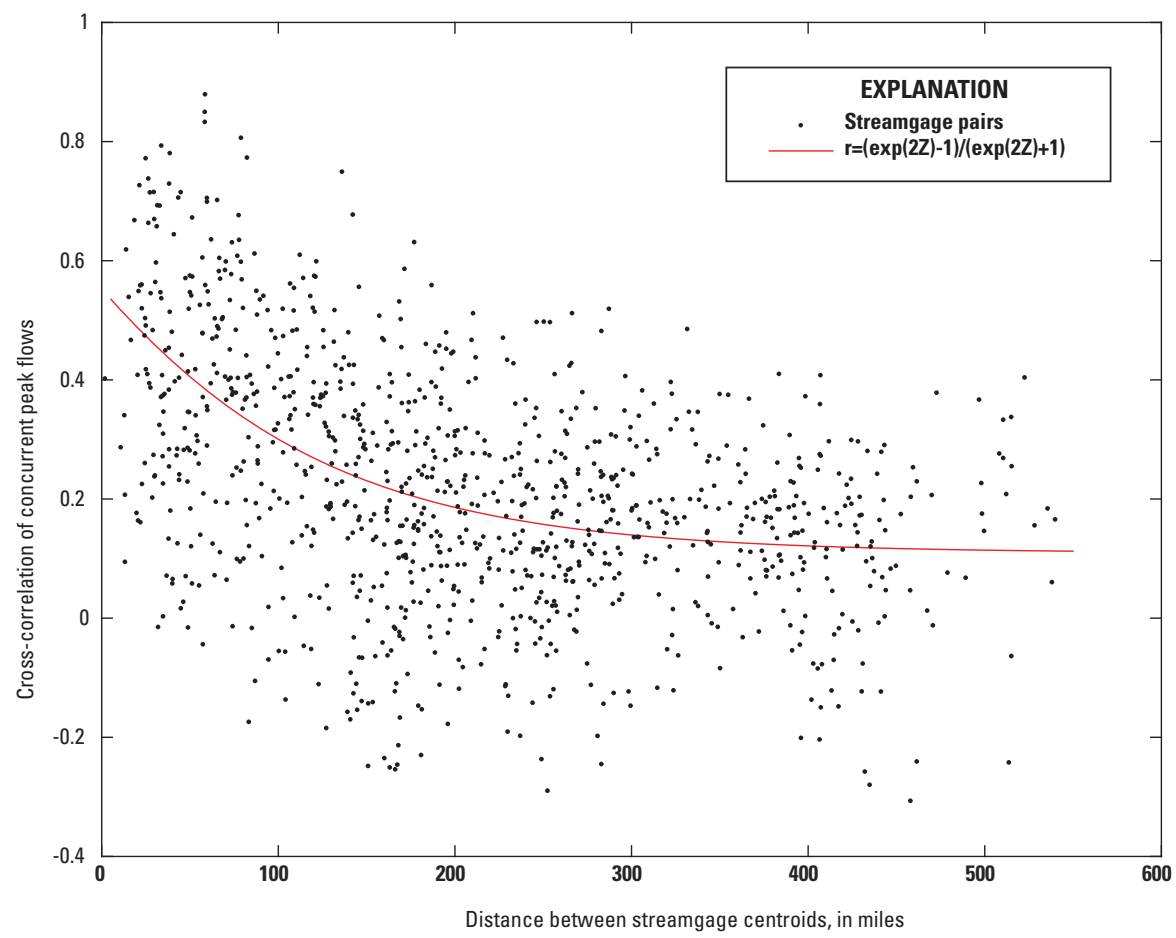

Figure 1-2. Relation between untransformed cross-correlation of logs of annual peak flow and distance between basin centroids based for 1,032 station-pairs with concurrent record lengths $\geq 50$ years from 52 streamgages in Arizona and neighboring states. 
Thus, the "Constant" model is chosen as the best regional skew model for Arizona. Table 1-2 provides the final results for the constant skew model denoted "Constant."

The pseudo $R_{\delta}^{2}$, which describes the estimated fraction of the variability in the true skew from site-to-site explained by each model, is included in table 1-2 (Gruber and others, 2007; Parrett and others, 2011). A constant model does not explain any variability, so the pseudo $R_{\delta}^{2}$ equals 0 . The posterior mean of the model error variance, $\sigma_{\delta}^{2}$, for the constant model is $\sigma_{\delta}^{2}=0.08$.

The average sampling error variance (ASEV) in table 1-2 is the average error in the regional skew estimator at the sites in the dataset. The average variance of prediction at a new site $\left(\mathrm{AVP}_{\text {new }}\right)$ corresponds to the mean square error (MSE) used in Bulletin 17B to describe the precision of the generalized skew. The constant model has an $\mathrm{AVP}_{\text {new }}$, equal to 0.08 , which corresponds to an effective record length of 85 years. $\mathrm{An} \mathrm{AVP}_{\text {new }}$ of 0.08 is a marked improvement over the Bulletin 17B national skew map, whose reported MSE is 0.302 (Interagency Committee on Water Data, 1982) for a corresponding effective record length of only 17 years. Thus the new regional model has almost four times the information content (as measured by effective record length) of that calculated for the Bulletin 17B map.

\section{B-WLS/B-GLS Regression Diagnostics}

To determine if a model is a good representation of the data and which regression parameters, if any, should be included in a regression model, diagnostic statistics have been developed to evaluate how well a model fits a regional hydrologic dataset (Griffis, 2006; Gruber and others, 2008). In this study, the goal was to determine the set of possible explanatory variables that best fit annual peak flows for the Arizona study area affording the most accurate skew prediction, while also keeping the model as simple as possible. This section presents the diagnostic statistics for a B-WLS/B-GLS analysis, and discusses the specific values obtained for the Arizona regional skew study.

A Pseudo Analysis of Variance (Pseudo ANOVA) for the Arizona regional skew analysis is presented in table 1-3. The table contains regression diagnostics/goodness of fit statistics that are explained below.

In particular, the table describes how much of the variation in the observations can be attributed to the regional model, and how much of the residual variation can be attributed to model error and sampling error, respectively. Difficulties arise in determining these quantities. The model errors cannot be resolved because the values of the sampling errors $\eta_{i}$ for each site $i$, are not known. However, the total sampling error sum of squares can be described by its mean value,

$\sum^{\operatorname{Var}}\left[{ }^{\wedge}\right]$. Because there are $n$ equations, the total variation due to the model error $\delta$ for a model with $k$ parameters has a mean equal to $n \sigma_{\delta}^{2}(k)$. Thus, the residual variation attributed to the sampling error is $\sum_{i=1}^{n} \operatorname{Var}\left[\hat{y}_{i}\right]$, and the residual variation attributed to the model error is $n \sigma_{\delta}^{2}(k)$.
For a model with no parameters other than the mean (that is, the constant skew model), the estimated model error variance $o_{\delta}^{2}(0)$ describes all of the anticipated variation in $\gamma_{i}=\mu+\delta_{i}$, where $\mu$ is the mean of the estimated station sample skews. Thus, the total expected sum of squares variation due to model error $\delta_{i}$ and due to sampling error $\eta_{i}=\hat{\gamma}_{i}-\gamma_{i}$ in expectation should equal $n \sigma_{\delta}^{2}(0)+\sum_{i=1}^{n} \operatorname{Var}\left[\hat{\gamma}_{i}\right]$. Therefore, the expected sum of squares attributed to a regional skew model with $k$ parameters equals $n\left[\sigma_{\delta}^{2}(0)-\sigma_{\delta}^{2}(k)\right]$, because the sum of the model error variance $n \sigma_{\delta}^{2}(k)$ and the variance explained by the model must sum to $n \sigma_{\delta}^{2}(0)$. Table 1-3 considers a model with $k=0$ (a constant model).

This division of the variation in the observations is referred to as a Pseudo ANOVA because the contributions of the three sources of error are estimated or constructed, rather than being determined from the computed residual errors and the observed model predictions, while also ignoring the impact of correlation among the sampling errors.

Pseudo ANOVA results for the constant model are contained in table 1-3. The constant model does not have any explanatory variables, thus the variation attributed to the model is 0 . As shown in table 1-3, the constant model has a sampling error variance over two and half times larger than its model error variance.

The Error Variance Ratio (EVR) is a modeling diagnostic used to evaluate if a simple OLS regression is sufficient, or a more sophisticated WLS or GLS analysis is appropriate. The EVR is the ratio of the average sampling error variance to the model error variance. Generally, an EVR greater than 0.20 indicates that the sampling variance is not negligible when compared to the model error variance, suggesting the need for a WLS or GLS regression analysis. The EVR is calculated as

$$
E V R=\frac{\mathrm{SS}(\text { sampling error })}{\mathrm{SS}(\text { model error })}=\frac{\sum_{i=1}^{n} \operatorname{Var}\left(\hat{\gamma}_{i}\right)}{n \sigma_{\delta}^{2}(k)}
$$

For the Arizona study-area data, EVR had a value of 2.7 for the constant model. The sampling variability in the sample skew estimators was larger than the error in the regional model. Thus an OLS model that neglects sampling error in the station skew estimators may not provide a statistically reliable analysis of the data. Given the variation of record lengths from site-to-site, it is important to use a WLS or GLS analysis to evaluate the final precision of the model, rather than a simpler OLS analysis.

The Misrepresentation of the Beta Variance $\left(\mathrm{MBV}^{*}\right)$ statistic is used to determine whether a WLS regression is sufficient, or if a GLS regression is appropriate to determine the precision of the estimated regression parameters (Griffis, 2006; Veilleux, 2011). The MBV* describes the error produced by a WLS regression analysis in its evaluation of the precision of $b_{0}^{W L S}$, which is the estimator of the constant $\beta_{0}^{W L S}$, because the covariance among the estimated station skews, $\hat{\gamma}_{i}$ generally has its greatest impact on the precision of 
Table 1-2. Regional skew models for Arizona study area.

[Standard deviations are in parentheses. $\sigma_{\delta}^{2}$ is the model error variance. ASEV is the average sampling error variance. AVPnew is the average variance of prediction for a new site. Pseudo $R_{\delta}^{2}$ (percent) describes the fraction of the variability in the true skews explained by each model (Gruber and others, 2007).]

\begin{tabular}{|c|c|c|c|c|c|}
\hline \multirow{2}{*}{ Model } & Regression Parameter & \multirow{2}{*}{$\sigma_{\delta}^{2}$} & \multirow{2}{*}{ ASEV } & \multirow{2}{*}{$\mathbf{A V P}_{\text {new }}$} & \multirow{2}{*}{$R_{\delta}^{2}$, in percent } \\
\hline & $b_{1}$ & & & & \\
\hline Constant: & -0.09 & 0.08 & 0.003 & 0.08 & 0 \\
\hline$\hat{\gamma}=b_{1}$ & $(0.06)$ & $(0.02)$ & & & \\
\hline
\end{tabular}

Table 1-3. Pseudo Analysis of Variance (ANOVA) table for the Arizona regional skew study for the constant model.

[EVR, error variance ratio; $\mathrm{MBV}^{*}$, misrepresentation of the beta variance; Pseudo $R_{\delta}^{2}$, fraction of variability in the true skews explained by the model]

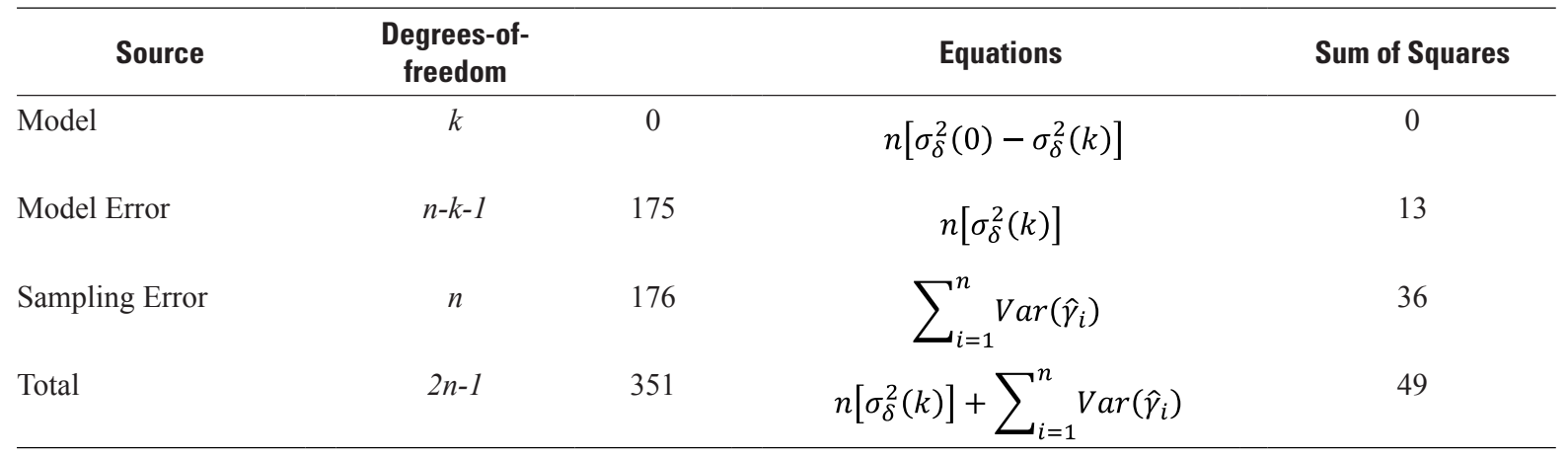

\section{Model Diagnostics}

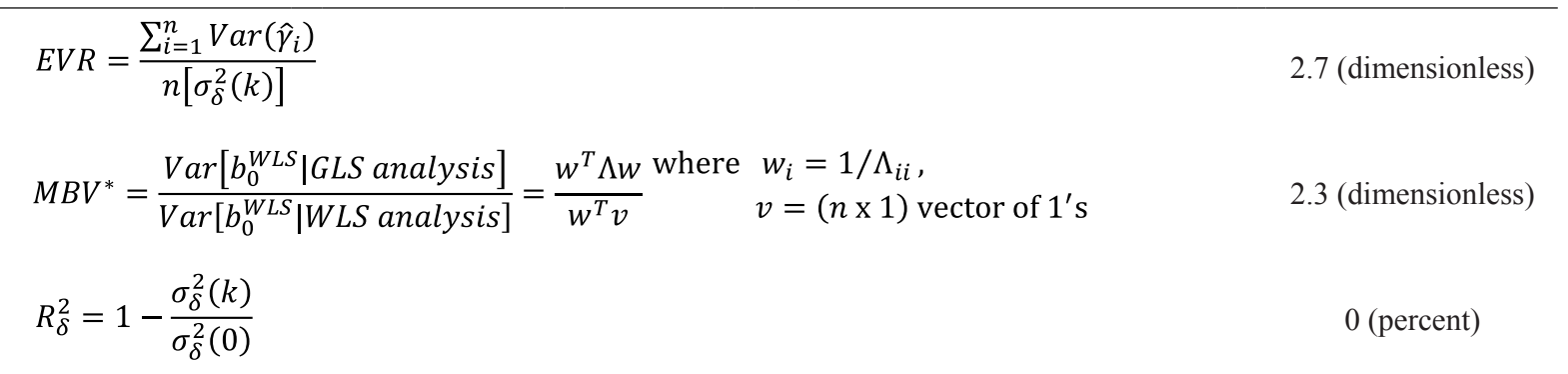


the constant term (Stedinger and Tasker, 1985). If the MBV* is substantially greater than 1 , then a GLS error analysis should be employed. The MBV* is calculated as,

$$
\begin{aligned}
& M B V^{*}=\frac{\operatorname{Var}\left[b_{0}^{W L S} \mid \text { GLS analysis }\right]}{\operatorname{Var}\left[b_{0}^{W L S} \mid \text { WLS analysis }\right]}=\frac{w^{T} \Lambda w}{\sum_{i=1}^{n} w_{i}} \\
& \text { where } w_{i}=\frac{1}{\sqrt{\Lambda_{i i}}}
\end{aligned}
$$

For the Arizona regional skew study, the $\mathrm{MBV}^{*}$ is equal to 2.3 for the constant model. This is a large value indicating the cross-correlation among the skew estimators has had an impact on the precision with which the regional average skew coefficient can be estimated; if a WLS precision analysis were used for the estimated constant parameter in the constant model, the variance would be underestimated by a factor of 2.3. Thus, a WLS analysis would seriously misrepresent the variance of the constant in the constant model. Moreover, a WLS model would have resulted in underestimation of the variance of prediction, given that the sampling error in the constant term in both models was sufficiently large enough to make an appreciable contribution to the average variance of prediction.

\section{Leverage and Influence}

Leverage and influence diagnostic statistics can be used to identify rogue observations and to effectively address lackof-fit when estimating skew coefficients. Leverage identifies those streamgages in the analysis where the observed values have a large impact on the fitted (or predicted) values (Hoaglin and Welsch, 1978). Generally, leverage considers whether an observation, or explanatory variable, is unusual, and thus likely to have a large effect on the estimated regression coefficients and predictions. Unlike leverage, which highlights points that have the ability or potential to affect the fit of the regression, influence attempts to describe those points which do have an unusual impact on the regression analysis (Belsley and others, 1980; Cook and Weisberg, 1982; Tasker and Stedinger, 1989). An influential observation is one with an unusually large residual that has a disproportionate effect on the fitted regression relations. Influential observations often have high leverage. For a detailed description of the equations used to determine leverage and influence for a B-WLS/B-GLS analysis see Veilleux and others (2011) and Veilleux (2011).

The leverage and influence values for the B-WLS/BGLS constant regional skew model for the Arizona study area are displayed in figure 1-3. The 14 sites included in the figure have high influence and (or) high leverage. The sites

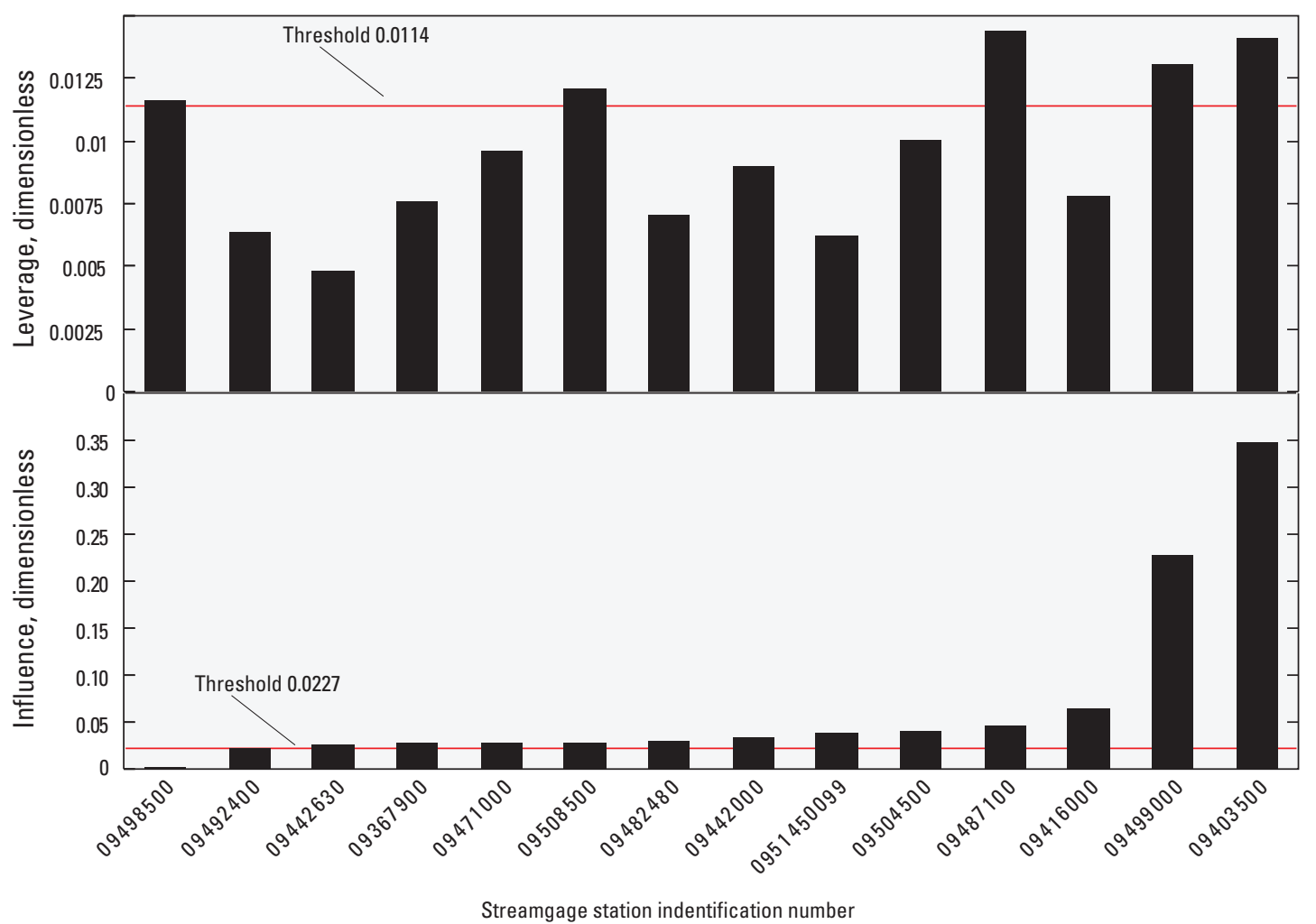

Figure 1-3. Leverage and influence diagnostic statistics for the Arizona study area B-WLS/BGLS Constant model. The solid line represents the threshold for high leverage, while the dotted line represents the threshold for high influence. 
are ordered, starting from the left, by increasing influence, as it identifies those sites that had a large impact on the fitted regression relation. Five sites in the regression had high leverage. The differences in leverage values for the constant model reflect the variation in record lengths among sites. The five sites with high leverage had pseudo record lengths ranging from 421 years to 172 years. The longer record lengths are associated with the incorporation of historical and paleoflood information. Streamgage 09403500 has the highest influence value due to its large residual, the second largest negative residual in the study (that is, the second largest negative unbiased station skew $=-1.03$ ), and its long pseudo record length (380 years, the second longest record length).

\section{References Cited}

Belsley, D.A., Kuh, E., and Welsch, R.E., 1980, Detecting influential observations and outliers, chap. 2 of Regression Diagnostics - Identifying Influential Data and Sources of Collinearity: New York, John Wiley \& Sons, Inc., p 6-84.

Cohn, T.A., Lane, W.L., and Baier, W.G., 1997, An algorithm for computing moments-based flood quantile estimates when historical flood information is available: Water Resources Research, v. 33, p. 2089-2096.

Cohn, T.A., Lane, W.L., and Stedinger, J.R., 2001, Confidence intervals for Expected Moments Algorithm flood quantile estimates: Water Resources Research, v. 37, no. 6, p. 1695-1706, at http://timcohn.com/Publications/ CohnLaneSted2001WR900016.pdf.

Cook, R.D., and Weisberg, S., 1982, Residuals and influence in regression: New York, Chapman and Hall, 230 p.

Eash, D.A., Barnes, K.K., and Veilleux, A.G., 2013, Methods for estimating annual exceedance-probability discharges for streams in Iowa, based on data through water year 2010: U.S. Geological Survey Scientific Investigations Report 2013-5086, 63 p. with appendix, at http://pubs.usgs.gov/ sir/2013/5086/.

Feaster, T.D., Gotvald, A.J., and Weaver, J.C., 2009, Magnitude and frequency of rural floods in the southeastern United States, 2006-Volume 3, South Carolina: U.S. Geological Survey Scientific Investigations Report 2009-5043, $238 \mathrm{p}$.

Gotvald, A.J., Feaster, T.D., and Weaver, J.C., 2009, Magnitude and frequency of rural floods in the southeastern United States, 2006-Volume 1, Georgia: U.S. Geological Survey Scientific Investigations Report 2009-5156, 120 p.
Griffis, V.W., Stedinger, J.R., and Cohn, T.A., 2004, Log Pearson type 3 quantile estimators with regional skew information and low outlier adjustments: Water Resources Research, v. 40, no. 10, W07503 17 p. [Also available at http://onlinelibrary.wiley.com/ doi/10.1029/2003WR002697/pdf.]

Griffis, V.W., 2006, Flood frequency analysis-Bulletin 17, Regional Information, and Climate Change: Ithica, Cornell University, Ph.D. dissertation, 482 p.

Griffis, V.W., and Stedinger, J.R., 2009, Log-Pearson type 3 distribution and its application in flood frequency analysis, III-sample skew and weighted skew estimators: Journal of Hydrology, v. 14, no. 2, p. 121-130.

Gruber, A.M., Reis, D.S., Jr., and Stedinger, J.R., 2007, Models of regional skew based on Bayesian GLS regression, paper 40927-3285, in Kabbes, K.C., ed., Proceedings of the World Environmental and Water Resources Congress - Restoring our natural habitat: American Society of Civil Engineers, Tampa, Fla., May 15-18.

Gruber, A.M., and Stedinger, J.R., 2008, Models of LPIII Regional Skew, Data Selection and Bayesian GLS Regression, paper 596, in Babcock, R.W., Jr., and Watson, R., eds., Proceedings of the World Environmental and Water Resources Congress - Ahupua'a: American Society of Civil Engineers, Honolulu, Hawai'i, May 12-16.

Interagency Advisory Committee on Water Data, 1982, Guidelines for determining flood flow frequency, Bulletin 17-B of the Hydrology Subcommittee: Reston, Virginia, U.S. Geological Survey, Office of Water Data Coordination, 183 p.

Lamontagne, J.R., Stedinger, J.R., Berenbrock, Charles, Veilleux, A.G., Ferris, J.C., and Knifong, D.L., 2012, Development of regional skews for selected flood durations for the Central Valley Region, California, based on data through water year 2008: U.S. Geological Survey Scientific Investigations Report 2012-5130, 60 p.

Martins, E.S., and Stedinger, J.R. , 2002, Cross-correlation among estimators of shape: Water Resources Research, v. 38, no. 11, p. 34-1-34-7, doi: 10.1029/2002WR001589.

Omernik, J.M., 1987, Ecoregions of the conterminous United States, map: Annals of the Association of American Geographers, v. 77, no. 1, p. 118-125, scale 1:7,500,000.

Parrett, C., Veilleux, A., Stedinger, J.R., Barth, N.A., Knifong, D.L., and Ferris, J.C., 2011, Regional skew for California, and flood frequency for selected sites in the SacramentoSan Joaquin River Basin, based on data through water year 2006: U.S. Geological Survey Scientific Investigations Report 2010-5260, 94 p., at http://pubs.usgs.gov/ sir/2012/5113/pdf/sir2012-5113.pdf 
Stedinger, J.R., and Tasker, G.D., 1985, Regional hydrologic analysis 1 - Ordinary, weighted, and generalized least

square compared: Water Resources Research, v. 21, no. 9, p. 1421-1432, at http://www.agu.org/journals/wr/v021/i009/ WR021i009p01421/WR021i009p01421.pdf.

Stedinger, J.R., and Cohn, T.A., 1986, Flood frequency analysis with historical and paleoflood information: Water Resources Research, v. 22, no. 5, p. 785-793.

Tasker, G.D., and Stedinger, J.R., 1986, Regional skew with weighted LS regression: Journal of Water Resources Planning and Management, American Society of Civil Engineers, v.112, no. 2, p. 225-237.

Tasker, G.D., and Stedinger, J.R., 1989, An operational GLS model for hydrologic regression: Journal of Hydrology, v. 111, p. 361-376.

Thomas, B.E., Hjalmarson, H.W., and Waltemeyer, S.D., 1997, Methods for estimating magnitude and frequency of floods in the Southwestern United States: U.S. Geological Survey Water-Supply Paper 2433, 205 p.

Reis, D.S., Stedinger, J.R., and Martins, E.S., 2005, Bayesian generalized least squares regression with application to log Pearson type 3 regional skew estimation: Water Resources Research, v. 41, W10419, 14 p.
Veilleux, A.G., 2009, Bayesian GLS regression for regionalization of hydrologic statistics, floods and Bulletin 17 skew: Ithica, Cornell University, M.S. thesis, 170 p.

Veilleux, A.G., 2011, Bayesian GLS regression, leverage and influence for regionalization of hydrologic statistics: Ithica, Cornell University, Ph.D. dissertation, 184 p.

Veilleux, A.G., Stedinger, J.R., and Eash, D.A., 2012, Bayesian WLS/GLS regression for regional skew analysis for regions with large crest stage gage networks, paper 2253, in Loucks, E.D., ed., Proceedings of the World Environmental and Water Resources Congress 2012- Crossing Boundaries: American Society of Civil Engineers, Albuquerque, New Mexico, May 20-24.

Veilleux, A.G., Stedinger, J.R., and Lamontagne, J.R., 2011, Bayesian WLS/GLS regression for regional skew analysis for regions with large cross-correlations among flood flows, paper 3103, in Beighley, R.E., and Killgore, M.W., eds., Proceedings of the World Environmental and Water Resources Congress 2011- Bearing Knowledge for Sustainability: American Society of Civil Engineers, Palm Springs, Calif., May 22-26. 


\title{
Appendix 2. StreamStats Development
}

\author{
By Lovina A.Turney, U.S. Geological Survey
}

\section{Geographical Information Systems and Basin Characteristic Data Processing}

StreamStats is an interactive web-based tool developed by the USGS for retrieving flood frequency and basin characteristic statistics for individual state applications ( $h t t p: / /$ water.usgs.gov/osw/streamstats/). StreamStats allows users to select a location, create a delineated watershed upstream of the user-selected location, and compute a variety of basin characteristic statistics. These characteristics can then be used to determine flood statistics in ungaged locations. Layers used to define watershed boundaries in StreamStats for Arizona are the 10-meter digital elevation model (DEM) from the National Elevation Dataset ([NED]; Gesch, 2007), the 1:24,000 USGS National Hydrography Dataset ([NHD]; Simley and Carswell, 2009), and the 1:24,000 National Watershed Boundary Dataset ([WBD]; U.S. Department of Agriculture, Natural Resources Conservation Service, 2011). Scripts and toolboxes used were developed by Esri (ArcToolboxes and ArcHydro9 tools), Bureau of Reclamation, U.S. Environmental Protection Agency, USGS StreamStats Team (StreamStats Tools), USGS (Hydrography Event Tools [HEM]), and the USGS Utah Water Science Center (NHD/WBD intersect tool).

\section{Edits and Adjustments}

Manual edits were made to the datasets needed to develop StreamStats for Arizona and submitted to the respective entities for incorporation into the national datasets. The NHD flow network was manually edited and adjusted to best incorporate man-made systems, such as pipelines, irrigation canals, and detention structures, so as to keep connectivity and maintain a realistic network of flow. There were some discrepancies when the NHD and the WBD datasets were merged and steps were taken to integrate the two datasets, including checking that each watershed had only one outlet, making sure that water features did not cross the WBD in the headwaters of the unit, and that the drainage features matched those displayed either on the topographic maps or the National Agriculture Imagery Program imagery.

\section{Preprocessing}

In the preprocessing step, the WBD of the 8-digit hydrologic unit code (HUC) was selected, and the 12-digit HUC polygons were extracted; these polygons were then used to extract the 12-digit HUC arcs that were used for the interior watershed boundary walls of the layer. The 12-digit HUC polygons were then combined into a single 8-digit HUC polygon. A buffered polygon was used to extract the outer boundary from the interior walls layer to make an outer wall. The NHD for the individual HUCs were clipped from the regional dataset using the 8-digit HUC polygon.

The NHD was evaluated for connectivity using the NHD utility tools; a network was created to check for loops within the NHD and disconnected segments. In areas of loops, the flowline was pared down to a single channel using imagery and topographic maps as a reference. For segments of the NHD that were not connected to the main network and should have been connected, the imagery and topographic maps were used to guide manual connectivity. The outlets of the WBD/ NHD were checked to be certain that there was a single outlet for each 12-digit HUC-WBD polygon. Also, the NHD and the WBD were checked for segments that crossed each other in an improbable hydrological fashion. Edits to either the NHD or the WBD were made with reference to imagery, topographic maps, or other sources as necessary, and all edits to the WBD were reconciled with the State WBD steward prior to implementation. Edits to the NHD were also tracked and either flagged as a StreamStats specific edit or flagged to be passed on to the State NHD steward and implemented into the NHD.

The DEMs for each HUC were created from the National $1 / 3$ arc second NED tiles. The tiles were seamed together, and a 5,000 $\mathrm{m}$ geographic buffer was used to clip out the DEM using the extract polygon area tool. After checking for holes in the clipped DEM, it was scaled and projected using project and scale tool to convert the z-units to 100 and project into USA Contiguous Albers Equal Area Conic. The DEMs crossing the international boundary with Mexico were created by resampling the 30-m DEMs available from Mexico to $10 \mathrm{~m}$ and merging them with the $10-\mathrm{m}$ U.S. DEMs. All polygons were checked to make sure they had a single outlet and that NHD did not cross the WBD in any of the headwaters area using the NHD/WBD intersect tools developed by the Utah Water Science Center. This tool buffered the NHD and the WBD and indicated places where they crossed. These instances were examined individually and corrected.

Sinks were created for units that had been identified as a "closed basin" (no outlet) or having areas with closed flow. The DEM was converted into an integer grid using map algebra to multiply each pixel by 100 , then the closed basin or basin with sinks were selected out and zonal statistics were run on those polygons to determine the minimum elevation 
in the specific polygon. The integer grid was symbolized by elevation and the lowest point was identified using the pixel inspector tool, and a point was added to the center of the cell. Once all points were added, they were converted to a raster, snapped to the DEM, and converted back to a polygon.

\section{Hydrodem Processing}

The hydrodem process uses DEMs, walls from WBD, and the streams layer from NHD to create the synthetic stream network used to create the watershed delineations. The hydrodem processing is completed in two phases, hydrodem and post-hydrodem. For the hydrodem phase, several datasets are created, including a flow directions grid, flow accumulation grid, sinklink (for units containing a sink), and a global flow accumulation grid. The global flow accumulation grid was created for downstream units to take into account both the flow from the individual unit and all units upstream. The post hydrodem process then uses these grids to create a geodatabase containing feature classes, stream grids, and catchment information to be used in the watershed delineation process. A global HUC ArcHydro Geodatabase is then created, which is used as the framework for StreamStats processing. The outer boundaries of each 8-digit HUC were collected into a single layer, converted to a raster and back into a polygon. A streams layer to connect the HUCs together was created and a geometric network created for the geodatabase. After completion of the xml and grid compilation, global parameters for each HUC in the global geodatabase were computed using the attribute tools in the ArcHydro 9 toolbox. The global parameters are used in gage watershed computation to create the global gage watershed.

A watershed created from a given starting point can either be entirely inside a HUC, or can cross the border into an adjacent HUC. If the watershed is contained entirely in a single HUC, the program will create a local watershed only. If the watershed extends into an adjacent HUC, the program will create a local watershed that stops at the boundary of the HUC of origin, and a global HUC of the entire watershed. The global parameters computed in the global geodatabase contribute to the global watershed calculations.

\section{Grid Creation}

Each parameter calculated by StreamStats requires a grid from which to do calculations; some of the grids were made for each individual HUC and other grids were made on a study-area-wide scale based on the amount of data contained in each grid. Grids were created for each subbasin and 24 grids were created at the study-area-wide level. All grids derived from the DEMs were created on an individual HUC level. These include elevation, in feet; slope, in percent; elevation greater than $5,000 \mathrm{ft}, 6,000 \mathrm{ft}$, and 7,500 ft, in percent; and slope greater than 30 percent and north-facing slope greater than 30 percent, in percent (table 2-1). Study-area-wide grids include annual and monthly averages for temperature and precipitation (Parameter-elevation Regressions on Independent
Slopes Model [PRISM Climate Group], 2008), land-cover data (National Land Cover Database [NLCD]; Homer and others, 2007), population (U.S. Census Bureau, 2012), soils (State Soil Geographic [STATSGO]; Schwarz and Alexander, 1995), high permeability aquifers and geologic units (Geology of the Conterminous US at 1:2,500,000; Schruben and others, 1998), and precipitation intensity (National Oceanic and Atmospheric Administration Atlas 14; Bonnin and others, 2006). Each grid was projected and clipped to the study area. For parameters that required percent-type calculation, a binary grid was created using the ArcGIS Con tools.

As part of an ongoing harmonization project with Instituto Nacional de Estadística Geografía y Informática, Mexico, GIS layers (DEM, precipitation, and land cover) were merged with Arizona datasets. Data were resampled where necessary and combined using raster mosaic tools. A transboundary WBD was developed by the Utah Water Science Center and the trans-boundary harmonized NHD dataset and North American PRISM dataset were obtained from the NHDPlus workgroup (McKay and others, 2012).

\section{Gage Snapping and Watershed Delineation}

Streamgages were plotted in ArcMap using their published coordinates and snapped to the NHD using an automated process that is part of the HEM. The published locations of streamgages often marked the location of gaging infrastructure on a stream bank, gage house, or bridge, rather than denoting the gage location along the stream. The HEM tools make sure that streamgages "snap" to an NHD flowline to ensure proper functionality in StreamStats. Many of the streamgages had to be manually snapped to the correct stream to account for locations that were snapping to a nearby tributary or stream, or a different stream of similar distance from the streamgage.

Streamgage watersheds were created using snapped streamgages and the Batch Global Water delineation tool in the ArcHydro 9 toolbar. This process created a watershed for each gage with all the basin characteristics, which were saved in a file geodatabase. The outputs from each were checked for accuracy and adjustments to locations, stream layers, or wall locations were made as necessary. If adjustments needed to be made to the stream layer or the wall location, the entire HUC was reprocessed through the hydrodem and post-hydrodem processes and statistics were recomputed.

\section{Basin Characteristics}

Seventy-two basin characteristics were computed at 448 streamgages, including mean annual and monthly precipitation and temperature (PRISM); precipitation intensity (NOAA Atlas 14); physical basin properties such as drainage area, slope, perimeter, and length (10-m DEM, 1:24,000 NHD, WBD); land-cover (NLCD); and soil properties (STATSGO). Of the 72 variables, 31 were selected as basin characteristics to be computed for watersheds delineated in StreamStats. Station statistics for all 72 variables can be found in table 2-1. 


\section{References Cited}

Bonnin, G., Martin, D., Parzybok, T., Lin, B., Riley, D., and Yekta, M., 2006, Precipitation frequency atlas of the United States: National Weather Service, National Oceanic and Atmospheric Administration Atlas 14, vol. 1, version 4.0, accessed July 01, 2013, 271 p. at http://hdsc.nws.noaa.gov/ hdsc/pfds/docs/NA14Voll.pdf.

Gesch, D.B., 2007, The national elevation dataset, in Maune, D., ed., Digital elevation model technologies and applications-The DEM users manual (2d ed.): Bethesda, Maryland, American Society for Photogrammetry and Remote Sensing, p. 99-118, accessed March 15, 2013, at http://topotools.cr.usgs.gov/pdfs/Gesch_Chp_4_Nat_Elev_ Data_2007.pdf. [See also http://ned.usgs.gov/.]

Homer, C., Dewitz, J., Fry, J., Coan, M., Hossain, N., Larson, C., Herold, N., McKerrow, A., VanDriel, J.N., and Wickham, J., 2007, Completion of the 2001 National Land Cover Database for the conterminous United States: Photogrammetric Engineering and Remote Sensing, v. 73, no. 4, p. 337-341.

McKay, L., Bondelid, T., Dewald, T., Rea, A., Johnston, C., and Moore, R., 2012, NHDPlus Version 2 User Guide: National Hydrography Dataset web page 168 p., at $f t p: / / f t p$. horizon-systems.com/nhdplus/NHDPlusV21/Documentation/NHDPlusV2_User_Guide.pdf.

Parameter-Elevation Regressions on Independent Slopes Model Climate Group, 2008, Normal annual precipitation grid for the conterminous United States: Oregon State
University Northwest Alliance for Computational Science and Engineering Web site, last accessed January 15, 2012, at http://www.prism.nacse.org/.

Schruben, P.G., Arndt, R.E., and Bawiec, W.J., 1998, Geology of the conterminous United States at 1:2,500,000 scale - A digital representation of the 1974 P.B. King and H.M. Beikman map: U.S. Geological Survey Digital Data Series 11, release 2, accessed March 15, 2012, at http://pubs.usgs.gov/dds/dds11/ index.html.

Simley, J.D., and Carswell, W.J., Jr., 2009, The National Map-Hydrography: U.S. Geological Survey Fact Sheet 2009-3054, 4 p. [Also available at http://pubs.usgs.gov/ fs/2009/3054/, also see http://nhd.usgs.gov/.]

Schwarz, G.E., and Alexander, R.B., 1995, Soils data for the conterminous United States derived from the NRCS State Soil Geographic (STATSGO) data base: U.S. Geological Survey Open-File Report 95-449, accessed March 15, 2012, at http://water.usgs.gov/GIS/metadata/usgswrd/XML/ ussoils.xml.

U.S. Department of Agriculture, Natural Resources Conservation Service [2011], Geospatial data gateway: U.S. Department of Agriculture Web page, accessed January 15, 2011, at http://datagateway.nrcs.usda.gov/.

U.S. Census Bureau, 2012, Data access tools: U.S. Census Bureau Web page, accessed March 15, 2012, at http://www. census.gov/main/www/access.html. 
Menlo Park Publishing Service Center, California

Manuscript approved for publication October 29, 2014

Edited by Chet Zenone and Kate Jacques

Design and layout by James E. Banton 

